\title{
WestVirginiaUniversity
}

THE RESEARCH REPOSITORY @ WVU

Graduate Theses, Dissertations, and Problem Reports

2017

\section{Revolutionary Pedagogy: A Historical Perspective on Improvising in Beethoven}

Julia Kinderknecht

Follow this and additional works at: https://researchrepository.wvu.edu/etd

\section{Recommended Citation}

Kinderknecht, Julia, "Revolutionary Pedagogy: A Historical Perspective on Improvising in Beethoven" (2017). Graduate Theses, Dissertations, and Problem Reports. 5977.

https://researchrepository.wvu.edu/etd/5977

This Dissertation is protected by copyright and/or related rights. It has been brought to you by the The Research Repository @ WVU with permission from the rights-holder(s). You are free to use this Dissertation in any way that is permitted by the copyright and related rights legislation that applies to your use. For other uses you must obtain permission from the rights-holder(s) directly, unless additional rights are indicated by a Creative Commons license in the record and/ or on the work itself. This Dissertation has been accepted for inclusion in WVU Graduate Theses, Dissertations, and Problem Reports collection by an authorized administrator of The Research Repository @ WVU.

For more information, please contact researchrepository@mail.wvu.edu. 


\title{
Revolutionary Pedagogy: A Historical Perspective on Improvising in Beethoven
}

\author{
Julia Kinderknecht \\ Dissertation submitted to the College of Creative Arts \\ at West Virginia University \\ in partial fulfillment of the requirements for the degree of \\ Doctor of Music in \\ Piano Performance
}

Peter Amstutz, D.M.A., Chair

Travis Stimeling, Ph.D., Research Advisor

James Miltenberger, D.M.A.

Beth Royall

Michael Vercelli, Ph.D.

Department of Music

Morgantown, West Virginia

2016

Keywords: Beethoven, Improvisation, Performance Practice, Pedagogy

Copyright 2016 Julia Kinderknecht 


\title{
ABSTRACT \\ Revolutionary Pedagogy: A Historical Perspective on Improvising in Beethoven
}

\author{
Julia Kinderknecht
}

This dissertation will investigate the historical significance and modern application of Beethoven's improvisations in performance, first by observing what we know through primary sources and eye-witness accounts, then by considering the reasons for the absence of improvisation in modern performance practice and the steps that could be taken towards reincorporating classical improvisation into modern pedagogy, and finally by offering historically-based improvisation exercises and written-out examples of improvisations in Beethoven's works to benefit modern pianists. 


\section{DEDICATIONS}

To Dr. Peter Amstutz, who patiently listens, encourages, and gives me freedom to grow, no matter how crazy my ideas are.

To Dr. John Salmon, who inspired me with the idea in the first place, provided me with resources, and pointed me in the right direction.

To Dr. John Cheek, who introduced Beethoven to me as a normal person who was capable of extraordinary things, and who made me believe the same about myself.

To my Savior, whose awesome paradox of Spirit and Truth, the written and the unwritten, Scriptura and Rhema, casts shadows throughout this little research project-just as He is reflected in so many unexpected corners of this life. 


\section{ACKNOWLEDGEMENTS}

I would like to express my sincere thanks to Dr. Travis Stimeling, my research advisor, for his advice, patience and encouragement through this whole process. Not only did he push me to do my very best, but he consistently went out of his way to cheer me on and keep me motivated. Dr. Stimeling, you represent so many things that I want to be as a teacher. Thank you for everything. I also want to thank my husband, who has been my biggest supporter through all of this. He has picked me up when I was the most discouraged, cheered the loudest when I succeeded, and told me to go to bed when I needed to. I love you so much, Noah. Besides belonging to Jesus, having you as my husband is my greatest distinction in life. 


\section{TABLE OF CONTENTS}

Table of Figures..........................................................................

Review of the Existing Scholarship about Beethoven and Improvisation............................

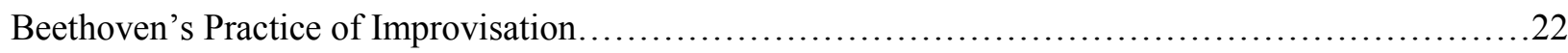

The Transition Away from Improvisation in Music History.........................................5

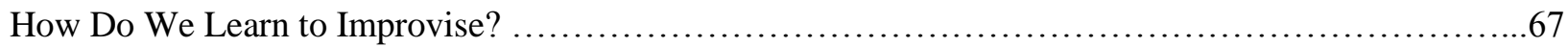

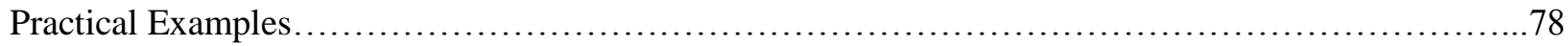

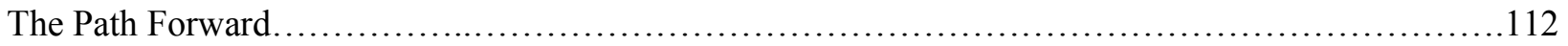

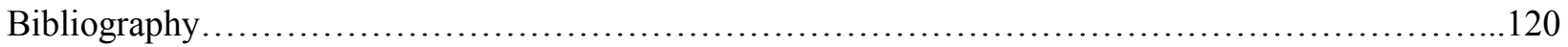




\section{TABLE OF FIGURES}

2-1: Sonata in E major, (Op. 14 No. 1), Movement 1, mm 1-11..................................... 31

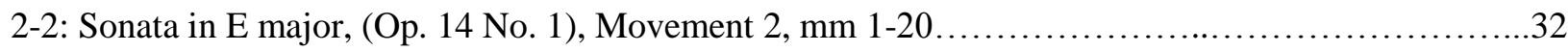

2-3: Sonata in E major, (Op. 14 No. 1), Movement 2, mm 30-48................................33

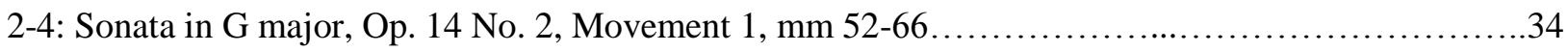

2-5: Sonata in A major, Op. 2, no. 2, Movement 1, mm 157-61..................................45

2-6: Sonata in D major, Op. 10, no. 3, Movement 1, mm. 180-183 ..............................45

2-7: Sonata in G major, Op. 16, Movement 3, mm. 76-77.....................................46

2-8: Sonata in c-sharp minor, Op. 27, no. 1, Movement 3, mm. 25-26............................46

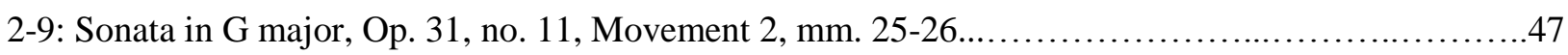

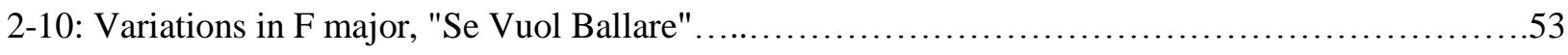

4-1: Sonata in c-sharp minor, Op. 27, no. 1, Movement 1, mm. 1-7 ............................ 76

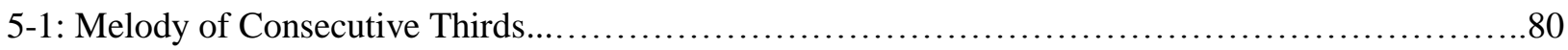

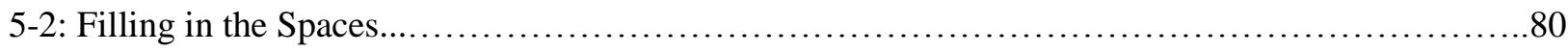

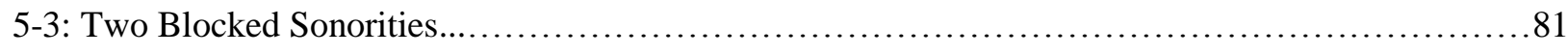

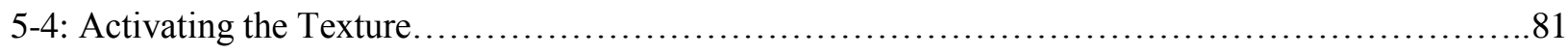

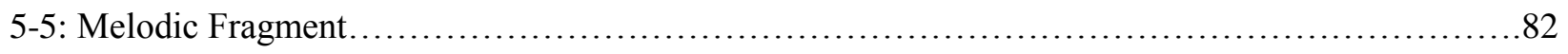

5-6: Transforming Melodies into Passagework............................................. 82

5-7: Sonata Op. 13 in C minor ("Pathetique"), Movement 3, mm. 1-21. First statement of refrain........85

5-8: Sonata Op. 13 in C minor ("Pathetique”), Movement 3, mm. 57-72. Second statement of refrain....86

5-9: Sonata Op. 13 in C minor ("Pathetique"), Movement 3, mm. 117-136. Third statement of refrain...87

5-10: Sonata Op. 13 in C minor ("Pathetique"), mvt. 3, mm. 169-183. Fourth statement of refrain........88

5-11: Sonata Op. 13 in C minor ("Pathetique"), Movement 3, mm. 119-124, embellished by John

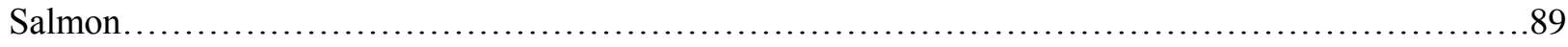


5-12: Sonata Op. 13 in C minor ("Pathetique"), Movement 3, mm. 60-70, embellished by author........90

5-13: Sonata Op. 13 in C minor ("Pathetique"), Movement 3, mm. 61-65, embellished by author........91

5-14: Concerto No. 1 in C major, Movement 3, mm. 49-68.................................... 92

5-15: Concerto No. 1 in C major, Movement 3, mm. 49-61....................................93

5-16: Sonata in a minor, Op. 2 No. 3, Movement 4, mm. 301-312 .............................. 94

5-17: Sonata Op. 2 No. 3 in a minor, Movement 4, mm. 306-307, embellished by Salmon...............94

5-18: Sonata No. 12 in A flat Major, Op. 26, Movement 2, mm. 1-4 .............................. 95

5-19: Sonata No. 12 in A flat Major, Op. 26, Movement 2, mm. 1-4, embellished by author.............96

5-20: Sonata No. 12 in A flat Major, Op. 26, Movement 2, mm. 17-21............................ 96

5-21: Sonata No. 12 in A flat Major, Op. 26, Movement 2, mm. 17-21, embellished by author..........97

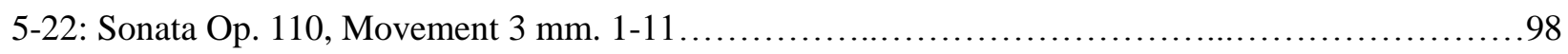

5-23: Sonata Op. 110, Movement 3 mm. 4-9, embellished by Salmon............................99

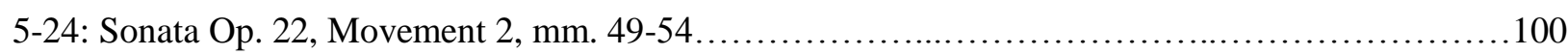

5-25: Sonata Op. 22, Movement 2, mm. 50-53, embellished by Salmon..........................101

5-26: Carl Czerny, “A Systematic Introduction to Improvisation,” pages 7-9...................103-105

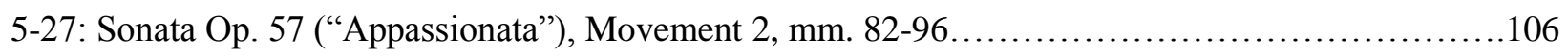

5-28: Sonata Op. 57 (“Appassionata”), Movement 2, mm. 95-96, embellished by Salmon..............106

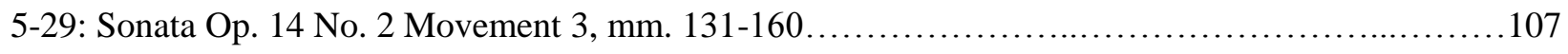

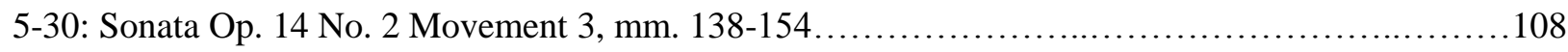

5-31: Carl Czerny, “A Systematic Introduction to Improvisation," page 23........................110 
Review of the Existing Scholarship on Improvisation and Beethoven

The ultimate goal of this dissertation is to make the reader aware of the need for, the practicality of, and the existing options for incorporating historically informed improvisation into modern piano pedagogy, particularly in the music of Beethoven. This research will present arguments in five layers: 1), a review of the existing literature on the subject of improvisation and performance practice in the music of Beethoven, and other relevant scholarship; 2), a portrayal of Beethoven as an improviser first and foremost via eye-witness accounts, and illustrations of the ways he improvised both in free fantasies and within the context of "written-down" repertoire; 3) an examination of the reasons that improvisation has disappeared from piano pedagogy and performance practice; 4) a presentation of pedagogical methodologies that incorporate a historically informed approach to improvisation in Beethoven's works; and 5), an application of the descriptions of Beethoven's improvisations to the creation of exercises and written out examples of improvising in Beethoven's music in a way that is consistent with his own practice of improvisation. Modern performance practice in classical piano repertoire is generally opposed to the idea of deviating from the written score. As a result, in order to successfully make the argument in favor of such deviations, there is a need for a substantial research foundation of respected sources.

Biographies which contain reputable eye-witness accounts of Beethoven's performances are integral to the foundation of this research. As Beethoven increased in fame, the accounts of his performances from aristocratic audience members, and in some cases his own students, tend to become increasingly flowery and sensational. Therefore, in order to get a clear idea of what his performances were actually like, it is important to look at the specific facts that are mentioned, common threads that remain consistent in all the accounts, and also compare early (and often more critical) descriptions with later descriptions. This research, of course, is based upon precise descriptions of Beethoven deviating 
from the score, along with the more common descriptions of his rapturous free fantasies. Many biographies and books on Beethoven as a pianist contain specific references to his improvisations within the score, and they will be discussed more specifically later. Especially important are sources which describe Beethoven using the improvisatory practice of Eingang; inserting free fantasies into written-out compositions at fermate, etc.; adding "difficulties" to written-out scores; varying the reprise of written-out material; and generally describing the centrality of his free fantasy skills. By closely examining these primary sources, we can derive a historically accurate method of demonstrating and teaching improvisation in Beethoven's works for the piano.

Although there is a large quantity of material pertaining only to improvisation, Beethoven as a pianist, or the proper performance of Beethoven's works, there is a definite need for a scholarly work that unites these three, being totally dedicated to the historical foundation for and practical execution of improvising in Beethoven. While many biographies contain chapters on Beethoven as an improviser, they rarely provide a thorough account of all the types of improvisation he used. Many books on Beethoven as a pianist come closer to achieving this goal, but they do not offer examples or exercises which pianists could use to try out Beethoven's own style of improvising. Some papers or textbooks which are devoted to improvisation provide exercises for free improvisation, but rarely do they attempt to write out examples of how Beethoven might have actually deviated from the score in his own works. Very few pedagogical sources make the argument for improvisation in Beethoven's works according to historical examples. It is the goal of this dissertation to fill those cavities in the literature and provide a thorough account of Beethoven's own practice of improvisation in performance, clear written-out examples of how he may have improvised in his own works, and an argument for the introduction of improvisation in modern performance practice.

In order to present a complete perspective on how to introduce improvisation into the modern pedagogy, it is essential to consult textbooks or handbooks which contain exercises and methods which are designed to help pianists learn to improvise. Fortunately, these types of books do exist, though they 
are almost entirely directed at jazz pianists. Those that have been written for classical musicians are much fewer and seem to have been largely disregarded in academic music. Still, there is great value in examining the methods used by jazz pianists in teaching other pianists how to improvise, as these methods can be adapted for classical musicians. There is also a need for books which generally speak of the value of improvisation in pedagogy, the philosophy of improvisation, and scientific benefits of improvisation for the classical performer. These types of sources are valuable for bolstering the argument in favor of improvisation as a valuable addition to modern piano pedagogy.

The current literature that supplies the foundation for this research can be divided into the following five categories: 1), the use of improvisation in music pedagogy; 2), writings on improvisation as a performance practice, focused on Beethoven or not; 3), biographies of Beethoven and books about Beethoven as a pianist, most of which include helpful insights regarding his performances; 4), improvisatory elements discovered in the course of analysis of the works of Beethoven; and 5), scientific or philosophical perspectives on improvisation. Within these five categories there are, of course, many smaller ones, and they will be discussed at the head of each new section. The scholarly works discussed in this literature review do not constitute an exhaustive list of works on improvisation; rather they represent a sample of the most important works on the topic. This literature review is intended to demonstrate the need for and also the necessary foundation for a research project which is focused on improvising in Beethoven.

\section{Improvisation in Pedagogy}

The use of improvisation in piano pedagogy is centuries old. One can find references to it in the pedagogical writings of C.P.E. Bach (1714-1788) and Carl Czerny (1791-1857), and many others. Many of these references aim to describe appropriate improvisation and they condemn tasteless improvisation, providing students with guidelines by which to determine the best choices to make in improvisation. The 
modern literature on improvisation in pedagogy can be divided into three important categories: The use of improvisation in classical piano pedagogy, the use of improvisation in the teaching of music theory, and the marriage of jazz improvisation techniques and classical playing.

The use of improvisation in classical pedagogy is more widespread than one might realize, though it remains controversial and rarely observed in concerts or in recordings. There are, it is important to note, many solid resources available for pianists who wish to develop improvisational skills. In 1941, Carl Whitmer wrote a detailed, methodical handbook called The Art of Improvisation: A Handbook of Principles and Methods for Organists, Pianists, Teachers, and All who Desire to Develop Extempore Playing, Based upon Melodic Approach. ${ }^{1}$ It is designed to help keyboard performers develop improvisation skills via a lengthy series of drills in creative engagement with the instrument. It is bursting with clever exercises and very little prose. While it seems to be an effective curriculum for improvisation, it unfortunately seems to have received little attention over the years. This handbook will certainly be useful in the research at hand, as it provides an example of well-reasoned exercises in improvisation.

There are some sources devoted to the art of improvising in the styles of particular eras, such as Michael Callahan's 2012 article “Incorporating Long-Range Planning into the Pedagogy of BaroqueStyle Keyboard Improvisation,"2 and Julie Cumming's 2013 article "Renaissance Improvisation and Musicology."3 These are not directly helpful to a research project on improvising in the style of Beethoven, but the pedagogical methods employed in these sources can be applied to the same pedagogy in the style of Beethoven.

\footnotetext{
${ }^{1}$ Carl T. Whitmer, The Art of Improvisation: A Handbook of Principles and Methods for Organists, Pianists, Teachers, and All who Desire to Develop Extempore Playing, Based upon Melodic Approach. (New York: M. Witmark \& Sons, 1941).

${ }^{2}$ Michael Callahan, "Incorporating Long-Range Planning into the Pedagogy of Baroque-Style Keyboard Improvisation." Music Performance Research, published by Royal Northern College of Music, Vol. 5, 2012. ${ }^{3}$ Julie E. Cumming, "Renaissance Improvisation and Musicology." Music Theory Online Volume 19, Number 2, June 2013. McGill University, 2013.
} 
Lee Iacocca offers a helpful perspective aimed at music teachers in his 2013 article "Teaching Improvisation Confidently."4 Rolf Hind also wrote an article in 2006 called "Some Thoughts on Improvisation" ${ }^{, 5}$ with practical ideas on incorporating improvisation into modern pedagogy. Hind recommends the pedagogical works of György Kurtág, who is a Romanian composer and pianist and a notable teacher. In addition to these articles aimed at teachers, there are also textbooks they might use which are devoted to teaching students how to improvise. It seems that piano faculty at the university level could easily copy pages of exercises or concepts out of these books and give them to their students to use during their daily practice. Ruth and Norman Lloyd wrote a textbook entitled Creative Keyboard Musicianship: Fundamentals of Music and Keyboard Harmony through Improvisation. ${ }^{6}$ Although it may be outdated, being written in 1975 , this textbook could be a very helpful resource for keyboard harmony classes or to be used in applied lessons. In addition, the 2011 textbook Musical Creativity: Strategies and Tools in Composition and Improvisation, ${ }^{7}$ by Mazzola, Park, and Thalmann, can be applied in various contexts, including music theory, composition, and applied lessons.

The attempts to incorporate jazz improvisation techniques into classical playing are few, but well worth mentioning. Bronwyn LeBlanc-Kinne’s 2014 dissertation “Incorporating Beginning Jazz Improvisation Activities and Exercises into an Intermediate-Level Classical Piano Curriculum: A Guide for Private Piano Teachers" ${ }^{8}$ is a highly intelligent and historically rich examination of improvisation in the performance practice of Beethoven's day, and application of jazz methods in modern classical pedagogy. Improvisation is something that can and should be taught, and jazz pedagogues are well-

\footnotetext{
${ }^{4}$ Iacocca, Lee. "Teaching Improvisation Confidently." Music Educators Journal 100, no. 1 (2013): 17.

${ }^{5}$ Hind, Rolf. 2006. "Some thoughts on improvisation". Contemporary Music Review. 25 (5-6): 631-632.

${ }^{6}$ Lloyd, Ruth, and Norman Lloyd, Creative Keyboard Musicianship: Fundamentals of Music and Keyboard Harmony through Improvisation. (New York: Dodd, Mead, 1975).

${ }^{7}$ Mazzola G., Joomi Park, and Florian Thalmann. Musical Creativity: Strategies and Tools in Composition and Improvisation. Berlin: Springer, 2011.

${ }^{8}$ LeBlanc-Kinne, Bronwyn, "Incorporating Beginning Jazz Improvisation Activities and Exercises into an Intermediate-Level Classical Piano Curriculum: A Guide for Private Piano Teachers." Dissertation, San Diego State University, 2014.
} 
equipped to offer effective methods of teaching it. This dissertation contains well-researched historical accounts of Beethoven improvising and is a tremendous resource for this project.

There have been a few recent efforts to revive the practice of improvisation in the teaching of music theory. The idea behind these efforts is that when students learn to be creative with the fundamental tools and building blocks of music, they will both understand and remember them better. Improvisation is often akin to constant experimentation, and experimenting with music theory helps students to be more focused and aware of the processes. In 1964 Hans Tischler published the textbook Practical Harmony: An Integrated Course in the Principles of Harmonic-Melodic Writing, Keyboard Improvisation and Modulation. ${ }^{9}$ While it may be old-fashioned, it represents a perspective on music theory as more than conceptual knowledge, and gives it practical application. 46 years later, in 2010, Ed Sarath wrote Music Theory through Improvisation: A New Approach to Musicianship Training. ${ }^{10}$ While his approach may not be as "new" as he might like to believe, it appears to be highly effective and comprehensive in its coverage of various topics. These sources are instructive in the quest to learn how to teach improvisation effectively to young pianists, as many of their methods can be applied in practical performance. The world of improvisation has been walled off for most modern pianists, and these sources make it a bit more accessible.

One of the themes which must be addressed within this topic of improvisation in modern pedagogy has to do with blurring the lines between creator and performer. Modern academic music has so rigidly segregated performers and composers, discouraging composers from performing their own works and discouraging performers from composing their own works, that we have almost forgotten what a foreign concept this would have been in the time of Beethoven. These pedagogical tools can help to

\footnotetext{
${ }^{9}$ Tischler, Hans. Practical Harmony: an Integrated Course in the Principles of Harmonic-Melodic Writing, Keyboard Improvisation and Modulation. (Boston: Allyn and Bacon, 1964).

${ }^{10}$ Sarath, Ed. Music Theory through Improvisation: A New Approach to Musicianship Training. (New York: Routledge, 2010).
} 
correct this arbitrary distinction. Manipulation of language through creativity is essential to mastery of that language. Why should the mastery of music be any different?

\section{Performance Practice}

One of the most important fields of study that benefits this research is improvisation in performance practice. To be more specific, improvisation in historical performance practice is the most directly applicable literature for this research project. While some may agree that improvisation is a valuable skill and deserves a place in modern pedagogy, many may not be aware of the historical basis which this dissertation will be exploring. Improvisation was a staple of refined musicianship well into the $19^{\text {th }}$ century, and is a fundamental aspect of the musical language of the time. One of the goals of this research is to demonstrate that a thorough training in music performance must include not only the masterpieces, but also the original performance practice associated with those masterpieces.

The "star witness" of this research is Dr. John Salmon, an innovative and adventurous pianist who delivered a lecture in 2002 entitled "Improvising in Beethoven"" at a keyboard literature conference at the University of North Carolina at Greensboro. The theme of the conference was the music of Beethoven, and Salmon chose to present evidence which supports his thesis that Beethoven was a constant and creative improviser, and that we as modern pianists have the option of imitating his example in our performances of his pieces. Salmon's research on this subject has been immensely helpful to this project, and it will be expanded upon. In particular, Salmon's arguments for improvising in Beethoven's works and his demonstrations in performance are enormously valuable to the writing of this dissertation. He has also compiled a lengthy list of primary sources which reference Beethoven's improvisational skills, and this will be particularly helpful in the first chapter of the dissertation.

\footnotetext{
${ }^{11}$ Salmon, John. "Improvising in Beethoven." Lecture at Focus on Piano Literature, Greensboro, NC, June, 2002. June 1, 2016.
} 
More general sources which deal with improvisation include the 2009 Musical Improvisation: Art, Education, and Society, ${ }^{12}$ edited by Gabriel Solis and Bruno Nettl, and the 2015 Improvisation Studies Reader: Spontaneous Acts ${ }^{13}$, edited by Rebecca Caines and Ajay Heble. Both of these books have many contributing authors who deal with diverse topics related to improvisation. This research project has drawn heavily from a chapter by William Kinderman in Solis' and Nettl's book, entitled "Improvisation in Beethoven's creative process." ${ }^{14}$ Kinderman's chapter tells a beautiful story of Beethoven's relationship with improvisation, mostly consisting of excerpts from his friends' letters or Beethoven's own remarks. Caines' and Heble's book, while deeply thought-provoking and beautifully presented in both organization and topic, is of very little use for this project. The authors of this book press deeply into the improvisational practices of many cultures, in many styles and in various art forms — such as theatre, dance, and poetry — and they offer many thoughtful insights about improvisation as a philosophical issue. Caines' and Heble's work offers very little to the research project at hand, however. The goal of this research is to provide very practical guides in historically accurate improvisation to modern pianists, and "Spontaneous Acts" steers rather wide of that mark.

There are a few sources which describe improvisation in eras before Beethoven's time, such as Improvising Early Music: The History of Musical Improvisation from the Late Middle Ages to the Early Baroque $^{15}$ by Rob C. Wegman, Johannes Menke, Peter Schubert, and Dirk Moelants, published in 2014. Other sources focus on improvisation or performance practice in general after the time of Beethoven, such as Kenneth Hamilton's witty offering from 2008 After the Golden Age: Romantic Pianism and

\footnotetext{
${ }^{12}$ Solis, Gabriel, and Bruno Nettl. Musical Improvisation: Art, Education, and Society. (Urbana: University of Illinois Press, 2009).

${ }^{13}$ Caines, Rebecca, and Ajay Heble. The Improvisation Studies Reader: Spontaneous Acts. (London: Routledge, 2015).

${ }^{14}$ Kinderman, William. "Improvisation in Beethoven's Creative Process." In Musical improvisation: Art, Education, and Society, ed. Gabriel Solis and Bruno Nettl, 296-312. Urbana: University of Illinois Press, 2009.

${ }^{15}$ Wegman, Rob C., Johannes Menke, and Peter Schubert. Improvising Early Music: the History of Musical Improvisation from the Late Middle Ages to the Early Baroque. (Leuven: Leuven University Press, 2014).
} 
Modern Performance. ${ }^{16}$ These scholarly works would be invaluable for a broader investigation into piano improvisation throughout music history. While they will be undoubtedly useful for future research, for now they are only tangentially related to this project. However, they remain extremely important to consider in framing the context of this research.

In her fascinating 2014 dissertation "Hidden Histories of Piano Improvisation (1850-1930): Functions, Concepts, and Case Studies of Early Recordings," ${ }^{17}$ Chiawei Lin exposes the thriving practice of improvisation after the life of Beethoven which often goes overlooked. She cleverly examines changes in pedagogy and also the influence of expanding technology which so dramatically changed performance practice in the $20^{\text {th }}$ century, giving us the standards that we have today. Her dissertation will prove very useful in the third chapter of this document, where topics such as changes in performance practice will be discussed.

Tilman Skowroneck's 2010 work entitled Beethoven the Pianist: Musical Performance and Reception ${ }^{18}$ has been extremely helpful to this research. The concise, insightful information presented by Skowroneck is particularly impressive and useful. Although initially presented as dry and unassuming, this rich collection of insights into Beethoven's actual pianistic abilities, in all their glory and shortcomings, is a treasure. The section devoted to Beethoven's improvisatory skills, although short, is full of important observations from Beethoven's contemporaries and Beethoven himself, along with insightful comments from the author, and has been more valuable to this research than many books which have longer chapters on improvisation.

\footnotetext{
${ }^{16}$ Hamilton, Kenneth. After the Golden Age: Romantic Pianism and Modern Performance. (New York: Oxford University Press, 2008).

${ }^{17}$ Lin, ChiaWei. 2014. Hidden histories of piano improvisation (1850-1930): functions, concepts, and case studies of early recordings. http://search.proquest.com/docview/1627792848? accountid=14505.

${ }^{18}$ Skowroneck, Tilman. Musical Performance and Reception: Beethoven the Pianist. (Cambridge, GB: Cambridge University Press, 2010).
} 
Another interesting resource in the same vein as Skowroneck's book is Timothy Jones' 2001 Beethoven, the Moonlight and Other Sonatas, Op. 27 and Op. $31^{19}$, which is a thorough study of "keyboard culture" of the time, of Beethoven's life during the composition of these sonatas, and of the sonatas themselves. Robert Taub's 2002 Playing the Beethoven Piano Sonatas ${ }^{20}$ is a similar source which aims to offer a modern perspective on the performance of these works, which is particularly useful for the third chapter of this dissertation. Taub describes with great eloquence the grandeur of Beethoven's improvisations, but he then goes on to assert that we as performers have the "responsibility" (p. 65) of internalizing the notes so well that we fool ourselves and our audiences into thinking that we are actually improvising, but while never deviating from the written notes. There is a general consensus in the modern view that our aim, in light of Beethoven's great skills as an improviser, should be to convincingly pretend to improvise when we play his works. This view appears rather shallow in light of Beethoven's own great flexibility with the written score. Furthermore, Taub's encouragement appears contrived when one considers the marked similarity between different performances of the same pieces in modern recordings, some of which are almost identical.

Two sources which come very close to sharing the thesis of this research project are Kevin Daniel Woosley’s 2012 dissertation “The Lost Art of Improvisation: Teaching Improvisation to Classical Pianists"21 and David Polan's 1994 article "Classic Improvisation: The 'Eingang' in Early Beethoven."22 There is of course some overlap between these sources, and there will be some overlap between these sources and this dissertation, but neither exactly hits the target for which this research aims. Woosley's dissertation is not written terribly well, but it is usable insofar as it contains solid research and valid reasoning. Polan's article has been very enlightening and useful for this project. The Eingang, an improvised "lead-in" or cadenza on a fermata, is rarely even discussed in modern piano pedagogy, and

\footnotetext{
${ }^{19}$ Jones, Timothy, Dr, Inc ebrary, and American Council of Learned Societies. Beethoven, the Moonlight and Other Sonatas, Op. 27 and Op. 31. (Cambridge, UK; New York: Cambridge University Press, 1999).

${ }^{20}$ Taub, Robert. Playing the Beethoven Piano Sonatas. (Portland, Or.: Amadeus Press, 2002).

${ }^{21}$ Woosley, Kevin Daniel. The Lost Art of Improvisation: Teaching Improvisation to Classical Pianists. 2013. http://lib-ebook.colorado.edu/ebook/Dissertation--3550094.pdf.

${ }^{22}$ Polan, David. “The Eingang in Early Beethoven.” Performance Practice Review. 7, no. 1 (1994): 78-84.
} 
Polan meticulously unpacks the many uses of this fascinating piece of historical performance practice in an engaging, logical way. Polan's article will benefit the first chapter of this dissertation enormously, and Woosley's research will certainly come in handy throughout the project.

Books which address performance practice more generally include Classical and Romantic Performing Practice 1750-1900²3, a 2004 book by Clive Brown, and Mayumi Orgura Randall's 1993 dissertation "The History of Piano Improvisation in Western Concert Music."24 Two articles which address the role of improvisation more specifically are Robin Moore's 1992 article "The Decline of Improvisation in Western Art Music: An Interpretation of Change, ${ }^{, 25}$ a philosophical and opinionated paper which covers a huge range of music history, and Bruno Nettl's 2013 article "Contemplating the Concept of Improvisation and its History in Scholarship." ${ }^{26}$ Incidentally, you will see Nettl's name appear several times in this literature review and in my bibliography. He has a fascination with improvisation as a concept and his expertise extends even to the musics of India and the Middle East. Moore's article is emotionally charged and makes a passionate argument for the return of improvisation in modern repertoire. Other sources that directly inform my research are primary sources such as "Recollections from My Life" ${ }^{, 27}$ by Carl Czerny and Ernest Sanders (1956), and Czerny’s important, if a bit overconfident, work "On the Proper Performance of all Beethoven's Works for the Piano." ${ }^{28}$ Both of these primary sources contain vast insights into performance practice of Beethoven's day.

Scholarly research on jazz improvisation is helpful to this research in that it steps further into the deeper questions of improvisation, helping musicians to think objectively about a skill which is otherwise

\footnotetext{
${ }^{23}$ Brown, Clive. Classical and Romantic performing practice 1750-1900. (Oxford: Oxford University Press, 1999).

${ }^{24}$ Randall, Mayumi Ogura. 1993. The History of Piano Improvisation in Western Concert Music.

${ }^{25}$ Moore, Robin. "The Decline of Improvisation in Western Art Music: An Interpretation of Change." International Review of the Aesthetics and Sociology of Music, 23, No. 1 (June 1992): 61-84.

${ }^{26}$ Nettl, Bruno. "Contemplating the Concept of Improvisation and Its History in Scholarship." Music Theory Online, 19 (2013). Available at http://openmusiclibrary.org/article/85545/.

${ }^{27}$ Czerny, Carl, and Ernest H. Sanders. Recollections From My Life. (New York: The Musical Quarterly, 1956).

${ }^{28}$ Czerny, Carl, Paul Badura-Skoda, and Carl Czerny. 1970. On the proper performance of all Beethoven's works for the piano ; Reminiscences of Beethoven, and, chapters II and III from volume IV of the Complete theoretical and practical piano forte school: op. 500. [Wien]: Wiener Urtext Ausgabe.
} 
vague and indefinable, especially for classical musicians. Ingrid Monson's important 1995 work Saying Something: Jazz Improvisation and Interaction ${ }^{29}$ is a thorough, very intelligent investigation of jazz improvisation, along with Paul Berliner's 2013 Thinking in Jazz: The Infinite Art of Improvisation. ${ }^{30}$ Lloyd Peterson's 2006 book Music and the Creative Spirit: Innovators in Jazz, Improvisation, and the Avant $\operatorname{Garde}^{31}$ offers a more historical perspective on the development of improvisation, which is helpful for tracing the departure of improvisation from the classical style and its integration into the jazz style. Patrick Joseph Boyle's interesting 2012 dissertation entitled "Improvisation and the Politics of Error"32 focuses on the inner workings of jazz improvisation, and it also includes exercises which can be used in a variety of styles to develop more secure improvisational skills. Boyle's dissertation in particular can be helpful in discovering ways of inspiring and helping classical pianists to master the skill of improvisation.

It is important to acknowledge the vast literature on the subject of improvisation in modern-era performance. One such source is from a mid $-20^{\text {th }}$ century pianist named Grace Castagnetta, who wrote about her experiences with classical improvisation in a 1942 newspaper article entitled "On Improvisation." ${ }^{, 33}$ It is arguable that Ms. Castagnetta's audiences were perhaps even more stiffened against the idea of improvisation than modern audiences would be, because of the drastic changes occurring in composition and in performance expectations. In her article she recounts positive and negative reactions from her audiences, and makes a case for the importance of improvisation in performance, culminating in the pithy remark: "Thus improvisation in the ultimate sense is composition

\footnotetext{
${ }^{29}$ Monson, Ingrid T. Saying Something: Jazz Improvisation and Interaction, 2nd ed. (Chicago: University of Chicago Press, 1996).

${ }^{30}$ Berliner, Paul. Thinking in Jazz: The Infinite Art of Improvisation. (Chicago: University of Chicago Press, 1994).

${ }^{31}$ Peterson, Lloyd. Music and the Creative Spirit: Innovators in Jazz, Improvisation, and the Avant Garde. (Lanham, MD: Scarecrow Press, 2006).

${ }^{32}$ Hartenberger, Russell, and Boyle, Patrick. 2012. Improvisation and the Politics of Error. Thesis / Dissertation ETD. http://hdl.handle.net/1807/65461.

${ }^{33}$ Grace Castagnetta, "On Improvisation," New York Times, Apr 261942.
} 
in reverse." ${ }^{34}$ This is an important source of information about one pianist's genuine experience with improvisation in the concert world.

More philosophical articles on improvisation drawn from personal experience include Nick FoxGieg's 2010 article "In Strange Paradox: Rationalizing Improvisation,"35 which considers historical aspects as well as his personal experiences improvising with his own performance group. Others in this category are Kyle Gann’s 2006 article “A Statement on Free Improvisation,, ${ }^{36}$ Matthew Sansom’s 2001 article "Imaging Music: Abstract Expressionism and Free Improvisation,"37 and William Fredrickson's 2007 article "Commentary Improvisation.",38 Madelon Hooykaas writes about defining improvisation and compares her experiences as an improviser with her experiences as a photographer in her 2006 article "Notes on Improvisation." ${ }^{, 39}$ Cristina Zavalloni describes improvisation as a musical language and relates her personal experiences as an improviser in her 2006 article "On Improvisation." 40 Stuart Jones writes about his career as an experimental performer in his article "Making It Up As You Go Along."41 Benjamin Piekut provides an interesting history of modern improvisation in his article "Indeterminacy, Free Improvisation, and the Mixed Avant-Garde: Experimental Music in London, 1965-1975."42 In general, much of the scholarly writing on modern improvisation seems to be largely based on personal experiences and opinions, so Piekut's objective article seems to be rather an exception. It is also worth noting that most scholarly work on modern improvisation in performance has to do with "free improvisation" rather than extemporaneous music within an older classical style. Because of this, most of

\footnotetext{
${ }^{34}$ Ibid.

${ }^{35}$ Fox-Gieg, Nick, and Margaret Schedel. 2010. "In Strange Paradox: Rationalizing Improvisation". Leonardo Music Journal. 20 (1): 13-15.

${ }^{36}$ Gann, Kyle. 2006. "A Statement on Free Improvisation". Contemporary Music Review. 25 (5-6): 619-620.

${ }^{37}$ Sansom, Matthew. 2001. "Imaging Music: Abstract Expressionism and Free Improvisation". Leonardo Music Journal. 11 (1): 29-34.

${ }^{38}$ Fredrickson, W. E. 2007. "Commentary Improvisation". Journal of Music Teacher Education. 16 (2): 7-9.

${ }^{39}$ Hooykaas, Madelon. 2006. "Notes on improvisation". Contemporary Music Review. 25 (5-6): 447-449.

${ }^{40}$ Zavalloni, Cristina. 2006. "On improvisation". Contemporary Music Review. 25 (5-6): 539-540.

${ }^{41}$ Jones, Stuart. 2001. "Making It Up as You Go Along". Leonardo Music Journal. 11 (1): 61-64.

${ }^{42}$ Piekut B. 2014. "Indeterminacy, free improvisation, and the mixed avant-garde: Experimental music in London, 1965-1975". Journal of the American Musicological Society. 67 (3): 769-823.
} 
these sources will not be directly useful in this research project. They are worth noting, however, as important contributions to the literature on improvisation.

\section{Biographies}

This is by far the largest category in the literature pertaining to this project. It would be neither practical nor helpful to address each biography that will be cited in this paper, but there are a few notable works which are of interest and great importance. The eye-witness accounts of Beethoven's performances are, as stated previously, the most valuable resources for this project. "The Beethoven Companion, ${ }^{, 43}$ a rich history written in 1929 by Romain Rolland, George Arnold Pfister, and Edgar Stephen Kemp, provides a straightforward, easy-to-navigate collection of specific and accurate primary sources. Another fascinating primary source is the 1904 "Beethoven, as Revealed in His Own Words: The Man and the Artist," relevant categories, occasionally interjecting helpful historical context for the reader's benefit. There are many wonderful descriptions of Beethoven's frequent improvisations in performance provided in these books. They will be particularly helpful in the first chapter of this project.

Some sources in this category follow the events of Beethoven's life only as they pertain to a narrower topic, such as "Goethe and Beethoven," 1931, which, of course, only traces the life of Beethoven through his relationship with Johann Wolfgang Goethe. Another contribution from William Kinderman is his 2009 biography simply entitled "Beethoven." 46 This biography follows Beethoven's career by using his most famous compositions as

\footnotetext{
${ }^{43}$ Scherman, Thomas, and Louis Leopold Biancolli. The Beethoven Companion. (Garden City, NY: Doubleday \& Company, Inc., 1972).

${ }^{44}$ Beethoven, Ludwig van, Friedrich Kerst, and Inc ebrary. Beethoven, as Revealed in His Own Words: The Man and the Artist. Wellington: Floating Press, 2009; 1904.

${ }^{45}$ Rolland, Romain. Goethe and Beethoven. (New York: B. Blom, 1968).

${ }^{46}$ Kinderman, William. Beethoven. (Berkeley: University of California Press, 1995).
} 
milestones and therefore has a more composition-oriented flavor. Unfortunately, neither of these works is extremely useful in writing a thesis about improvising in Beethoven, although they may offer helpful tangential information.

Biographical works that are especially helpful to this research include books such as "The Creative World of Beethoven,"47 edited by Paul Henry Lang. Written in 1971, this work investigates Beethoven's compositional process as seen through the eyes of many contributing authors, including Maynard Solomon and Myron Schwager. This book spends a great deal of time on Beethoven's sketches, thus removing the veil that is often drawn over Beethoven's flawed and very human journey of creation. Modern performance practice is so deeply entrenched in the magnificent finished product of Beethoven's masterpieces that it has forgotten the mistakes and the difficulties behind them, thus never inviting performers to enter into that process either. One of the great ambitions of this project is to reveal Beethoven as a human composer, and this source will be helpful in reaching this goal. One of the truly great members of this category is none other than the first biography, "The Life of Ludwig van Beethoven" ${ }^{48}$ by Alexander Wheelock Thayer. Though the first English edition did not appear until 1921, the majority of this important work was written during Beethoven's life. It is both comprehensive and beautiful, a true masterpiece. Thayer lists countless occasions when Beethoven improvised, describing them in vivid detail and providing a great deal of information that is useful to this research.

A biographical work which applies more directly to this research is The Pianist as Orator: Beethoven and the Transformation of Keyboard Style ${ }^{49}$ by George Barth. Written in 1992, this book is focused on the question of how we should categorize Beethoven's contribution to the history of performance practice, contrasting his impetuous style with the reserved performances of Mozart and Haydn, and highlighting the great impact his concerts made on the music scene. In addition, this section

\footnotetext{
${ }^{47}$ Lang, Paul Henry. The Creative World of Beethoven. (New York: W.W. Norton, 1971).

${ }^{48}$ Thayer, Alexander Wheelock, Henry Edward Krehbiel, Hermann Deiters, and Hugo Riemann. 1921. The life of Ludwig van Beethoven. New York: The Beethoven Association.

${ }^{49}$ Barth, George. 1992. The pianist as orator: Beethoven and the transformation of keyboard style. Ithaca, N.Y.: Cornell University Press.
} 
could not be concluded without referencing the extremely useful Beethoven Encyclopedia ${ }^{50}$ by Paul Nettl. Paul Nettl is the father of Bruno Nettl, and he wrote this wonderful resource in 1956. Constructed exactly like an encyclopedia, you simply can flip through the pages until you find the category that you are searching for. The section on improvisation was highly instructive and very useful.

\section{Improvisatory Elements Discovered in the Course of Analysis}

It is rather difficult to actually define this category, as it contains many different kinds of scholarly works. The two features they all have in common are a) they aim to provide analysis of Beethoven's works via the rules of theory or composition, rather than discussing them in reference to performance practice or biographical considerations; and b) they reference improvisation or contain helpful insights related to improvising in the style of Beethoven. Richard Marc Friedman wrote a dissertation entitled "The Original Cadenzas in the Piano Concertos of Beethoven: An Analysis," one might imagine, contains very useful information pertaining to the execution of improvised cadenzas in the style of Beethoven. William S. Newman's 1969 masterpiece The Sonata Since Beethoven ${ }^{52}$ is a treasure trove of information about the evolution of this genre beginning with late Beethoven and progressing through the beginning of the $20^{\text {th }}$ century. It offers valuable insight into the increasingly complex progress of composition over the romantic era and demonstrates the journey away from spontaneous performance culture of the eighteenth century to the more serious, academic music of the nineteenth and twentieth centuries. Barry Cooper's fascinating book from 1990, Beethoven and the Creative Process,${ }^{53}$ is another source which probes the creative elements needed to both compose and also to improvise. These analytical works are helpful for pianists who want to learn to enter into the creative process of Beethoven.

\footnotetext{
${ }^{50}$ Nettl, Paul. Beethoven Encyclopedia. New York: Philosophical Library, 1956.

${ }^{51}$ Friedman, Richard. 1989. The Original Cadenzas in the Piano Concertos of Beethoven: An Analysis.

${ }^{52}$ Newman, William S. The Sonata Since Beethoven. New York: W.W. Norton, 1983.

${ }^{53}$ Cooper, Barry. Beethoven and the Creative Process. Oxford: Clarendon Press, 1990.
} 


\section{Improvisation in Science, Philosophy and Society}

The scientific and philosophical sources on improvisation have a great deal in common, as they offer objective perspectives on the nature and benefits of improvisation. To begin with, the scientific sources are very academic and normally present a case study involving control groups and various experiments. This category is helpful for addressing some of the more practical benefits of improvisation, but does not apply directly to improvising in Beethoven. It is more tangentially related to the topic of this project than previous categories, but still important to address. There are two very interesting articles which consider the relationship between improvisation and anxiety, but from two very different perspectives. The first is a 2008 study by Youngshin Kim called "The Effect of Improvisation-Assisted Desensitization, and Music-Assisted Progressive Muscle Relaxation and Imagery on Reducing Pianists' Music Performance Anxiety." 54 This study, of course, covers the ways in which improvisation can benefit pianists who struggle with anxiety. The second is the 2013 "Fearless Improvisation: A Pilot Study to Analyze String Students' Confidence, Anxiety, and Attitude toward Learning Improvisation, ${ }^{, 55}$ by Michael Alexander. This study is focused on string students rather than pianists. It seeks to measure the confidence level of string students in the context of improvisation, finding males and females to be markedly different in the results of the study. This study assumes that improvising will induce a level of anxiety in students, and investigates the patterns of the anxiety.

It is the observation of the author that many classically-trained musicians experience anxiety related to the prospect of having to improvise. The extreme emphasis on perfection, the repetitive nature of most practice regimens, and the attention to minute details in most of classical pedagogy is sometimes

\footnotetext{
${ }^{54}$ Kim Y. 2008. "The effect of improvisation-assisted desensitization, and music-assisted progressive muscle relaxation and imagery on reducing pianists' music performance anxiety". Journal of Music Therapy. 45 (2): 165-91.

${ }^{55}$ Alexander, Michael L. 2012. "Fearless Improvisation: A Pilot Study to Analyze String Students' Confidence, Anxiety, and Attitude toward Learning Improvisation". Update: Applications of Research in Music Education. 31 (1): 25-33.
} 
incompatible with spontaneous creativity, leaving students with little context for confident experimentation in music. Interestingly enough, however, students can learn to overcome performance anxiety by becoming familiar with improvisation, as Kim's article suggests. Therefore, it seems clear that improvisation is a kind of terrible hurdle in academic music that is rarely crossed, but if it is, it has the potential to diminish the very anxiety that made it so frightening.

Some of the more basic psychological studies on improvisation include Aaron Lee Berkowitz's 2009 dissertation "Cognition in Improvisation: The Art and Science of Spontaneous Musical Performance," Frezza, and the 2009 “The Role of Emotion in Musical Improvisation: An Analysis of Structural Features ${ }^{\text {"58 }}$ by Malinda J. McPherson, Monica Lopez-Gonzalez, Summer K. Rankin, and Charles J. Limb. These sources consider fascinating aspects of the human mind at work during improvisation, such as emotion, factors of style and instrument choice, and practice versus flow. In addition, there is an interesting book from 2003 called Improvisation: Methods and Techniques for Music Therapy Clinicians, Educators, and Students ${ }^{59}$ by Tony Wigram, which considers the application of improvisation in music therapy.

Philosophical perspectives on improvisation can be helpful in arguing the case for its importance in music. One of the most valuable gems in the entire bibliography of this research is Bruce Ellis Benson's 2003 book The Improvisation of Musical Dialogue: A Phenomenology of Music. ${ }^{60}$ Benson writes extensively in this book about improvisation in history, in performance practice, and in human

\footnotetext{
${ }^{56}$ Berkowitz, Aaron Lee. 2009. Cognition in Improvisation: The Art and Science of Spontaneous Musical Performance. Thesis (Ph. D., Dept. of Music)--Harvard University, 2009.

${ }^{57}$ Biasutti M., and Frezza L. 2009. "Dimensions of music improvisation". Creativity Research Journal. 21 (2-3): 232-242.

${ }^{58}$ McPherson MJ, M Lopez-Gonzalez, SK Rankin, and CJ Limb. 2014. "The Role of Emotion in Musical Improvisation: An Analysis of Structural Features". PloS One. 9 (8).

${ }^{59}$ Wigram, Tony. Improvisation: Methods and Techniques for Music Therapy Clinicians, Educators, and Students. New York; London: J. Kingsley Publishers, 2004.

${ }^{60}$ Benson, Bruce Ellis. The Improvisation of Musical Dialogue: A Phenomenology of Music. Cambridge: Cambridge University Press, 2003.
} 
nature. He asks probing questions and makes provocative statements, such as this from his preface:

"Those who long for neatly tied theories will likely be disappointed with my view of music in which the lines between composition and performance are hardly 'neat.' But I think that 'messiness' simply reflects actual musical practice." ${ }^{\prime 1}$ He also discusses Beethoven in a very insightful way, such as in this excerpt from a passage in which he contrasts the methods of Beethoven with those of Rossini: "simply appealing to the score and its requirements doesn't necessarily establish that performers of Beethoven either are or must be 'executant artists.' Do Beethoven scores leave room for the performer to act as 'co-creator?' That depends on how we construe what the performer does in performing them. Furthermore, to what extent is the performer obligated to reproduce the expectations of the composer? Merely because Beethoven had stricter expectations for his performers than did Rossini does not automatically place stricter obligations on performers of his music." 62

Another notable member of this area of literature is an artistic and pithy article (perhaps better described as a poem) by none other than Frederic Rzewski. Published in 2006, "On Improvisation" ${ }^{63}$ is clearly meant to be "performed" by reading it out loud, and the various sections have "tempo markings" and other directives for counting off units of time. There are many clever remarks sprinkled throughout, such as the one attributed to his friend Steve Lacy, who was asked to describe improvisation in fifteen seconds. Lacy says: "In fifteen seconds, the difference between composition and improvisation is, that in composition you have all the time you want to think about what you will say in fifteen seconds, while in improvisation you have fifteen seconds to think about it." ${ }^{64}$

Other philosophical writings on improvisation include Stephen Nachmanovitch's 1990 book entitled Free Play: Improvisation in Life and Art, ${ }^{65}$ Giancarlo Schiaffini's 2006 article "Never Improvise

\footnotetext{
${ }^{61}$ Bruce Ellis Benson, The Improvisation of Musical Dialogue: A Phenomenology of Music (Cambridge: Cambridge University Press) 2003, xi.

${ }^{62}$ Benson, Improvisation of Musical Dialogue, 18.

${ }^{63}$ Rzewski, Frederic. “On Improvisation.” Contemporary Music Review 25, no. 5 (2006): 491-5.

${ }^{64}$ Rzewski, “On Improvisation,” 492.

${ }^{65}$ Nachmanovitch, Stephen. 1990. Free Play: Improvisation in Life and Art. New York: G.P. Putnam's Sons.
} 
Improvisation," ${ }^{, 66}$ Hideki Kato's 2006 article “On Improvisation," ${ }^{, 67}$ and David Rothenberg's 2002 book Sudden Music: Improvisation, Sound, Nature. ${ }^{68}$ These sources are very similar in tone and purpose, possibly with the exception of Schiaffini's article, which is more practical in its approach. These authors make the case for understanding all music as "unfinished" art, considering improvisation as connected to nature, and understanding improvisation as a developing skill. While they do not directly impact a project on improvising in Beethoven, these are helpful sources for inspirational and insightful definitions, ideas and observations.

There are a few sources on improvisation which are mostly philosophical in tone and language, but deal with improvisation through the lens of culture or society. In the Course of Performance: Studies in the World of Musical Improvisation ${ }^{69}$ is an interesting book edited by Bruno Nettl and Melinda Russell, published in 1998. There are several chapters from various contributing authors, each with a different expertise in how improvisation functions in the musics of other cultures. "The Complexity of Improvisation and the Improvisation of Complexity: Social Science, Art and Creativity"70 by Alfonso Montuori is another important source on improvisation in culture, published in 2003. One very interesting member of this category is "Composing the Body: Narrative in the Age of Improvisation, 1770-1867,",71 by Rebeccah Bechtold, whose 2012 dissertation unpacks the significance of improvisation in slave songs and their influence over European improvisation. These sources are almost of no use to this project, unfortunately. They are, however, a significant contribution to the literature on improvisation, and contain many interesting insights.

\footnotetext{
${ }^{66}$ Schiaffini, Giancarlo. 2006. "Never Improvise Improvisation". Contemporary Music Review. 25 (5-6): 575-576.

${ }^{67}$ Kato, Hideki. 2006. "On Improvisation". Contemporary Music Review. 25 (5-6): 629-630.

${ }^{68}$ Rothenberg, David. Sudden Music: Improvisation, Sound, Nature. Athens: University of Georgia Press, 2002.

${ }^{69}$ Nettl, Bruno and Melinda Russell. In the Course of Performance: Studies in the World of Musical Improvisation. Chicago: University of Chicago Press, 1998.

${ }^{70}$ Montuori, Alfonso. 2003. "The Complexity of Improvisation and the Improvisation of Complexity: Social Science, Art and Creativity". Human Relations. 56 (2): 237-255.

${ }^{71}$ Bechtold, Rebeccah, Patricia Loughran, Justine Murison, Leon Chai, and Gillen Wood. 2012. Composing the Body: Narrative in the Age of Improvisation, 1770-1867. http://hdl.handle.net/2142/34575.
} 
Two notable sources in this category which deal with Beethoven specifically are the 2012 book Vanishing Sensibilities: Schubert, Beethoven, Schumann, ${ }^{72}$ by Kristina Muxfeldt, and the 2004 Beethoven after Napoleon - Political Romanticism in the Late Works ${ }^{73}$ by Stephen C. Rumph. While these two books focus on different aspects of culture, they both consider Beethoven's music within the context of the society of the time. Muxfeldt discusses sensitive topics such as censorship, sexual innuendo and freedom of the press in her bold narrative on music in the early romantic period. She also considers the role of improvisation in this volatile social scene. Rumph offers a fascinating glimpse into Beethoven's political views, making the case that Beethoven was not as liberal as many assume him to be because of his ties to Napoleon, and that he was, in his later years, more strongly affiliated with conservative German views. Neither of these are directly applicable to this project, but they do offer perspectives which paint a contextual environment for the research at hand.

\section{Conclusion}

It should be fairly clear that research on improvising in Beethoven is both supported and needed in the current literature. While there are many important works that offer evidence for Beethoven's own practice of improvisation, these works are largely focused on a purely historical perspective and rarely make the connection to modern pedagogy. Similarly, there are several modern perspectives on proper performance practice, but they seldom make a meaningful use of Beethoven's own practice as an instructive resource. Therefore, this research will be built on distinguished and consequential scholarship, but will also serve to fill an empty space in the current literature on improvisation and Beethoven.

\footnotetext{
${ }^{72}$ Muxfeldt, Kristina. Vanishing Sensibilities: Schubert, Beethoven, Schumann. New York: Oxford University Press, 2012.

${ }^{73}$ Rumph, Stephen C. Beethoven after Napoleon: Political Romanticism in the Late Works. Berkeley: University of California Press, 2004.
} 


\section{Beethoven's Practice of Improvisation}

To begin with, let us establish some basic definitions. Because the type of improvisation this research discusses is largely unfamiliar in modern performance practice, it is helpful to illustrate the contrast between modern perspectives of improvisation and the historical perspective which we will be applying to Beethoven. Modern perspectives of improvisation are often centered around "free" improvised works, where a performer enters the stage without any constraint or structure to inform the improvisation, and therefore delivers an entirely new composition which is created in the moment. Discussions such as this one, from pianist Grace Castagnetta, tend to dominate the common view of improvisation: "A perfect state of relaxation and enjoyment is the most important ingredient of improvisation. Then it is possible to create extemporaneous composition without premeditation, having its mainspring in the realm of the unconscious. There is no premeditation possible in true improvisation. For whenever that element enters, the creatively inspired becomes tainted with the ingeniously counterfeit coin of clever trickery and precious finesse." 74 This type of improvisation is certainly intimidating to pianists who have never tried to play music which is not written down. The utter lack of structure is terrifying, especially in an art form which has become so dependent upon the structure of the written score.

In contrast to the perspectives described above, this research aims to describe a quite different sort of improvisation. The improvisation discussed in this paper is based upon clear structure and is informed by various aspects of its environment, such as the information in the written score, the particular audience, and the appropriate responses to the needs of the moment. The improvisation described in this research is more like the following description from Pier Francesco Tosi, who explains how a singer adds spontaneous embellishment to the first and second repeated sections of a song: "In the first they require

\footnotetext{
${ }^{74}$ Grace Castagnetta, "On Improvisation," New York Times, Apr 261942.
} 
nothing but the simplest Ornaments, of a good Taste and few, that the Composition may remain simple, plain and pure; in the second they expect, that to this Purity some artful Graces be added, by which the Judicious may hear, that the Ability of the Singer is greater; and in repeating the Air; he that does not vary it for the better, is no master." ${ }^{, 75}$ Modern understandings of improvisation are often limited to free fantasies which aim for "pure improvisation," where every sonority is original and unpremeditated. This research, in contrast, is primarily focused on improvisation which has been rationally applied to existing musical information, such as the practice of embellishing repeated material that Tosi describes. The tradition of developing the ability to improvise within a composition and "vary it for the better" was a central idea in historical performance practice, and it remained an important quality of a "master" of music even in the time of Beethoven.

Some more recent compositions have improvisational aspects, such as aleatory works like Henry Cowell's Mosaic Quartet (String Quartet No. 3), John Cage's Music of Changes, or even open-ended works such as Terry Riley's In C. These compositions do offer a basic structure and basic musical materials for performers to work with, and so one might argue that improvisation has not in fact disappeared from modern performance practice, but rather it has been reappropriated to serve modern and post-modern styles. However, the improvisational qualities of these works are also quite different from the historical improvisation described in this chapter. Improvising in Beethoven is a process of responding intelligently and incisively to a pre-existing masterpiece, and producing something which is consistent with the original intent of the work and only serves to enhance the existing music. Aleatory music, such as in the pieces described above, is based on the idea that performers create something fresh and new every time the piece is performed, so that the work is redefined every time. Improvising in Beethoven is not redefining Beethoven. It is simply performing Beethoven's music a little more like he would have performed it.

\footnotetext{
${ }^{75}$ Pier Francesco Tosi, Observations on the Florid Song, trans. J. E. Galliard (London, Printed for J. Wilcox, 1742) 93.
} 
The musical improvisation addressed in this paper is defined simply as any performer's extemporaneous creation of music, original addition to the written score, or deviation from the written score, which is offered as complementary to the time and circumstances at hand - to meet the needs of the moment. Much of the improvisation addressed in this paper is practiced and prepared beforehand, though the final product may not be entirely based on previous rehearsals. ${ }^{76}$ Improvisation is a skill that must be practiced and developed with as serious an attitude as is devoted to the learning of any Beethoven piano sonata. A successful improvisation is assembled with building blocks of music that have been practiced many, many times before.

Beethoven is known for his protractive method of composition — sketches upon sketches upon blotted and bloodied sketches. This, of course, gives modern musicians the impression that the finished score is the product of intense, excruciating effort and should be hailed as an artifact of divine genius. Dr. John Salmon, a performer and scholar who offers many controversial perspectives on proper performance of Beethoven's music, observes,

Knowing what we do about Beethoven's work habits, and those endless sketches, it is natural to conclude that his compositional process paralleled some torturous Hegelian dialectic, each draft ultimately playing the role of thesis, and then antithesis, finally leading to a grand synthesis, the finished composition. Or, to invoke another important

\footnotetext{
${ }^{76}$ For more reading on this subject, read:

Hartenberger, Russell, and Boyle, Patrick, "Improvisation and the Politics of Error." Dissertation, University of Toronto, 2012.

Skowroneck, Tilman. Musical Performance and Reception: Beethoven the Pianist. Cambridge, GB: Cambridge University Press, 2010.

LeBlanc-Kinne, Bronwyn, "Incorporating Beginning Jazz Improvisation Activities and Exercises into an Intermediate-Level Classical Piano Curriculum: A Guide for Private Piano Teachers.” Dissertation, San Diego State University, 2014.
} 
$19^{\text {th }}$ century construct, it is easy to view the compositions that survived as the result of some rigorous, Darwinian natural selection. ${ }^{77}$

Beethoven's music is normally viewed as ultimately sacred, perhaps more than any other composer. His written works have been assigned a permanent place in the museum of masterpieces, and many classical musicians hesitate to directly alter his compositions. Dr. Salmon declares that "of all the classical composers, Beethoven is the one whose compositions seem most off-limits to alteration. They have attained the status of platonic ideals, immutable and perfect. For no other composer is the text - the urtext - treated with more respect." It is one of the primary aims of this research to expose the irony that Beethoven was a daring improviser, but his music is treated as such a very fragile thing.

It must be understood that during his lifetime, Beethoven was known as an improviser first and foremost. A 1799 report in the Allgemeine musikalische Zeitung claims that Beethoven "shows himself to the greatest advantage in improvisation," extempore playing was it was less successful in the performance of printed compositions; for, since he never took the time or had the patience to practice anything, his success depended mostly on chance and mood."79

In particular, the aim of this chapter is to compile and interpret various eye-witness accounts of Beethoven improvising. This research is mostly concerned with accounts of Beethoven improvising within the context of already-composed music, like adding spices or fresh vegetables to prepackaged food, although more famous accounts of his free fantasies are included as well. This chapter will serve as a foundation for subsequent chapters, which will discuss the question of how Beethoven's performance habits should influence modern performers of his works. We will first consider Beethoven's personal

\footnotetext{
${ }^{77}$ John Salmon, "Improvising in Beethoven" (lecture, University of North Carolina at Greensboro, Greensboro, NC, June, 2002).

${ }^{78}$ William Kinderman, "Improvisation in Beethoven's Creative Process," in Musical Improvisation: Art, Education, and Society, edited by Gabriel Solis and Bruno Nettl, (Urbana: University of Illinois Press, 2009), 297.

${ }^{79}$ Friedrich Kerst, ed., Beethoven, as Revealed in His Own Words: The Man and the Artist (1904; repr., Auckland, NZ: The Floating Press, 2009) ProQuest ebrary, 45.
} 
beliefs about "perfectionism" in performance, then his own practice of improvisation in performance, and finally his instructions to his students about deviating from the written score.

\section{Beethoven and Perfection}

In all of our reverence for Beethoven, ${ }^{80}$ we may overlook or simply not be aware of his shocking and perverse reputation as a musician in the late classical era. It may surprise many piano students to know that, in his day, the great Beethoven was admired as a daring performer and improviser more than a composer. His improvisations drew crowds of amazed listeners, but his compositions, which are today held in the highest esteem, defied the conventional practices of the day to the point of frequent ridicule. It is interesting that Beethoven's legacy today is rather the opposite. His revolutionary improvisations and unconventional performances, while they were his defining qualities during his life, have little effect on today's performance practice, while his compositions remain central to his legacy, even though they were often received poorly during his lifetime. This section examines Beethoven's revolutionary performance practices in five categories: 1) his preeminence as an improviser rather than as a composer, 2) his powerful technique, 3) his pedaling, 4) his rampant changes in tempo, and 5) his frequent inaccuracies in performance. The purpose of this section is to illuminate Beethoven's liberal performing style, creating a foundation for a more focused discussion of his practice of improvisation.

\footnotetext{
${ }^{80}$ For various examples of this pervasive attitude, read the following:

Burnham, Scott. Beethoven Hero. Princeton: Princeton University Press, 1995.

Bowen, José A. "The Value of Beethoven." 19th-Century Music 22, no. 1 (1998): 91-99.

Newman, William S. "The Beethoven Mystique in Romantic Art, Literature, and Music." The Musical Quarterly 69, no. 3 (1983): 354-87. http://www.jstor.org/stable/742177.
} 


\section{Known First as an Improviser}

The classical aesthetic was based on restraint, logic, and order. Beethoven's music rebelled against those ideals in every respect, and as a result his contemporaries were not gentle or flattering in their reactions to his music. They were, however, intrigued by his improvisations, even though Beethoven's unbridled passion was most clearly seen in his extemporaneous performance. While we have countless negative reviews of Beethoven's written works in performance, few negative reviews of his improvisations have survived. On the contrary, even the foremost performers of his day tipped their hats to his superior skills as an extempore pianist.

Tilman Skowroneck, in his work Musical Performance and Reception: Beethoven the Pianist, lists many contemporary reviews of Beethoven's playing that demonstrate that Beethoven was known first and foremost as a performer and improviser for much of his career. The Allgemeine Musikalische Zeitung (AMZ), a general music newspaper, reviewed Beethoven's variations on La Stessa, La Stessissima, WoO 73, in the following way: "van Beethoven may be able to improvise, but he does not know how to write 17 variations." ${ }^{81}$ Skowroneck says "This is one of several examples of reviews where Beethoven's works are criticized, but his status as 'one of the most foremost pianists' is never questioned." ${ }^{\circledR 2}$ Beethoven performed his First Piano Concerto at The Akademie of April 2, 1800, and received a disparaging review from the $A M Z$, although they admitted that Beethoven "extemporized masterfully." 83 Even Carl Czerny, usually considered Beethoven's most famous student and also one of Beethoven's most ardent worshipers, is forced to admit that until Beethoven was forty years old, his improvisations were considered extraordinary but his performances of written works were considered "less successful." 84 Czerny explains that because Beethoven "never had the patience or took the time to

\footnotetext{
${ }^{81}$ Tilman Skowroneck, Musical Performance and Reception: Beethoven the Pianist (Cambridge, GB: Cambridge University Press, 2010), 145.

${ }^{82}$ Ibid.

${ }^{83}$ Ibid.

${ }^{84}$ Ibid.
} 
practice them again, his success usually depended on coincidence and his mood." ${ }^{85}$ Thomas Scherman and Louis Leopold Biancolli observe, "Where Beethoven especially shone was in his improvisations. His improvisations, indeed, were better than his performances of published pieces, for after coming to Vienna, Beethoven had little time, or inclination, to practice." 86 Beethoven's student, Ferdinand Ries, said "His extemporizations were the most extraordinary things that one could hear. No artist that I ever heard came at all near the height which Beethoven attained. The wealth of ideas which forced themselves on him, the caprices to which he surrendered himself, the variety of treatment, the difficulties, were inexhaustible." 87

\section{Expressive Technique}

If Beethoven was known for his performing before his composing, it was because of his legendary expressive power. ${ }^{88}$ Skowroneck recounts,

It was in 1792 that the short, homely Beethoven exploded over Vienna. His playing —and it was as a pianist, not as a composer, that he made his initial impact-was overwhelming. And it was overwhelming not so much because Beethoven was a great virtuoso (which he probably wasn't) but because he had an ocean-like surge and depth that made all other playing sound like the trickle of a rivulet. Certainly Vienna had heard pianists who had a more polished delivery-Mozart, Clementi, Wolffl, and Cramer, to mention but four. Beethoven's playing probably was rough in comparison. But a pianist with Beethoven's elemental force and conception was entirely unknown up to that time: a shellburst among the bows and arrows of his contemporaries. ${ }^{89}$

In their definitive work The Beethoven Companion, Thomas Scherman and Louis Leopold

Biancolli explain,

\footnotetext{
${ }^{85}$ Ibid.

${ }^{86}$ Thomas Scherman and Louis Leopold Biancolli, The Beethoven Companion, 1st ed. (Garden City, N.Y: Doubleday, 1972), 104.

${ }^{87}$ Beethoven, Beethoven, 45.

${ }^{88}$ For more advanced discussion on the notion of expression and the dramatic upheaval associated with Beethoven's revolutionary use of it, read: Bonds, Mark Evan. Absolute Music: The History of an Idea. (New York : Oxford University Press, 2014).

${ }^{89}$ Skowroneck, "Beethoven the Pianist," 104
} 
In many things, Beethoven was ahead of his time, and so was his piano playing. It had unprecedented power, personality and emotional appeal. In many respects he can be considered the first romantic pianist: the one who broke all of the laws in the name of expression (for in the nineteenth century the word "expression" was to take the place of the eighteenth-century "taste"); the one who thought orchestrally and achieved orchestral effects on the piano. In that he was alone in his day, and his like was not to be seen until the maturity of Franz Liszt. ${ }^{90}$

Beethoven's expressive power left a deep impression on the musical scene during his life, but other aspects of his performing were more offensive to the refined ears of Vienna. He seems to have frequently sacrificed clarity and accuracy for raw expression and emotion. Beethoven's use of pedal, his treatment of tempos and his tolerance of missed notes are three characteristics that are frequently cited in the public's reviews of his performances.

There are not many accounts of Beethoven's use of the pedal, but the ones that have been passed down are far from complimentary. Johann Baptist Cramer, a famous pianist of the day, visited Beethoven in Vienna in the year 1800. He was highly critical of Beethoven's performances of his works, saying "One day, he would play it with great spirit and expression, but the next day he would sound moody and often muddled to the point of becoming indistinct." ${ }^{\text {91 }}$ Hummel's disciples were even harsher in their critiques of this performer who dared to rival Hummel in virtuosity but surpassed him in raw energy and expression. Czerny relates their complaints that he was guilty of "...creating nothing but confused noise in the way he used the pedal." ${ }^{92}$ Czerny hints that Beethoven used a great deal more pedal in performance than he notated in his scores. ${ }^{93}$

This aspect of Beethoven's performing style is interesting because of the vast differences between the pianos that he would have used and the pianos that we use today. The wooden frames of early $19^{\text {th }}$ century instruments caused the sound to decay more rapidly than in our large, metal framed Steinways.

\footnotetext{
${ }^{90}$ Scherman, Biancolli, The Beethoven Companion, 102-103

${ }^{91}$ Skowroneck, "Beethoven the Pianist," 146

92 Skowroneck, "Beethoven the Pianist." 147

${ }^{93}$ Sandra P. Rosenblum, "Pedaling the piano: A brief survey from the eighteenth century to the present." Performance Practice Review 6, no. 2 (1993): 160.
} 
This natural quality of the fortepiano lent itself to the usual clarity and brilliance of Classical era music. Beethoven's deviation from this norm must have been very marked, as his instrument could not create too muddled a sound regardless of how much pedal he used.

Possibly the most interesting quality of Beethoven's individualistic playing style is his frequent tempo changes. Modern performance practice of Beethoven's works tends to be rather steady in tempo unless tempo changes are indicated, but Beethoven himself seems to have had a much more liberal relationship with tempo. Anton Schindler, an associate of Beethoven's and one of his earliest biographers, gives us the following report of his performance of the Sonata in E major, Op. 14 No. 1: "In the seventh bar of the first allegro movement, as well as in the following bar, he retarded the tempo, touching the keys more forte, and holding down the fifth note. By these means he imparted to the passage an indescribable earnestness and dignity of character." ${ }^{94}$ Consider this description by comparing it to Example 1 . The ritardando that Beethoven used is not notated, nor is his elongation of the "fifth note," which we shall take to mean the A-naturals in the soprano lines of measures seven and eight.

${ }^{94}$ Scherman, Biancolli, The Beethoven Companion. 109 
Example 1: Sonata in E major (Op. 14 No. 1), Movement 1, mm 1-11
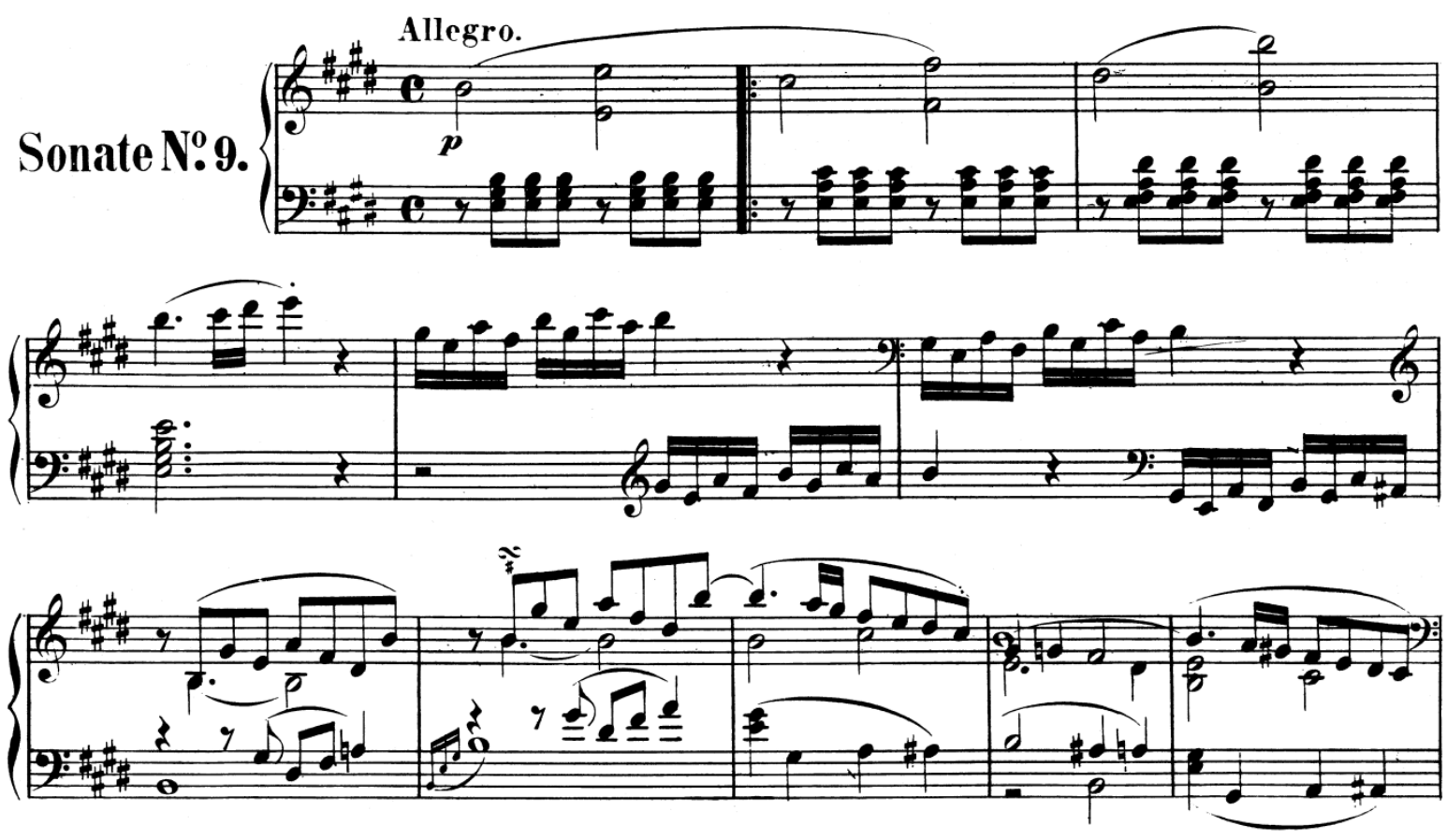

Source: Beethoven, Ludwig van. Sonaten für das Pianoforte. New York: Edwin F. Kalmus, n.d. (1933$70)$.

Schindler also tells us that in the same sonata, "On the introduction of the middle movement...the dialogue became sentimental. The prevailing tempo was andante, but not regularly maintained; for every time that [the descending eighth notes were] introduced, a little pause was made on the first note." 95 One can observe Example 2 to see that such a pause is not indicated either in measure four or in measure twelve. $^{96}$

\footnotetext{
${ }^{95}$ Scherman, Biancolli, The Beethoven Companion, 110

${ }^{96}$ The expressive power of rubato reached its peak in the music of Chopin, and Beethoven seems to foreshadow this iconic style in his performances a generation earlier. For further discussion of the romantic uses of rubato, especially in Chopin, read the following:

Chapter 7 (Titled "Chopin: From the Miniature Genre to the Sublime Style") in: Rosen, Charles, The Romantic Generation. Cambridge, Mass: Harvard University Press, 1995.

All of: Rink, John, and Jim Samson. Chopin Studies 2. Cambridge: Cambridge University Press, 1994. especially the chapter by David Rowland entitled "Chopin's Tempo Rubato in Context."
} 
Example 2: Sonata in E major (Op. 14 No. 1), Movement 2, mm 1-20
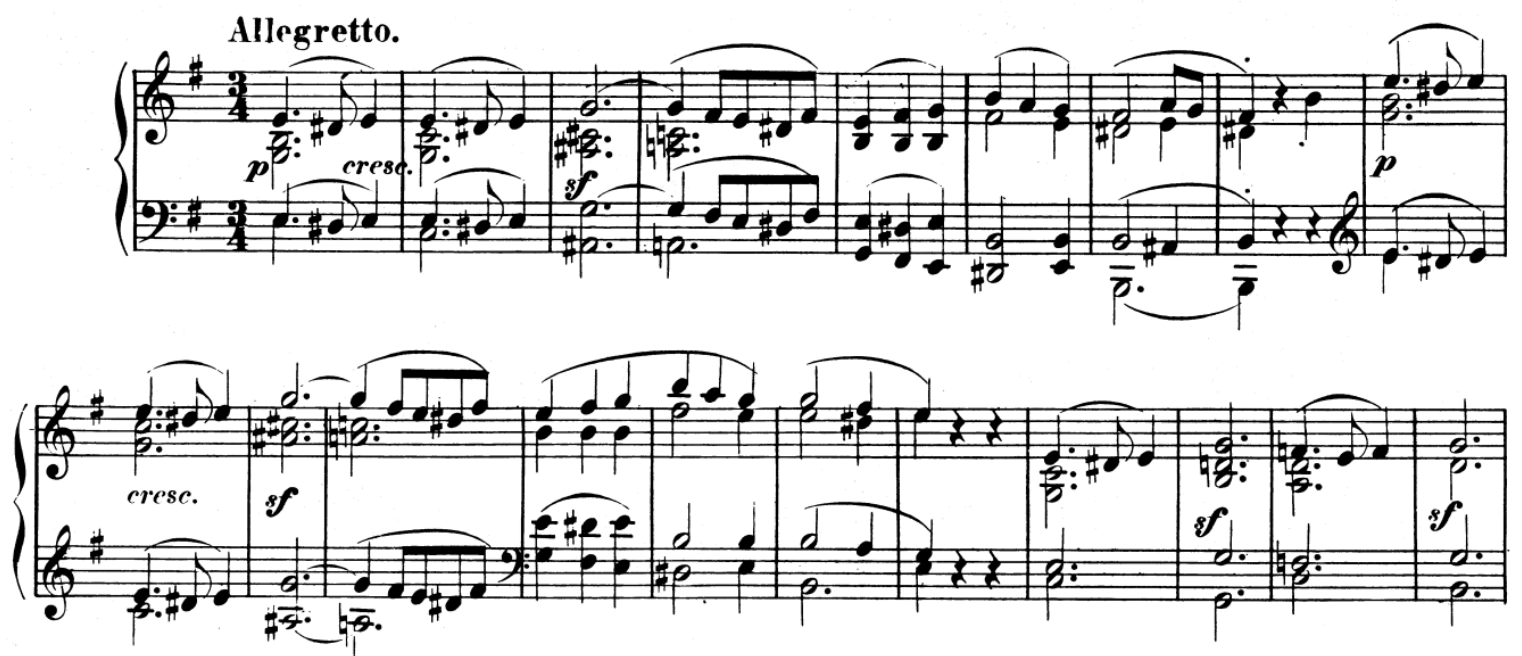

Source: Beethoven, Ludwig van. Sonaten für das Pianoforte. New York: Edwin F. Kalmus, n.d. (193370).

Schindler also claims that, although the movement is marked Allegretto, Beethoven performed it as an Allegro Furioso. ${ }^{97}$ He says that Beethoven inserted a very long pause upon arriving at the climactic d minor seventh chord in measure 40 (see Example 3), after which he continued the same tempo. ${ }^{98}$

\footnotetext{
${ }^{97}$ Scherman, Biancolli, The Beethoven Companion, 110.

${ }^{98}$ Ibid.
} 
Example 3: Sonata in E major (Op. 14 No. 1), Movement 2, mm 30-48
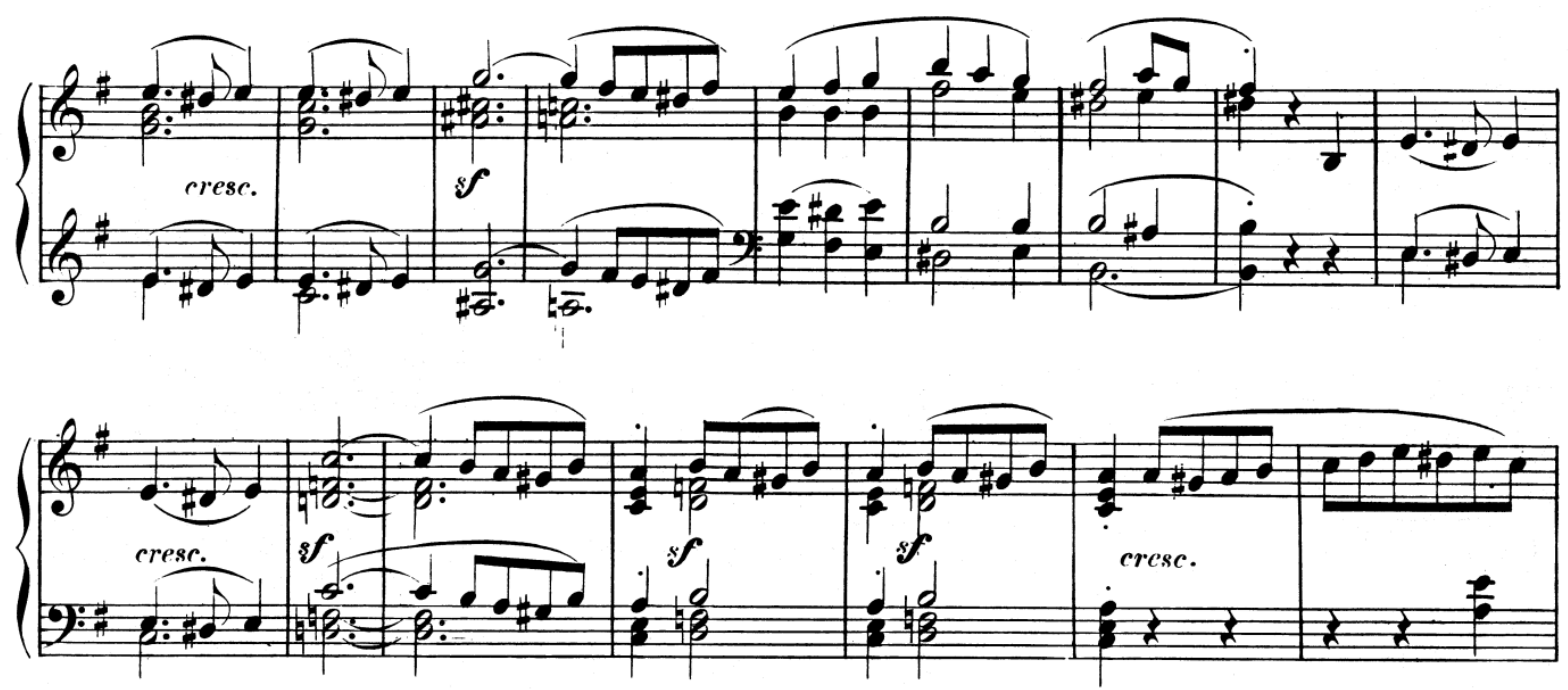

Source: Beethoven, Ludwig van. Sonaten für das Pianoforte. New York: Edwin F. Kalmus, n.d. (193370).

Another interesting recollection of Schindler's has to do with the first movement of the G major sonata,

op. 14. Schindler describes,

Various as were the tempi which Beethoven introduced in this movement, yet they were all beautifully prepared, and, if I may so express myself, the colors were delicately blended with one another. There were none of those abrupt changes which the composer frequently admitted in some of his other works with the view of giving a loftier flight to the declamation. Those who truly enter into the spirit of this fine movement will find it advisable not to repeat the first part; by this allowable abridgment, the gratification of the hearer will be unquestionably increased, while it may possibly be diminished by frequent repetitions of the same phrases... ${ }^{99}$

From this quote we can conclude the following: Beethoven employed many various tempi which were easily blended into one another; Beethoven was prone to abrupt changes of tempo in his other performances, a tendency which was unusually softened in this case; Beethoven was prone to adding

\footnotetext{
${ }^{99}$ Scherman, Biancolli, The Beethoven Companion. 109
} 
these abrupt changes in tempo for the purpose of expressive declamation; and we are given an opinion (whether it is Schindler's own opinion or it is advice based on Beethoven's performance, we do not know) that a truly authentic performance of this piece would not repeat the opening of the first movement (see Example 4 to observe the repeat in question).

Example 4: Sonata in G major, Op. 14 No. 2, Movement 1, mm 52-66

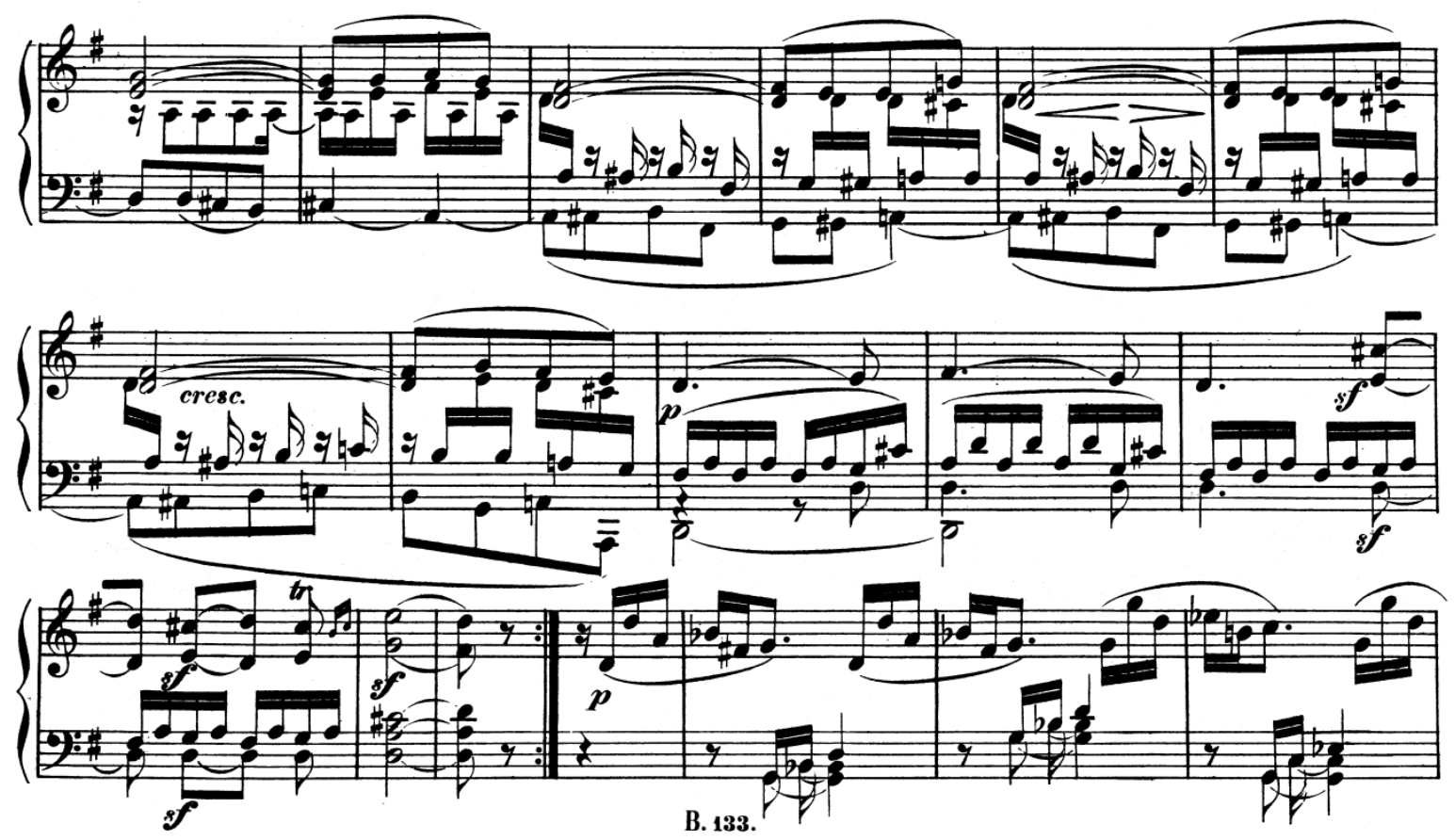

Source: Beethoven, Ludwig van. Sonaten für das Pianoforte. New York: Edwin F. Kalmus, n.d. (1933$70)$.

Schindler makes some more general comments about other sonatas which read as follows: "The two sonatas in Op. 14; the first sonata (F minor) in Op. 2; the first sonata (C minor), Op. 10; the Sonate pathetique (C minor) Op. 13; the Sonata quasi Fantasia in C sharp minor, Op. 27; and some others, all are pictures of feeling; and in every movement, Beethoven varied the tempo according as the feelings 
changed." ${ }^{100}$ It is worth noting that Schindler had direct access to Beethoven both personally and in performance, so perhaps his remarks are of more importance and relevance to modern performance than are the modern traditions of performance practice, which claim to be based upon historically informed performance decisions but are frequently very different from what we discover in Schindler's accounts.

\section{"Wrong Notes"}

One aspect of Beethoven's performance style that is consistent in accounts from his entire lifetime is his preference for passion and honesty over perfection and accuracy. Among the most humorous account is found in the recollections of Anton Reicha, a fellow composer and a lifelong friend of Beethoven's. Reicha says that Beethoven asked him to turn pages at his performance of a Mozart concerto at court, and Reicha remembers, "I was mostly occupied in wrenching the strings of the pianoforte which snapped, while the hammers stuck among the broken strings. Beethoven insisted on finishing the concerto, and so back and forth I leaped, jerking out a string, disentangling a hammer, turning a page, and I worked harder than Beethoven."101 It is important to note that Beethoven was more concerned with presenting the music to the audience than presenting a perfect version of the music. It is also interesting to note that he managed to break and damage so many strings while playing music by Mozart, which, in contemporary performance, is usually played so delicately. This we must attribute to his consistently powerful playing style.

Thomas Scherman and Louis Leopold Biancolli affirm,

In that he produced new effects, broke all the rules, used an extraordinarily wide dynamic palette, and was highly expressive in his playing, Beethoven was the direct link to the romantic pianists. Unlike the disciplined Mozart or Cramer, he played as he felt, unclassically, wrong notes and all. The chances are that he never, even at his best, was an

\footnotetext{
${ }^{100}$ Scherman, Biancolli, The Beethoven Companion, 110.

${ }^{101}$ Ibid, 105.
} 
accurate pianist, and his worst at times must have been distressingly sloppy, even before deafness set in. ${ }^{102}$

One characteristic of Beethoven's music which is often referenced is his lovely legato touch. This was considered a great novelty in a world accustomed to Mozart's detached pianistic style. Returning to the recollections of Anton Schindler, who admits that Beethoven frequently fell short "on the score of pure execution," 103 we also find that "all music performed by his hands appeared to undergo a new creation. These wonderful effects were, in a great degree, produced by his uniform legato style, which was one of the most remarkable peculiarities of his playing."104

French virtuoso Camille Pleyel wrote the following in a letter after witnessing Beethoven perform in 1805:

He has unlimited technical skills but no schooling, and his execution is not polished, that is, his playing is not clean. He has much fire, but he pounds slightly too much; he realizes diabolical difficulties, but not entirely neatly. All the same he gave me much pleasure when improvising. He does not improvise coldly like Woelfl. He realizes whatever enters his head and he is extremely daring. Sometimes he does astonishing things. ${ }^{105}$

We can now better understand how Beethoven managed to break all of those strings in his performance of the Mozart concerto. The criticisms, though mixed with wonder, go on. Italian composer Luigi Cherubini called Beethoven's playing “rough.”106 In 1807, Clementi’s reaction was that Beethoven's playing was "Not... polished...frequently impetuous, like himself, yet always full of spirit."107 Johann Friedrich Nisle, though impressed with Beethoven's improvisations, complained that his technique was "inferior to some others regarding elegance and technical advantages. He also played rather loudly because of his bad hearing." 108

\footnotetext{
${ }^{102}$ Ibid, 106.

${ }^{103}$ Ibid.

${ }^{104}$ Ibid.

${ }^{105}$ Skowroneck, "Beethoven the Pianist," 146.

${ }^{106}$ Ibid, 147.

${ }^{107}$ Ibid.

${ }^{108}$ Ibid.
} 
This eloquent summary of Beethoven's powerful, if imperfect, performance style is from Dr.

Timothy Jones, who writes thoughtfully about Beethoven's impact on Viennese culture in his book

Beethoven, the Moonlight and other Sonatas. He explains,

Since the early 1780s, when Mozart had been the dominant virtuoso in Vienna, a highly articulated non-legato style had been considered exemplary. It was characterised by faultless technical ease, a light touch, the smooth production of an even and brilliant "perlé" tone in rapid passagework, the subtle inflection of melodic lines imitating the ideal of vocal delivery, and the controlled poise with which the player addressed the keyboard. Above all, a good balance should be struck between taste (Geschmack) and feeling (Empfindung). During the 1790s this style was perpetuated in Vienna by older figures such as Joseph Gelinek (1758-1825) and by rivals from Beethoven's own generation like Hummel and Wölfl, both of whom had personal contacts with Mozart. In contrast, Beethoven is reported to have performed with a more pronounced finger legato, and to have used the undampened resonance of his instruments with less discrimination than his rivals. He played more forcefully than exponents of the older style, but his passagework was sometimes comparatively untidy and he lacked the poise and grace that were the hallmarks of performances by Wölfl and Hummel. His tonal range was wider, but it was perceived to be used with more brutality... while many commentators were struck by the affective power of his playing, they did not necessarily value other aspects of its originality. During his first decade in Vienna it was in fact more likely to be cited to his detriment than to his advantage. ${ }^{109}$

\section{Examples of Beethoven Improvising}

Carl Czerny describes Beethoven's ability to perform "In the free-variation form, such as his Choral Fantasy Op. 80 or the choral finale of the Ninth Symphony, which both give a faithful picture of this variety of his improvisation." 110 This "free variation" style would likely not seem very "free" to listeners, who would doubtless be astounded by Beethoven's spontaneous creation of music so powerful and resolute. Czerny offers another category of improvisation that Beethoven used, describing it as a

\footnotetext{
${ }^{109}$ Timothy Jones, Beethoven, the Moonlight and Other Sonatas, Op. 27 and Op. 31 (New York: Cambridge University Press, 1999), 3.

${ }^{110}$ Skowroneck, "Beethoven the Pianist." 156
} 
"mixed style, where one thought followed another in potpourri fashion, as in the solo Fantasy Op. 77."111 This distinction between the varieties of Beethoven's improvisational styles, in this case his more strict style and his "mixed" style, is consistent in the accounts of others who heard him play. In 1812 Friedrich Starke, a military band leader and music editor, describes three different styles of improvisation that he heard from Beethoven: a simple polyphonic style (gebundener Stil), a fugato style, and a chamber style. ${ }^{12}$ Dr. Timothy Jones remarks, “from eye-witness reports it can be surmised that Beethoven’s improvisations contained four basic melodic styles: elaborate virtuoso figuration; irregular melodies suggesting recitative style; cantabile melodies analogous to aria styles; and strict contrapuntal style."113

The categories seem to multiply with more investigation. While the exact meaning of these categories must remain a mystery, as we have no transcriptions and certainly no recordings of them, we can conclude and wonder at the fact that Beethoven was able to develop his improvisational abilities as to create such nuanced distinctions between genres of extempore playing. It is helpful to know from Czerny that Beethoven was able to spontaneously create music that matched the quality and nature of such masterpieces as the chorale finale of his Ninth Symphony and the Fantasia Op. 77. Additionally, the fugal style mentioned by these eye-witness reports may have paralleled the fugues in the sonatas Op. 106 and 110. Perhaps the "recitative" style of improvisation lives on in the compelling recitative section at the recapitulation of Tempest sonata, op. 31 no. 2, among other examples.

Dr. John Salmon has attempted to consolidate the numerous categories of Beethoven's improvisations by providing the following list: Improvised preluding, reharmonization of songs, free fantasies on suggested themes, improvised fugues, piano/violin duet or four-handed capriccios, crossgeneric excursions (such as adding a two hour coda to the finale of the Eroica symphony), Eingang and Durschgang (leadins or improvisations at fermate), embellishing the refrains of rondos (in the Pathetique and $\mathrm{C}$ major concerto), adding notes to various portions of sonata allegro movements, spontaneous

\footnotetext{
${ }^{111}$ Ibid.

112 Nettl, Paul. 1956. Beethoven encyclopedia. New York: Philosophical Library. Pages 97-98

113 Jones, Timothy, The Moonlight and Other Sonatas, 58
} 
developments in the secondary theme area of the exposition of a sonata, ornamented strains of a slow melody, improvising themes and variations, improvised recitative, and various, freely added ornamentation. ${ }^{114}$ This research will divide this list into four larger categories: 1) free improvisation, 2) improvising on a theme, 3) improvised cadenzas, and 4) improvised alterations. This section will define each of these categories and then examine particular events from Beethoven's life that belong in each one.

First, there is the large category of improvisation without reference to existing music. It is the kind of improvisation that, for Beethoven, might yield itself to fugues as strict as that in the Sonata in B flat, op. 106, or a meandering monologue as poignant and unpredictable as the Fantasia for Piano, op. 77. The product of this type of improvisation is a new "composition" of almost any genre, which in Beethoven's case was created spontaneously before an audience. For our purposes, we shall call this "free improvisation." This includes preluding, free fantasies, improvised fugues, and improvised recitative. Second, there is the category of a free-standing improvisation based on a given theme. We shall call this “improvising on a theme." This includes free fantasies based on a given theme, and improvised variations based on a given theme. Third, there are the improvisations that emerge from within a performance of written music, but which depart widely from the written score, even leaving it behind altogether. In this research these types of extempore playing will be referred to as "improvised cadenzas." This will include the normal idea of cadenzas, in addition to codas, Eingangs, Durschgangs, and any other unplanned segments of music inserted or attached to pre-existing music. Lastly, there is improvised music which occurs within a performance of written music, serving to embellish it or spontaneously modify it rather than to disrupt it. This will be referred to as "improvised alterations." This includes reharmonizations, embellished refrains in rondo movements, added notes to sonata allegro movements, ornamented slow movements, and any other kind of ornamentation or addition that is not specifically written down.

\footnotetext{
${ }^{114}$ Salmon, "Improvising in Beethoven," (lecture).
} 


\section{Free Improvisation}

While there are mysteries about Beethoven's "free improvisation" style, what remains proven is its enormous emotional impact on Beethoven's audience. Beethoven's faithful student Ferdinand Ries remembered, "His extemporizations were the most extraordinary things that one could hear. No artist that I ever heard came at all near the height which Beethoven attained. The wealth of ideas which forced themselves on him, the caprices to which he surrendered himself, the variety of treatment, the difficulties, were inexhaustible." ${ }^{115}$ Baron de Tremont, who heard Beethoven improvise many times in 1809, claimed that the improvisations were more emotionally powerful than anything else in Beethoven's playing. ${ }^{116}$ Beethoven's improvisations also seemed to reveal his tender side, a rarely seen facet of his complex, blustery personality. William Kinderman tells the story of Antonia Brentano nee Birkenstock, a sickly woman among Beethoven's acquaintances who often had to retreat to the lonely solitude of her home. During these episodes, she remembers how Beethoven often visited her, saying he "came in, seated himself without any further ado in her antechamber and improvised; when he had 'said everything and given solace' to the sufferer in his own language, he left as he had come, without taking notice of anybody else."117

\section{Improvising on a Theme}

Many accounts of Beethoven's improvisations mention the extraordinary way that he handled a theme that was given to him. One among many humorous accounts is from Czerny, who says,

I still remember how one day Gelinek told my father that he was invited to a party that evening where he was to oppose a foreign virtuoso in a pianistic duel. -I'll fix him,

\footnotetext{
115 Beethoven, Kerst, Beethoven, as Revealed in His Own Words, 45

${ }^{116}$ Nettl, Beethoven Encyclopedia, 97

${ }^{117}$ William Kinderman, "Improvisation in Beethoven's Creative Process," in Musical Improvisation: Art, Education, and Society, ed. Gabriel Solis and Bruno Nettl (Urbana: University of Illinois Press, 2009), 298.
} 
Gelinek added. Next day my father asked Gelinek about the outcome of the battle. Gelinek looked quite crestfallen and said: - Yesterday was a day I'll remember. That young fellow must be in league with the devil. I've never heard anybody play like that. I gave him a theme to improvise on, and I assure you I've never even heard Mozart improvise so admirably. Then he played some of his own compositions, which are marvelous - really wonderful - and he manages difficulties and effects at the keyboard that we never even dreamed of. "-I say, what's his name?" asked my father with some astonishment. "- - He is a small, ugly, swarthy young fellow and seems to have a willful disposition, answered Gelinek; - Prince Lichnowsky brought him to Vienna from Germany to let him study composition with Haydn, Albrechtsberger, and Salieri, and his name is Beethoven. ${ }^{118}$

Václav Jan Křtitel Tomášek, a Czech composer who made the acquaintance of Beethoven, claimed that Beethoven "shows himself to the greatest advantage in improvisation, and here, indeed, it is most extraordinary with what lightness and yet firmness in the succession of ideas Beethoven not only varies a theme given him on the spur of the moment by figuration (with which many a virtuoso makes his fortune and-wind) but really develops it."119 Creating variations on a theme was a standard skill of keyboard players in the $18^{\text {th }}$ and early $19^{\text {th }}$ centuries. However, it appears that Beethoven distinguishes himself from the norm, by not only subjecting the theme to the basic, predictable embellishments that audiences had come to expect, but by truly transforming it.

Beethoven managed to not only gain admirers through his improvisations on themes, but he also made some enemies. Alexander Wheelock Thayer, the earliest biographer of Beethoven, tells this story that took place in 1800, when Beethoven entered into a playful competition with the showy virtuoso Daniel Steibelt:

Steibelt responded to a performance of Beethoven's Clarinet Trio Op. 11 with polite condescension, offering in turn a showy improvisation on a popular operatic theme-the same tune chosen by Beethoven for the variations forming the finale of his trio. Beethoven retaliated by seizing the cello part of a quintet by Steibelt...after placing it upside down on the music stand, he poked out a theme with one finger from its opening

\footnotetext{
${ }^{118}$ LeBlanc-Kinne, "Incorporating," 3-4

${ }^{119}$ Kinderman, "Improvisation,” 297
} 
bars. Offended, Steibelt walked out during Beethoven's ensuing brilliant improvisation and refused any further association with him. ${ }^{120}$

A similar scenario is played out in 1809 , this time with Ignaz Pleyel. Czerny recounts how Pleyel played for Prince Lobkowitz one evening in Vienna, and the highlight of the concert was a performance of Pleyel's latest string quartet. Beethoven was present at this recital and was prodded to perform, but he did not want to play and became increasingly irritable as the requests continued. Beethoven suddenly jumped up, ripped the second violin part of Pleyel's quartet off the stand, carried it to the piano and began to improvise. Czerny remembers, "Never had one heard something so ingenious, so captivating, so brilliant from him; but in the middle of his fantasy one could still hear plainly a banal run drawn from the violin part....He had built his entire beautiful improvisation upon this figure"121

\section{Improvised Cadenzas}

Most pianists are familiar with the concept of improvising a cadenza in the first movement of a concerto, before the return to the recapitulation. However, many may not be familiar with the practice of adding a small Eingang, (literally "entrance" in German) on select fermate within sonata movements and other solo repertoire for the piano. David Polan has written an exhaustive and insightful article on this subject, entitled "The Eingang in Early Beethoven."122 An Eingang is a "lead-in," or a short, cadenzalike improvisation that would stand as a prelude or musical preface, and often within a piece it would smooth the transition into a new section, usually a returning principal subject. It would normally serve to embellish a fermata over a dominant chord. Polan explains that the Eingang would be "recognized by certain notational conventions: the presence of a fermata before recurrent principal thematic material over a functioning dominant chord or a rest. In this way, the Eingang both served to elaborate the given harmony and to facilitate a smooth thematic transition. The properly constructed Eingang was not to be

\footnotetext{
${ }^{120}$ Ibid.

${ }^{121}$ Kinderman, "Improvisation,” 298

${ }^{122}$ Polan, David. “The Eingang in Early Beethoven.” Performance Practice Review. 7, no. 1 (1994): 78-84.
} 
too long, was not necessarily to be played in strict meter, and above all had to conform to the principle of unity of affect." 123

Eingangs were common, and they were used in accordance with widely understood conventions.

C.P.E Bach, in his Versuch über die wahre Art das Clavier zu spielen, describes the function and boundaries of the Eingang in the following ways:

Fermate over rests occur most frequently in allegro movements and are not embellished. [Embellished fermate] are usually found in slow, affetuoso movements and must be embellished, if only to avoid artlessness. In any event, elaborate decoration is more necessary here than in other parts of movements... [These elaborations] require a slow or at most a moderate tempo. Since such elaborations must be related to the affect of a movement, they can be successfully employed only when close attention is paid to a composer's expressive aim. ${ }^{124}$

Daniel Gottlob Turk also addresses the practice of Eingang in his 1789 Klavierschule. In his chapter on

"Extemporaneous Ornamentation," he offers the following rules for the proper execution of an

embellished fermata:

Fermate are either to be played without extempore elaborations (simple fermate) or they are embellished... Every embellishment must suit the character of the composition... The embellishment should not be too long; nevertheless, one is not bound as far as the meter is concerned... The duration of tones ... [is not] exactly specified; therefore it is possible now and then to linger somewhat longer, and in other places, on the contrary, to play a little faster, according to the demands of the affect...the appoggiaturas before the actual fermate, and in addition, even the main notes can also be embellished... By means of the transition one should lead skillfully into the principal subject, and especially into the given interval of the upper voice [the melody]. ${ }^{125}$

It is certain that the reader has already thought of countless points in Beethoven's piano music where fermate normally go plain and undecorated. It is important to consider the great contrast between the prevalence of improvised embellishments in Beethoven's lifetime and the absence of such

\footnotetext{
${ }^{123}$ David Polan, “The Eingang in Early Beethoven,” Performance Practice Review 7, no. 1 (1994): 82.

124 Polan, "Eingang in Early Beethoven," 80-81

125 Türk, Daniel Gottlob, and Raymond H. Haggh. School of clavier playing, or, Instructions in playing the clavier for teachers \& students. Lincoln: University of Nebraska Press, 1982.

Quoted in Polan, "Eingang in Early Beethoven," 80-81
} 
embellishments in the performances of today. It is also important, however, to consider the appropriate use of the Eingang. Polan offers the following thoughts on how to decide whether the use of an Eingang is warranted:

...in all such instances the question must be put forth: should an Eingang indeed be utilized? The determining factor of this "should" is dictated by two elements: the psychological expectancy of an Eingang's use-Do we want to hear something more? Is this an area that needs to be "filled in"? - and the suitability of its use under the affect governing the movement out of which the Eingang must come. ${ }^{126}$

Certainly, many of these questions can only be answered on stage, in the moment. Every concert is different, and every audience is different. In order to bring an honest performance to an audience, a performer must be flexible enough to meet the needs of the moment.

Beethoven, as it turns out, left many fermate undecorated in his early sonatas, and they seem to plead for proper embellishment. Polan takes great care to provide many such examples in his article, which I have also provided, but from different editions. Polan explains that the Eingang seems to be mostly appropriate in early Beethoven works, where he often left fermate undecorated.

${ }^{126}$ Polan, "Eingang in Early Beethoven," 80-81 
Example 5: Sonata in A Major, Op. 2, no. 2, mvt. 1, mm 158-62. Similar excerpt used on page 82 of Polan's article.

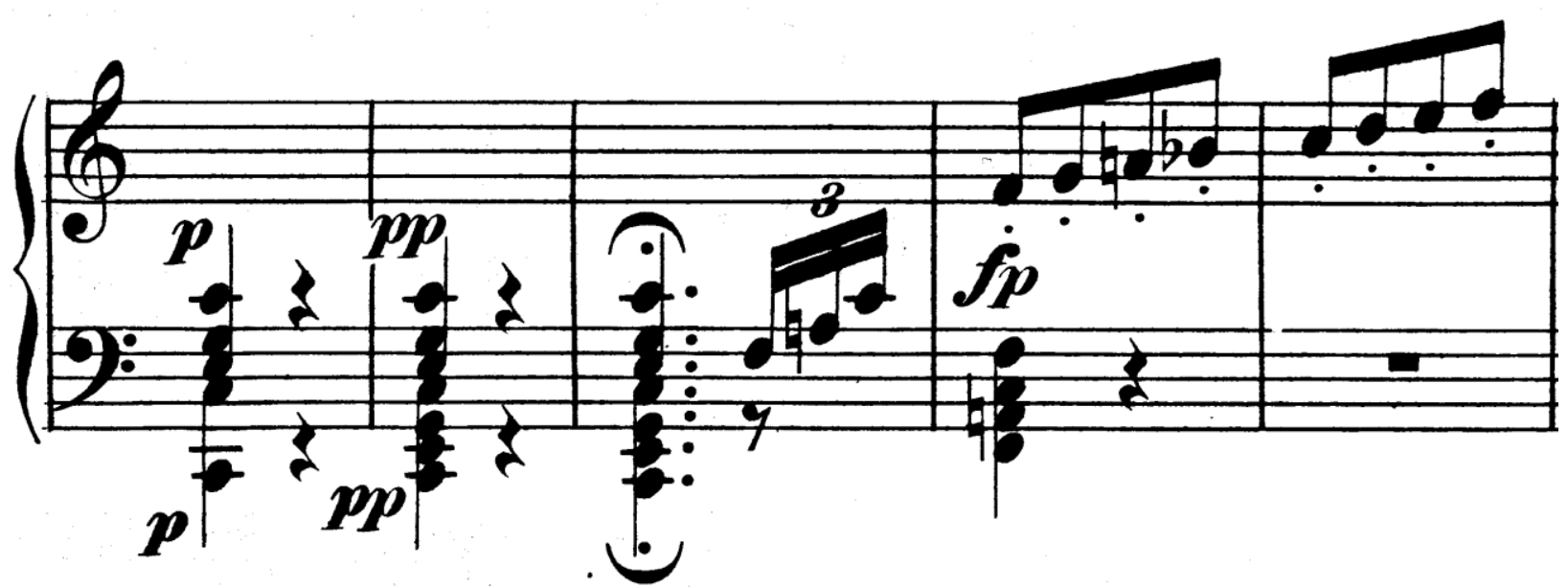

Source: Beethoven, Ludwig van. Sonaten für das Pianoforte. New York: Edwin F. Kalmus, n.d. (193370).

Example 6: Sonata in D major, Op. 10, No. 3, Mvt. 1, mm. 180-5. Similar excerpt used on page 83 of Polan's article.

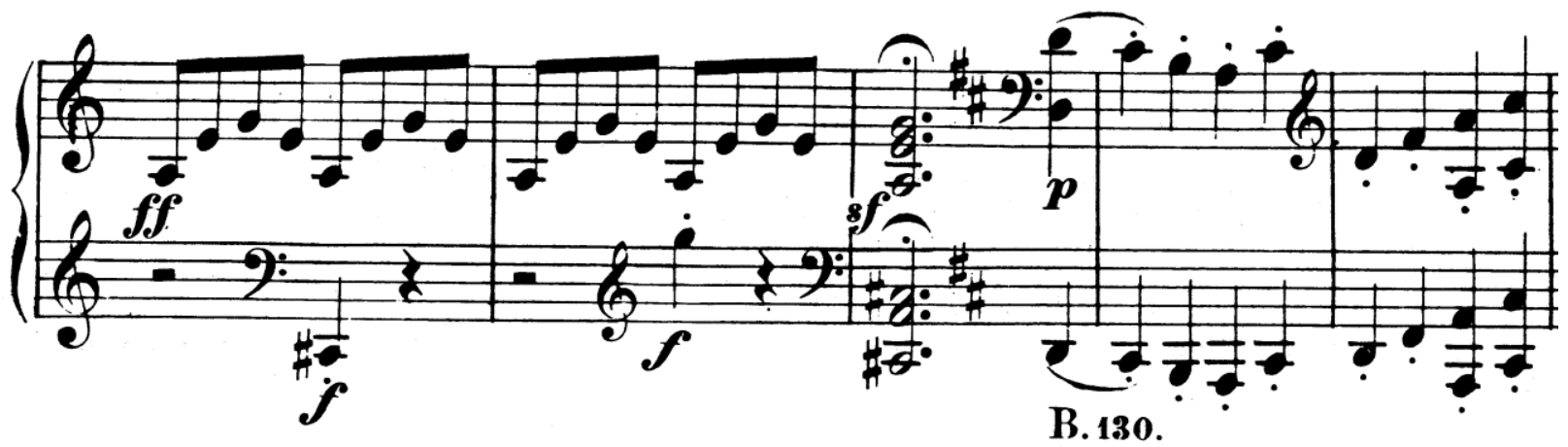

Source: Beethoven, Ludwig van. Sonaten für das Pianoforte. New York: Edwin F. Kalmus, n.d. (193370).

These Eingang-material fermate gradually disappear in later Beethoven. Polan points out,

"Interestingly, the number of instances in which an Eingang seems to be implied in Beethoven decreases 
in proportion to the number of his own written-out Eingange. Evidently he took a greater responsibility to write out Eingange as his style developed."127

Example 8: Sonata in E flat major, Op. 27, No. 1, Mvt. 3, mm. 25-26. Similar excerpt used on page 83 of Polan's article.

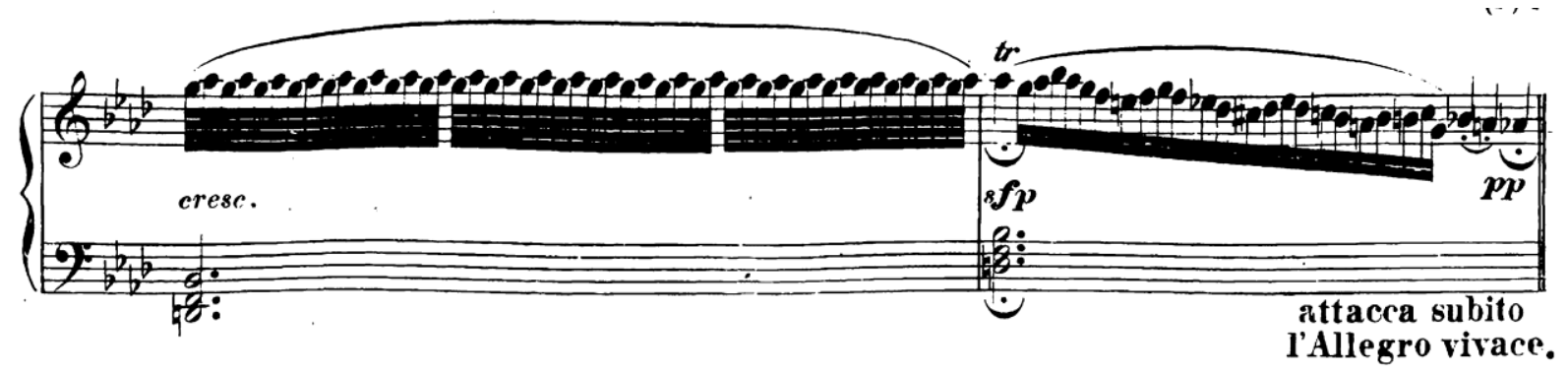

Source: Beethoven, Ludwig van. Sonaten für das Pianoforte. New York: Edwin F. Kalmus, n.d. (193370).

Example 9: Sonata in G major Op. 31, no. 11, Mvt. 2, mm. 25-26. Similar excerpt used on page 82 of Polan's article.
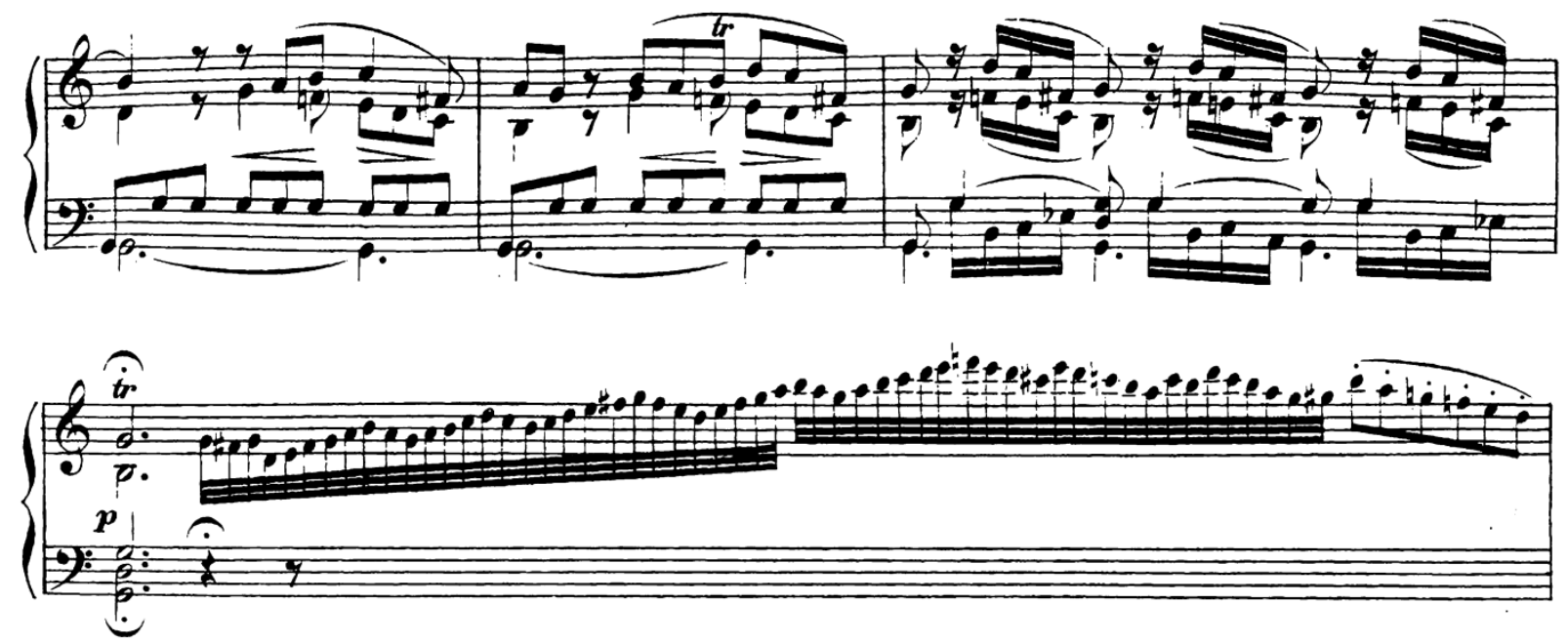

Source: Beethoven, Ludwig van. Sonaten für das Pianoforte. New York: Edwin F. Kalmus, n.d. (193370).

${ }^{127}$ Polan, "Eingang in Early Beethoven," 82 
These Eingange directly from the mind of Beethoven serve as the most logical teachers for musicians who wish to apply Eingange to his earlier works. They are short and musically unsubstantial for the most part, but they provide the listener with a clear signal that the argument has been developed and a new chapter approaches. Polan says, "These observations of Beethoven's handiwork, as derived from a theoretical approach provided by C. P. E. Bach and Türk, may serve as a prescription for the filling in of areas left by Beethoven to be executed at the performer's discretion. It must be emphasized that the impression to be created should always be one of spontaneity and of appropriateness to the movement or section at hand." 128

Why is it that practices such as the Eingang have so completely disappeared from modern performance practice and pedagogy? Polan observes, "While the Eingang has been accepted as readily applicable in early Classic composers, such as Stamitz or C. P. E. Bach, or to later masters such as Haydn and Mozart, its suitability for Beethoven has until now not been generally acknowledged. Perhaps the most frequently given reason for this is the so-called 'apology' letter which Beethoven wrote to Carl Czerny." ${ }^{129}$ Many are aware of this humorous letter which was written after Beethoven publically rebuked Czerny for adding notes to his quintet for piano and wind instruments. Beethoven writes to Czerny with much earnestness,

Dear Czerny! Today I cannot see you, but tomorrow I will call on you myself to have a talk with you.- - I burst forth so yesterday that I was sorry after it had happened; but you must pardon that in a composer who would have preferred to hear his work exactly as he wrote it, no matter how beautifully you played in general.-I shall make amends publicly at the Violoncello Sonata. Be assured that as an artist I have the greatest wishes for your success and will always try to show myself- Your true Friend Beethoven ${ }^{130}$

This letter is often used to justify the iron bars over Beethoven's music, and the unspoken laws against creativity in performances of his works. In fact, it seems to be this particular letter which is cited

\footnotetext{
${ }^{128}$ Polan, "Eingang in Early Beethoven," 78

${ }^{129}$ Ibid.

${ }^{130}$ Alexander Wheelock Thayer, The Life of Ludwig van Beethoven (New York: The Beethoven Association, 1921) 641.
} 
most often when performers try to explain why they refuse to alter a single note in Beethoven's scores. The words from the pen of the "composer who would have preferred to hear his work exactly as he wrote it" ring in the ears of almost every classical pianist in modern musical culture, and understandably so. It is important to know the rest of the story, however. For example, what was it exactly that Czerny did to provoke such a reaction from Beethoven, and in consequence such an apology letter? Fortunately, we have a description of the offensive performance from Czerny himself: "I took the liberty, in my youthful levity, to make many alterations, — such as introducing difficulties into the passages, making use of the upper octaves, \&c., \&c. Beethoven sternly and deservedly reproached me for this in the presence of Schuppanzigh, Linke, and the other performers."

Such an extensive alteration of this score becomes even more shocking when one examines the piano part itself, which is quite flashy and virtuosic and certainly not in need of elaboration. Furthermore, it is clear that Czerny's adventurous embellishments were not drawn from common performance practice as described by C.P.E. Bach or Daniel Gottlieb Turk, nor were they compatible with the written-out embellishments that can be observed in Beethoven's own later works. ${ }^{132}$ In the last chapter of this dissertation some examples will be provided of tasteful and distasteful attempts at improvisation in Beethoven's works.

There is another eye-witness account of a performance of this same quintent which may lend some clarity to Beethoven's own improvisational practice in this category. The unfortunate incident involving Czerny's public embarrassment occurred on Feb 11, 1816. Nineteen years earlier, Beethoven himself was performing the same piece with the famous oboist Friedrich Ramm, and Ferdinand Ries recalls,

In the last allegro a fermata occurs several times before the theme begins again. In one of these pauses Beethoven suddenly started improvising, taking the rondo subject as his theme and entertaining himself and the others for quite some time. This was not the case

\footnotetext{
${ }^{131}$ Polan, "Eingang in Early Beethoven," 78

${ }^{132}$ Ibid.
} 
with his accompanists, however; they were very annoyed and Mor. Ramm was even angry. It did indeed look rather droll to see these gentlemen, expecting to begin any moment, raising their instruments to their mouths incessantly and then quietly putting them down again. At last Beethoven was satisfied and returned to the rondo. The whole society was enchanted. ${ }^{133}$

It appears, then, that Beethoven was not so attached to the score as written that he would not make major changes in performance. His addition of an improvisation at a fermata is consistent with the performance practice of the time, although, in typical Beethoven fashion, it was far grander and more dramatic than the audience or the other musicians expected. Shorter Eingangs actually appear written out at the fermate in this score, but Beethoven apparently discarded the Eingang he had written out and devised a stunning cadenza to fit the moment. David Polan observes, "It would seem apparent that Beethoven changed this written-out elaboration spontaneously, substituting a much more involved one. This is perhaps indicative of the manner in which written-out Eingange were treated, i.e. simply as a guide or suggestion provided by the composer." 134

\section{Improvised Alterations}

As if these dramatic examples of Beethoven's cadenzas were too tame, there are also examples provided by eye witnesses who describe Beethoven unapologetically changing the written notes midperformance. In order to better understand the relative normalcy and the novelty of Beethoven's improvisations, it is helpful to understand the improvisation conventions of the time. The 1796 Jahrbuch der Tonkunst von Wien und Prag (Yearbook of Music of Vienna and Prague), written by Johann Ferdinand Schönfeld, contains instructions on the performance practice of the day. With regards to spontaneous embellishment of instrumental performances, this yearbook explains, "There are places where it is advantageous to insert much ornamentation. This, however, must be done with care and

\footnotetext{
${ }^{133}$ Robert Winter and Bruce Carr, Beethoven, Performers, and Critics: The International Beethoven Congress, Detroit, 1977. Detroit: Wayne State University Press, 1980. 55-56.

${ }^{134}$ Polan, "Eingang in Early Beethoven," 78
} 
consideration in such a way that the basic emotion does not suffer, but is enhanced. The adagio, which because of its simple melodic layout often becomes the playground of ornamentation, does not allow fast passage work and scales, but instead well-selected chromatic lines which sigh and languish and then die out.",135

While there are many examples of Beethoven's improvised alterations to written works, this section will focus on two important accounts which paint a relatively thorough picture of the extent of this creativity. In a passage from his "Notizen über Beethoven" 1852, Carl Czerny describes this mysterious habit of Beethoven's in his performances of piano sonatas:

In the form of the first movement or the final rondo of a sonata, where he concluded the first part in a regular manner and also introduced a middle melody etc. in the related key in that part; in the second half, however, he surrendered to his enthusiasm, completely freely, but still using the motive in all possible ways. In an allegro the whole was enlivened with bravura passages, which most of the time were more difficult than one could find in his composed works. ${ }^{136}$

It appears that Czerny is referring to the "third theme" or "closing theme" in the exposition of the sonata allegro movement when he says "second half." How exciting it would be to know exactly how Beethoven "enlivened" these expositions. We must be content with the knowledge, however, that Beethoven treated sonata allegro and rondo movements very freely in the way he applied improvised alterations.

Another example is found in the humorous account of Beethoven's accompaniment of the famous singer Ferdinand Heller. Heller was singing the "Lamentations of Jeremiah" during Holy Week in 1785, and the young, impetuous Beethoven accepted a challenge to try and shake Heller off of the melody by improvising a wild new harmonization in the accompaniment. Heller was known for his sturdy sense of pitch, and was determined that Beethoven could not improvise an accompaniment strange enough to confuse him. Franz Gerhard Wegeler, a childhood friend of Beethoven's, claims that the fifteen-year-old

\footnotetext{
${ }^{135}$ Schönfeld, Johann Ferdinand. Jahrbuch der Tonkunst von Wien und Prag, (München: E. Katzbichler, 1796$), 167$.

${ }^{136}$ Skowroneck, "Beethoven the Pianist," 156
} 
squarely defeated Heller "by means of some bold modulations, even though he kept on playing the melody together with the singer." 137

This playful account reveals Beethoven's staggering abilities and his humorously loose relationship with perfection and literal performances of the written score. Dr. Salmon sums it up: "In a word, Beethoven was a performer not bound by the text, his or anybody else's...Rather, the printed page seems to have served only as a springboard for his incredible imagination and communicative spirit. In this context, Czerny's reported reprimand of 1816 diminishes in importance, and should hardly serve as an interpretive guideline for performers. ${ }^{138}$

\section{How did Beethoven Teach Improvisation?}

In addition to the multiple examples of Beethoven deviating from the written score, we also have examples of him requesting that his students do the same. Ferdinand Ries offers a relatively conservative account of Beethoven's pedagogical approach to improvisation, saying

I remember only two occasions where Beethoven instructed me to add a few notes to his compositions - once in the Rondo of the Sonata Pathétique (Op. 13), and again in the theme of the Rondo of his first concerto in $\mathrm{C}$ major, where he specified several doublings to make it more brilliant...In playing he would give now the right, now the left hand of a particular passage a beautiful but nonetheless inimitable expression; only in extremely rare cases would he add notes or ornamental decorations." 139

It is of utmost importance to note that even if modern pianists were to only imitate this description of the "extremely rare" cases when Beethoven improvised, it would revolutionize modern performance practice. Ries says elsewhere that Beethoven "seldom introduced notes or ornaments not set down in the composition. ${ }^{\text {140 }}$ We have reason to believe that this was a rather slanted perspective on Beethoven's performances, especially considering Ries's sensational accounts of Beethoven's frequent improvisations.

\footnotetext{
137 Skowroneck, "Beethoven the Pianist," 158.

${ }^{138}$ Salmon, "Improvising in Beethoven."

${ }^{139}$ International Beethoven Congress, Winter, and Carr, Beethoven, 106-107

${ }^{140}$ Scherman, Beethoven Companion, 107
} 
Even if it were a faithful representation, however, this Beethovenian practice of infrequent additions to the written score would be radical if applied on the modern stage. Furthermore, Ries also said that Beethoven always played strictly in time. ${ }^{141}$ It is made very plain in several unbiased accounts that Beethoven's tempo was elastic and rarely steady, so we know that Ries was being overly conservative on this account. It is possible that he had a reason for wanting to portray Beethoven as less of a musical renegade than he truly was, but it is hard to say why Ries would make these claims about Beethoven. However, it is paramount to recognize that even a few embellishments of the rondo in the famous Pathetique sonata would be an enormous deviation from normal performance practice today.

On November 2, 1793, Beethoven wrote a letter of instruction to Eleonore von Breuning, to whom he had dedicated the variations in F major, Se vuol ballare. He said "The variations will prove a little difficult to play, particularly the trills in the coda; but let that not frighten you. It is so disposed that you need play only the trills, omitting the other notes because they are also in the violin part." ${ }^{142}$ This practical suggestion to omit superfluous notes seems rather controversial in a musical culture that cherishes every note that Beethoven penned.

\footnotetext{
${ }^{141}$ Scherman, Beethoven Companion, 107

${ }^{142}$ Beethoven, Kerst, Beethoven, 54
} 
Example 10: Variations in F major, "Se vuol ballare."
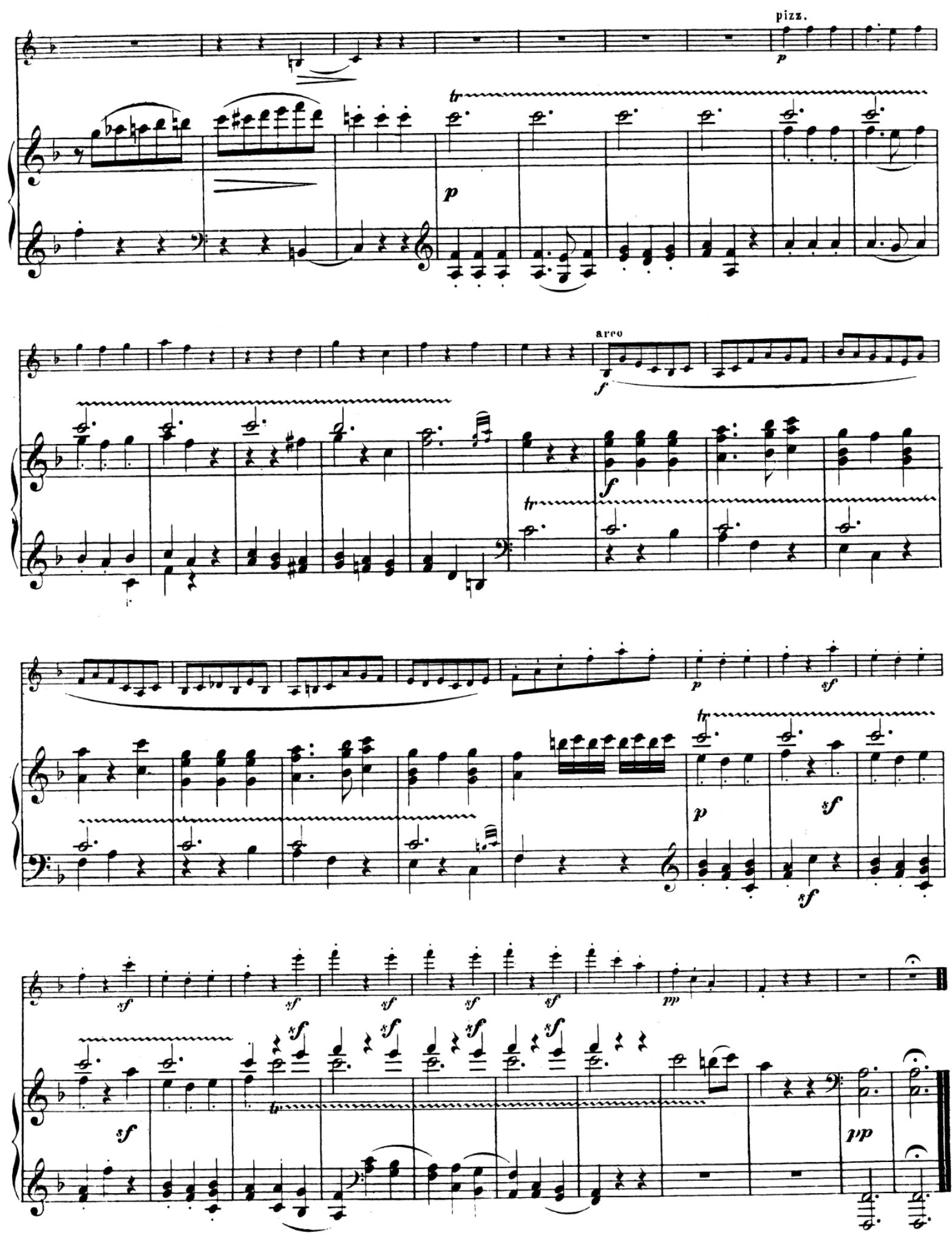

B. 1113 
Source: Beethoven, Ludwig van. Serie 12: Für Pianoforte und Violine, Nr. 103. Leipzig: Breitkopf und Härtel, 1862-90.

Ries also provides us with a humorous account of Beethoven's instructions to him regarding a certain cadenza. Ries remembers,

I had asked Beethoven to compose a cadenza for me, which he refused to do, directing me to make one myself which he would then correct. Beethoven was highly satisfied with my composition and changed little. There was, however, one very brilliant and difficult passage which he liked but which seemed too daring, and he therefore instructed me to compose another one. Eight days before the performance he wished to hear the cadenza again. I played [the same one] and again smudged the passage; again, somewhat irritated, he told me to change it. [This time] I did, but the new one did not satisfy me. I therefore practiced the other one most assiduously, without being able to become absolutely certain of it. In the public concert...I could not convince myself to choose the easier one; when I then launched brazenly into the more difficult one, Beethoven jerked violently in his chair. Nevertheless it worked perfectly and Beethoven was so overjoyed that he shouted loudly 'bravo!' This electrified the entire audience and gave me instantly a position among the artists. Afterwards, as he expressed his satisfaction to me, he added: 'But you are obstinate all the same. Had you missed that passage I would never have given you another lesson again.", 143

There are many things to notice in this story. First, that Beethoven was a rather overbearing teacher, expecting his students to comply with his demands regardless of their personal wishes. This domineering tendency is intriguingly balanced by Beethoven's urging that Ries create his own cadenza rather than making one for him. It is worth noting that when his student asked for a cadenza from Beethoven's own pen, Beethoven urged his student to expand his musical abilities by creating his own cadenza. It is probable that Ries would be unable to create a cadenza as lovely as Beethoven might create, but in this case Beethoven placed his student's creativity at a higher priority than his access to the greatest music.

\footnotetext{
${ }^{143}$ International Beethoven Congress, Winter, and Carr, Beethoven, 114
} 
It is also interesting to consider Beethoven's enthusiastic applause in this account when Ries victoriously performed the more difficult cadenza, despite Beethoven's insistence that he perform the easier one. There is some wisdom to be gained from Beethoven's teaching style. Improvisation is a practiced talent, and pianists should know their limitations. Secure performances of simple improvisations are to be preferred over sloppy, uncouth performances of impressive improvisations. At the same time, courageous accomplishments from our students are to be rewarded. This balance is difficult to describe, but Beethoven sets a good example of encouraging Ries to know his limitations, but showering him in ecstatic praise when he exceeds expectation. A teacher's greatest role is to help the student to see their own path more clearly, with all of its dangers and possibilities, and to encourage them every step of the way.

\section{Conclusion}

Beethoven had a marked distaste for performances without feeling. If anything can be clearly demonstrated about Beethoven's tastes in music, it is that music does not demand perfection, but it does demand honesty from the performer. Performances without honesty were empty shells in Beethoven's view. The best technique and the most flawless execution meant very little if the spirit of the music was not presented with the appropriate emotion. Beethoven often complained about the sterile, bloodless performances of his day, making statements like "As a rule, in the case of these gentlemen, all reason and feeling are generally lost in the nimbleness of their fingers." ${ }^{144}$ These reports of Beethoven's actual performance practice should challenge our beliefs and priorities on the stage, in the recording studio and in the practice room. Improvisation does not have to be the centerpiece of our performance practice, but honesty should be. It is certainly possible to give a performance which is entirely consistent with the composer's written score and is also entirely honest. For students who struggle to bring genuine emotion

${ }^{144}$ International Beethoven Congress, Winter, and Carr, Beethoven, 50 
to their performances, though, improvisation can be a helpful tool to help them access the personal qualities which every great performer must have and which made Beethoven an unforgettable artist. 
The Transition Away from Improvisation in Music History

As the previous chapter demonstrated, Beethoven came from a world where improvisation was common and expected. Beethoven himself indulged in dramatic deviations from the score. Bruce Ellis Benson, in his book The Improvisation of Musical Dialogue: A Phenomenology of Music, claims that "such improvisation would be highly questionable to performers today. In contrast, our conception of the role of a classical musician is far closer to that of self-effacing servant who faithfully serves the score of the composer. Admittedly, performers are given a certain degree of leeway; but the unwritten rules of the game are such that this leeway is relatively small and must be kept in careful check." ${ }^{145}$ After considering all of the weight of evidence supporting Beethoven's liberal application of improvisation, it should cause us to wonder how we have arrived at such a constrained approach to performance practice today. On modern stages one may hear improvised embellishments in Bach, and possibly an original cadenza in a Mozart concerto, but we are hard-pressed to remember even one occasion when we heard a single original note in a performance of Beethoven's music. John Salmon observes, “of all the classical composers, Beethoven is the one whose compositions seem most off-limits to alteration. They have attained the status of platonic ideals, immutable and perfect. For no other composer is the text - the urtext - treated with more respect." $" 146$

How, then, did we get from a free-thinking culture of composer/performers to a culture of "selfeffacing servants," and how might we return to a more authentic approach to improvisation? This chapter will present four theories on why and how performance practice has changed over the years: 1) improvisation is not a common aspect of classical training because of the decreased rigor of training in theory, resulting in an insufficient familiarity with the "language" of music; 2) the growing middle class in the $19^{\text {th }}$ century, which had a less refined appreciation for music, sparked an increasing friction between academic and popular styles of music; 3) the romantic concept of a divinely-inspired master

\footnotetext{
${ }^{145}$ Bruce Ellis Benson, The Improvisation of Musical Dialogue: A Phenomenology of Music. (Cambridge: Cambridge University Press, 2003), 5.

${ }^{146}$ Salmon, John. "Improvising in Beethoven.” Lecture at Focus on Piano Literature, Greensboro, NC, June, 2002.
} 
composer discouraged performers from changing the written notes; and 4) the modern interest in historically informed performances has been biased toward the use of period instruments and has sometimes disregarded other aspects of historical performance practice.

\section{Students are Unfamiliar with the Language of Music}

We must acknowledge that there is a difference between memorized performances of the musical language and fluency in the same language. One might compare some modern performances, which normally adhere to the written score, to a passionate recitation of memorized poetry in an unfamiliar language, while the historical tradition of improvisation could be compared to speaking fluently in the language. In order to be considered fluent in a particular language, one must be able to manipulate the components of that language in order to express original ideas. ${ }^{147}$ It should not be assumed that this chapter will argue that the modern masters are illiterate in the language of music. It is impossible to convincingly perform beautiful music without understanding it. However, this chapter will argue that the goal of fluency is largely missing from modern classical training, and it should be placed at a higher priority.

Much of a student's practical exposure to the language of music comes from music theory classes. The lowering of standards in music theory has contributed to an insufficient knowledge of the language, ultimately producing students who understand the basic principles of music theory but have not experimented with them in composition or in performance. Musicologist and performer Robert Levin provides the following perspective on modern theory training:

The decline in the stringency of music theory requirements in schools throughout the world has led to a situation in which performers master the syllabic surface of the works they play without sufficient knowledge of the language that underpins it. No wonder, then, that it is still relatively rare to hear a performance of Classical music that goes beyond the printed page; and when it

\footnotetext{
${ }^{147}$ The definition of "fluent" is given as "capable of using a language easily and accurately" and "having or showing mastery of a subject or skill" in the Merriam-Webster Dictionary. Since the goal of language is to communicate, the mastery of language must involve easy and accurate use of its components to communicate original ideas.

"fluent." Merriam-Webster.com, 2011, http://www.merriam-webster.com (23 October 2016).
} 
does, the embellishments and cadenzas presented are usually the product of careful preparation rather than risk-laden spontaneity. ${ }^{148}$

Beethoven understood this concept of the music language, and the necessity of being familiar with it, as evidenced by his response to Wegeler, who was astounded by Beethoven's ability to read fast and complicated music at top speed. Beethoven explained to Wegeler, "In reading rapidly a multitude of misprints may pass unnoticed because you are familiar with the language." ${ }^{149}$ There is much to be learned from this comment. Beethoven's relationship with the score, at least in this case, was not based on a meticulous reading of every note and marking. His fluency in the language of music allowed him to process the written score as a flawed representation of the music, not the totality of information needed to create music. It is interesting that Beethoven responded to Wegeler's amazement by bringing up misprints in the score, indicating that they were unnoticed because Beethoven already had guessed what the score would contain, and he played it without needing a perfect score to assist him. He was using the misprints as proof of his fluency in music. It could be compared to reading an email from a friend whose meaning you understand so perfectly that you do not even observe a few misspelled words.

Furthermore, improvisation requires a structured language in which to function in order to be meaningful to an audience, and this is why haphazard sounds cannot be considered improvisation. Robin Moore explains, "In an important sense, improvisation is not free. It is only an effective means of expression when incorporating a vocabulary, whether cognitively or intuitively understood, common to a group of individuals." ${ }^{150}$ Carol S. Gould and Kenneth Keaton agree with Moore in their article "The Essential Role of Improvisation in Musical Performance," saying, "The concept of harmonic progression is itself one of the fixed fundamental structures comprising the scaffolding of the Western musical tradition. While some players improvise with great abandon, they nonetheless must respect both the limits

\footnotetext{
${ }^{148}$ Robert D Levin, “Improvised Embellishments in Mozart's Keyboard Music.” Early Music, 20 (1992): 221.

${ }^{149}$ Friedrich Kerst, Beethoven, as Revealed in His Own Words: The Man and the Artist (Wellington: Floating Press, 2009; 1904), 52.

${ }^{150}$ Robin Moore, "The Decline of Improvisation in Western Art Music: An Interpretation of Change." International Review of the Aesthetics and Sociology of Music, 23, no. 1 (June 1992): 64.
} 
of the genre and of the musical logic itself; otherwise their performances lose intelligibility and become simply haphazard sequences of sound."151

This concept of fluent communication through music is greatly underemphasized in modern musical training. Interpretation of masterpieces is certainly accentuated, but creative engagement with masterpieces and direct communication with one's audience are sometimes ignored. Some modern musical training is born out of the idea that one's audience is expected to seek out meaning in the music they hear, rather than having meaningful thoughts intentionally communicated to them. Performers who subscribe to this view do not reach out to their audiences; rather, the audience is expected to reach out and grasp the music. "Because of our current attitudes about academic art," Moore later goes on to say, "many composers are not disturbed if they find they are unable to communicate easily to others through their music. On the contrary, some actually seem to pride themselves on maintaining such distance." ${ }^{\prime 52}$

\section{Effects of the Growing Middle Class}

The generations of musicians in the late nineteenth and early twentieth centuries experienced many changes in performance expectations due to changes in society. With the growing middle class came new musical styles, and Robin Moore makes the case that the lower and middle-class styles that permeated society in this time were actually very similar to the fluid, improvisatory styles of the eighteenth century upper class styles. Moore explains, "the increasing numbers of petit bourgeois and working class individuals interested in learning to play and compose art music from about 1850 grew up in a musical environment unique to their own social background. The musics they heard among friends, at dances, on the street, or in the course of everyday life, and that many of them improvised upon, bore some resemblance to court-derived styles, but were in fact stylistically distinct." ${ }^{\text {"153 }}$ Just as Mozart's familiarity with the art music that he grew up with caused him to be able to improvise on it so fluently,

\footnotetext{
${ }^{151}$ Carol S. Gould, Kenneth Keaton, "The Essential Role of Improvisation in Musical Performance," The Journal of Aesthetics and Art Criticism, 58, Issue 2 (Spring 2000) 146.

${ }^{152}$ Moore, "The Decline of Improvisation," 76

${ }^{153}$ Ibid., 70
} 
the popular styles that lower and middle class families grew up with also became associated with improvisation and a loose relationship with the written score.

However, art music itself continued in a quite different direction. Because it was now associated with the upper class, art music was no longer a widespread musical language heard on the streets and surrounding the children who would grow up to be composers. Furthermore, the composers who began to dominate the composition of art music were actually from lower class families, and therefore had even less familiarity with the sophisticated styles of art music. Bronwyn LeBlanc-Kinne describes the transition into the $20^{\text {th }}$ century, when improvisation had almost entirely ceased to be an expected part of classical performances. LeBlanc-Kinne says,

During this period, there was a shift in how professional musicians were trained. In the Baroque and Classical periods, most musicians were trained within a musical family and were surrounded by the upper class patronage, thus surrounded by Western art music at a young age. Professional musicians in the late nineteenth century such as Debussy, Bartók, and Schöenberg [sic] came from more humble backgrounds and were not from musical families, thus they had to study art music formally in order to obtain training in upper-class musical traditions. ${ }^{154}$

\section{Again from Moore,}

Musicians of Western art music in late $19^{\text {th }}$ century often came from poor families even further removed from high society and wealth than their counterparts a century earlier. Debussy's father ran a small china shop, for instance; his mother was a seamstress. Bartók's father was a school teacher. Both of these individuals received the majority of their musical education formally rather than in the home or community. The career of Arnold Schönberg (b. 1874) is similar. At the time of his birth, both parents struggled to make a living by selling and repairing shoes in Vienna's segregated Jewish quarter. Apparently neither of Schönberg's parents owned or played an instrument. His early musical experiences included listening to Austrian military ensembles, Jewish cantillation, popular entertainment in the Prater park, and dance bands... Schönberg's family was too poor to have attended many performances of art music in the city. Until his later teens, the majority of Schönberg's exposure to art music seems to have been from scores alone, and performances of music by himself and his friends. ${ }^{155}$

\footnotetext{
${ }^{154}$ Bronwyn LeBlanc-Kinne, "Incorporating Beginning Jazz Improvisation Activities and Exercises into an Intermediate-Level Classical Piano Curriculum: A Guide for Private Piano Teachers." (Dissertation, San Diego State University, 2014), 6.

${ }^{155}$ Moore, "The Decline of Improvisation," 71.
} 
Like many composers of the late nineteenth and early twentieth centuries, Schönberg learned the language of art music not as a child learns the language of his parents, but more as a high school student might learn a foreign language in higher studies. Moore goes on to say,

Schönberg epitomizes the late $19^{\text {th }}$ century musician in many ways: he was surrounded by a thriving ethnic and popular music tradition that he tended to ignore; became actively involved with art music only as a young adult; and trained as a composer in an institution rather than through involvement in the music of his larger social environment...It should not be surprising, given the substantially different life experiences of performers and composers of art music in the 1880 s and 90 s as opposed to those of earlier times, and related changes in pedagogic methods and contexts, that both the aesthetics of Western art music and its performance practice would change markedly during this period. The sense of communal involvement and understanding that one associates with improvisatory musical traditions, and that had existed between performer and audience in the courts of Europe, could no longer be associated with art music towards the end of the century. ${ }^{156}$

While the education of the composer was evolving, the nature of the audience was changing as well.

Composers lacked the "communal involvement" described by Moore, which had once been the result of a musically-educated upper class - who also served as the target audience of the music. The growing middle class was less educated about subtle nuance in music, such as shifting in and out of improvised and written music in performance. LeBlanc-Kinne observes,

With a less musically-educated audience who could not easily distinguish the difference between improvised and completely prepared performances, the importance of knowing the original form of a piece and how it was manipulated became less important. By the end of the nineteenth century, having less time, necessity, and opportunity to display improvisatory skills, piano teachers in turn focused their students in performing notated music with little or no attention to improvisation. ${ }^{157}$

During this time, art music was increasingly restricted to academic sectors of society, and developed an inaccessible and sometimes pretentious reputation with the middle class. With the majority of its audience being upper class or academic individuals, art music became increasingly unfamiliar to the average person. According to Robin Moore, "Composers of art music in our century find themselves in a unique and not entirely enviable position. While retaining a position of high regard in society, and

\footnotetext{
${ }^{156}$ Moore, "The Decline of Improvisation," 71

${ }^{157}$ LeBlanc-Kinne, “Incorporating Beginning Jazz Improvisation,” 7
} 
viewed by most as the epitome of creative effort, they have nevertheless lost the active support of a majority of the public. Far from enjoying a broad-based acceptance in their community, as Bach, Haydn, and Mendelssohn could boast, the modern composer finds consistent support and encouragement only from other academics."158

\section{The Divinely Inspired Composer}

Beethoven served as a catalyst for the transition away from the extreme rationality of the Enlightenment and into the Romantic fascination with nature, religion and spirituality. Rather than being viewed as experts in a craft, composers began to be viewed as divinely-inspired geniuses. As a result, performers were creatively inhibited by their awe of "masters" such as Beethoven, and were far less likely to change or add to any written notes. Carl Czerny was a loud voice in promoting this viewpoint, and his opinions have persisted regardless of their apparent conflict with Beethoven's own performance practice. Czerny remarks, "In the performance of [Beethoven's] works (and generally for all classical composers) the performer should throughout allow no alteration of the composition, no addition and no abbreviation.... For one wants to hear the artwork in its original form, as the Master thought and wrote it." 159

The great writer and music critic E.T.A. Hoffman claims, "The genuine artist lives only for the work, which he understands as the composer understood it and which he now performs. He does not make his personality count in any way. All his thoughts and actions are directed towards bringing into being all the wonderful, enchanting pictures and impressions the composer sealed in his work with

\footnotetext{
${ }^{158}$ Moore, "The Decline of Improvisation," 76

${ }^{159}$ Carl Czerny, Kunst des Vortrags der ältern und neuen Claviercompositionen oder: Die Fortschritte bis zur neuesten Zeit, Supplement [vol. 4] to the Vollständige theoretisch-practische Pianoforte-Schule, Op. 500 (Vienna: Diabelli, n.d.), 34. Cited in Hermann Danuser, ed., Musikalische Interpretation, Neues Handbuch der Musikwissenschaft 13 (Laaber: Laaber-Verlag, 1989), 302.
} 
magical power." 160 The reader of such a sentiment may have to suppress a chuckle because of the extravagant language, but this truly is a perfect snapshot of the Romantic perspective of the composer. It could be argued that Hoffman advocates a performance practice in which the "genuine artist" is not genuine at all, but rather an empty vessel for an unchanging sequence of sounds - a chameleon to adapt to the feelings of another musician. This is a vastly different perspective on the relationship between composer and performer than the one that existed in the lifetime of Beethoven.

\section{Emphasis on Historical Accuracy}

One development that seems to have especially taken hold in the last 40 years is the emphasis on acute historical accuracy in performances of early music. This emphasis seems to be mostly formed around performance on period instruments, which requires developing special skills because of the great differences between the modern piano and historical keyboard instruments, such as various key widths, key weight and action, sustainability of sound, unfamiliar pedals with many functions, etc. Pianists who are interested in fortepianos, harpsichords, clavichords, or other period instruments may spend many hours a day becoming accustomed to these foreign instruments, and they learn a great deal of Renaissance and Baroque repertoire. Interestingly, however, this great attention to detail and accuracy in reviving old sounds and repertoire does not often extend to reviving the improvisatory performance practice itself. In music as old as this, the tradition of improvisation was even more central to performance practice than it was in the day of Beethoven. Gould and Keaton go as far as to say that when performers sat down to play in early music such as this, "The resulting performance might relate to the score rather as a great jazz performance might relate to the melody and chords indicated in a fake book."161

This early music movement has also permeated the dominating perspective on performances of Beethoven's music. One particularly good example of this is from a panel discussion on "historical

\footnotetext{
${ }^{160}$ E.T.A. Hoffman, Musikalische Novellen und Aufsätze, (Regensburg, 1919), 69, quoted in Lydia Goehr, The Imaginary Museum of Musical Works: An Essay in the Philosophy of Music (New York: Oxford University Press, 1992), 1.

${ }^{161}$ Gould, Keaton, “The Essential Role,” 143.
} 
problems in Beethoven performance," moderated by Owen Jander, where the panelists were Ilse von Alpenheim, Eva Badura-Skoda, Malcolm Bilson, John Hsu, Sonya Monosoff, Daniel Stepner, and James Webster. This long conversation covered topics such as tone, dynamics, and, of course, choice of instrument, but never approached the topic of creative embellishment. The primary subject of conversation was which type of keyboard instrument to use for which of Beethoven's works. Most panel members were extremely concerned with how the changing instrument may compromise the performer's attempts to preserve the original sonorities of Beethoven's music. They agreed that it is best to only play the types of fortepiano to which Beethoven had access during his life, although there was some quarrelling over whether the five octave instrument or the six octave instrument is more appropriate for the middle period of Beethoven. Amazingly, the conversation even drifted into topics such as whether it is appropriate to build new replicas of old instruments, or if we should limit ourselves to only restoring old instruments. ${ }^{162}$ It begged the question of why these scholars, who are so very concerned with authentic historical sounds, are not more concerned with how to preserve authentic performance practice?

LeBlanc-Kinne explains that this interest in exact performances of early music is not a new idea, but actually it started almost immediately after Beethoven died. She attributes the decline of improvisation in classical music to the rise of the "serious concert pianist," who was expected to learn enormous amounts of music and not to change a note of it. The deification of Bach, Mozart, Beethoven and their kind led to the unspoken rules that pianists are not to change their compositions in the slightest way. LeBlanc-Kinne says,

Improvisation decreased as there was an increase of interest in Western art music and performing the pieces in a historically accurate manner. The increase of interest in Western art music gave rise to several conservatories. In 1862 at the St. Petersburg Conservatory, for example, Anton Rubinstein contributed to the development of the serious concert pianist by creating programs at the conservatory that focused on performing vast amounts of piano literature. Concert pianists like Clara Schumann wanted to remain faithful to the presentation of the music of master composers like Bach, Mozart, and Beethoven. As a result, she would present their works exactly as notated in

\footnotetext{
${ }^{162}$ International Beethoven Congress, Robert Winter, and Bruce Carr. Beethoven, Performers, and Critics: The International Beethoven Congress, Detroit, 1977 (Detroit: Wayne State University Press, 1980), 50.
} 
the score with little or no improvised material. Around the late nineteenth and early twentieth century, more composers and conductors like Ravel, Ferrucio, Busoni, and Mahler continued the passion to remain faithful to the notated score. Mahler expressly prohibited any un-notated ornaments, which contributed to a further break from old improvisation traditions. ${ }^{163}$

\section{Conclusion}

It appears that the reasons for the absence of improvisation in modern pedagogy are generally not beneficial, while the changes which could be made to reincorporate improvisation would benefit students in many ways. A more secure foundation in music theory will provide many pianists with the familiarity with the musical language that they need to improvise and become less dependent on the written score. Perpetuating the decline in thorough theory training, however, will not serve any musical purposes. Seeking to incorporate improvisatory elements of popular styles into classical pedagogy will only help to expand the audience of art music, which will then be able to better appreciate tasteful embellishment of masterpieces. However, keeping masterpieces in the static environment they currently inhabit will not deepen their impact on humanity or honor the creative culture that they were originally born into. It is a more honest approach to teach students that Beethoven, rather than being a divinely-inspired genius, was actually a flawed but remarkable human being. However, promoting the romantic concept of his untouchable talent will only keep him further from the real, terrible, beautiful humanity that his music illustrates. Historically informed performances do their audiences a great service in offering authentic experiences of old masterpieces, but they cannot be truly authentic if they are missing the all-important element of creative embellishment in performance.

\footnotetext{
${ }^{163}$ LeBlanc-Kinne, “Incorporating Beginning Jazz Improvisation,” 6-7.
} 
How Do We Learn to Improvise?

This chapter aims to synthesize the topics that have been addressed in the previous chapters through a pedagogical approach that accounts for the evidence of Beethoven's own practice of improvisation, corrects the path that has been taken away from the practice of improvisation over the last 150 years, and considers Beethoven's own methods of teaching improvisation. This pedagogy is grounded on three core assertions: 1) that improvisation can be "practiced," 2) that improvisation is situated between composition and performance, and 3) that Beethoven's music calls for performers to serve as "co-creators." As such, this pedagogy of improvisation will also indicate when it is appropriate to introduce improvisation into a performance scenario.

\section{Can Improvisation Be Practiced?}

After exploring many different kinds of eighteenth-century improvisation alongside contemporary attitudes toward it, it should be fairly clear that improvisation can be practiced and that a successful improviser may arrive at a performance with some preconceived ideas to deploy in their performance. Just as a jazz musician may practice "licks" or small segments of music in all keys to fill their arsenal with units of music that can be joined to meet the needs of a future moment, $16^{\text {th }}, 17^{\text {th }}$, and $18^{\text {th }}$ century European and European American keyboardists would have practiced passagework and harmonic progressions which would be scattered throughout their improvisations to create a new collection of pre-rehearsed sounds. ${ }^{164}$ Duke Ellington stated, “Anyone who plays anything worth hearing knows what he's going to play, no matter whether he prepares a day ahead or a beat ahead. It has to be with intent."165 Similarly, Yehudi Menuhin observed that "improvisation is not the expression of accident, but rather of the accumulated yearnings, dreams, and wisdom of our very soul."166

\footnotetext{
164 Thomas Scherman and Louis Leopold Biancolli, The Beethoven Companion, 1st ed. (Garden City, N.Y: Doubleday, 1972), 104.

${ }^{165}$ Gabriel Solis and Bruno Nettl, Musical Improvisation: Art, Education, and Society (Urbana: University of Illinois Press, 2009), ix
} 
Improvisation is usually the product of many hours of practice and experimentation. A pianist may not know exactly how the improvisation will turn out in the end, and what combination of which fragments of prepared music it might be, but a successful improvisation is often a collection of ideas and building blocks which have been studied and prepared beforehand. Ethnomusicologist Veit Erlmann gives a helpful definition of improvisation: "Création d'un énoncé musical, ou forme finale d'un énoncé musical déjà composé, au moment de sa réalisation en performance" [Creation of a musical utterance, or final form of a musical utterance already composed, at the moment of its realization in performance $]^{167}$. Improvisation, therefore, is not exclusively new music, but rather the "final form" or final assembling of pre-existing material.

Beethoven's own thoughts on how or whether to prepare improvisations are unclear. The practice of the day, however, can be easily understood from writings about eighteenth century performance practice. Most pianists were well-prepared for any performance scenario, and could easily whip out an improvisation on any number of familiar themes. While these improvisations were commonplace, Beethoven's improvisations drew attention because of their whimsical, genuine and unstudied flair. To many, it truly seemed as though Beethoven had not prepared his improvisations at all. Thomas Scherman and Louis Leopold Biancolli make the statement,

How much Beethoven prepared his improvisations we do not know. Most pianists did prepare, knowing full well that sooner or later they would be called upon to study an improvisation on "Batti, batti" or a similar well-known tune. And all pianists had at their command a thorough supply of passagework by the yard, which they could snip off and use for any possible contingency. But when Beethoven improvised, prepared passagework or no, it was evident to his hearers that after a while he was on his own, idea pouring after idea. ${ }^{168}$

Beethoven's own pithy remark is that "one improvises only if one pays no attention to what one plays[.] In the same manner one would improvise best and most truly in public [by] abandoning oneself

\footnotetext{
166 Ibid., ix

${ }^{167}$ Bruno Nettl and Melinda Russell, In the Course of Performance: Studies in the World of Musical Improvisation (Chicago: University of Chicago Press, 1998), 11.

168 Thomas Scherman and Louis Leopold Biancolli, The Beethoven Companion, 1st ed. (Garden City, N.Y: Doubleday, 1972), 104
} 
unrestrainedly [to] whatever comes into one's mind." 169 This sentiment is consistent with Beethoven's showy statements that contributed to his dramatic persona, but it is not consistent with his own practice. Tilman Skowroneck reveals the contrast between this statement and Beethoven's actual improvisation habits, explaining that Beethoven made notes on his scores regarding his improvised excursions, such as "lied varied, concluding with a fugue... and ended pianissimo. Every fantasy to be devised in this fashion and performed afterwards in the theater." ${ }^{170}$ Apparently Beethoven's free fantasies were subject to more preparation than he would have liked to admit.

The quality of an improvisation can suffer if the musician is over-prepared. The balance of appropriate spontaneity and appropriate preparation is hard to describe, but Beethoven's own practice can help to enlighten. Skowroneck refers to the note above and explains, "Doubtless the ideal formulated in the quotation was risky even for Beethoven, at least in the case of an exposed public performance. So he devised a concept to guide him along and he based several preparatory improvisations on this plan. Very detailed preparations of improvisations must, however, have been the exception for Beethoven." 171 Beethoven provided himself with basic framework, and probably basic passagework, but the empty spaces were filled with music that met the needs of the moment. Beethoven was a dramatic and passionate performer, but he was also able to make safe decisions for his improvisations. ${ }^{172}$

\section{The World between Composition and Performance}

Frederic Rzewski recounts a humorous but remarkably apt statement on improvisation in his poem/article "On Improvisation." One of his friends was asked to describe the difference between improvisation and composition in fifteen seconds, and his response was, "In fifteen seconds, the difference between composition and improvisation is, that in composition you have all the time you want

\footnotetext{
${ }^{169}$ Tilman Skowroneck, Musical Performance and Reception: Beethoven the Pianist (Cambridge, GB: Cambridge University Press, 2010), 158.

${ }^{170}$ Ibid.

${ }^{171}$ Ibid.

${ }^{172}$ Ibid., 159.
} 
to think about what you will say in fifteen seconds, while in improvisation you have fifteen seconds to think about it."173

West Virginia University professor Peter Amstutz frequently makes the observation that every pianist must to some extent "improvise" with dynamics and timing throughout any performance. He explains,

At the beginning of every piece, it is impossible to predict fully the tone and dynamic even of the very first sonority; therefore one must adjust to this first sound and continue with a meaningful phrase whose shape is determined by what has actually occurred, not just by what one has planned. One must have a clear intention with each note and phrase, not just at the beginning, to guide the sounds one produces; but one must also adjust one's inner intention on the basis of what actually happens as the instrument responds. The resulting 'conversation' between inner ideal and outer reality is indeed a form of spontaneous 'improvisation,' even when none of the composer's notes are changed. ${ }^{174}$

It seems fair to say that improvisation is a necessary skill for certain elements of all musical

processes. Bruce Ellis Benson notes:

I will argue that the process by which a work comes into existence is best described as improvisatory at its very core, not merely the act of composing but also the acts of performing and listening. On my view, improvisation is not something that precedes composition (pace Wolterstorff) or stands outside and opposed to composition. Instead, I think that the activities that we call "composing" and "performing" are essentially improvisational in nature, even though improvisation takes many different forms in each activity. As we shall see, if my claim is correct, the beginnings and endings of musical pieces may indeed be "real" (as opposed to merely "imagined"), but they are often messy. ${ }^{175}$

It is helpful to use spoken language as an analogy for improvisation. We improvise every day

when we are having normal conversations. We certainly do not invent new phrases or expressions to express every thought; rather, we normally use a collection of pre-existing building blocks, such as expressions we have heard or read or used before, and we may add to these our own new phrases which can sometimes occur to us in the moment. Improvisation can be just as simple (and, upon further

\footnotetext{
${ }^{173}$ Frederic Rzewski, “On Improvisation,” Contemporary Music Review 25, no. 5 (2006): 491-5.

${ }^{174}$ Peter Amstutz (Professor of Piano, West Virginia University) in discussion with the author, November 2016.

${ }^{175}$ Bruce Ellis Benson, The Improvisation of Musical Dialogue: A Phenomenology of Music. (Cambridge; New York: Cambridge University Press, 2003), 2.
} 
examination, surprisingly complex) as our every day conversations with friends, family and strangers.

Certainly our words are sometimes pre-rehearsed, and, as it has already been observed, there are occasions when it is appropriate to work out beforehand what one wants to say. However, no one could live a healthy, normal life if they tried to plan out every word, pause and inflection they used in conversation. Historically appropriate improvisation, therefore, seems to be quite similar to the use of human speech: it uses collections of pre-existing building blocks, and sometimes is meticulously rehearsed. However, in order to be persuasive, it should be as genuine and unstudied as possible.

This increasingly blurry line between composition and performance, where improvisation seems to hover without a clearly definable shape, is more difficult to discuss the more one tries to discuss it. Benson admits, "Those who long for neatly tied theories will likely be disappointed with my view of music in which the lines between composition and performance are hardly 'neat.' But I think that 'messiness' simply reflects actual musical practice."176

\section{Co-creating with Beethoven}

The heading of this section is surely enough to make many modern performers shiver. And rightly so, for it is widely assumed that Beethoven's compositions are locked down, never to be touched or altered in anyway. But Benson points out,

simply appealing to the score and its requirements doesn't necessarily establish that performers of Beethoven either are or must be "executant artists." Do Beethoven scores leave room for the performer to act as "co-creator?" That depends on how we construe what the performer does in performing them. Furthermore, to what extent is the performer obligated to reproduce the expectations of the composer? Merely because Beethoven had stricter expectations for his performers than did Rossini does not automatically place stricter obligations on performers of his music. $^{177}$

By referring to Rossini, Benson means to allude to the often extreme embellishments of Rossini's vocal works when performed by adventurous vocalists. Rossini's scores are certainly basic and austere

\footnotetext{
${ }^{176}$ Benson, The Improvisation of Musical Dialogue, $\mathrm{xi}$

${ }^{177}$ Ibid.,18.
} 
when compared to Beethoven's careful and plentiful markings—although Beethoven's scores look relatively unadorned when compared to such abundant information as one might find in one of the scores of Claude Debussy, for example. Benson points out, though, that more information in the score should not necessarily coincide with less embellishment in performance. Benson goes on to say, "As should become evident, even though I think the intentions of composers can be known (at least to some extent) and should be respected, composers are not the only participants in the musical dialogue who have intentions, nor do their intentions necessarily trump the intentions of all other participants. Moreover, there may be different ways of respecting those intentions." $" 178$

Discovering these "different ways" of respecting Beethoven's wishes is one of the primary goals of this research. The idea of improvising in Beethoven seems to run counter to viewpoints such as this one from E.T.A. Hoffmann, who says, "The genuine artist lives only for the work, which he understands as the composer understood it and which he now performs. He does not make his personality count in any way." "The diminished importance of the "artist" out of respect for the composer is an idea which has been propelled earnestly by Czerny, and even Ries to an extent, who desired to portray Beethoven as an elevated genius by every possible means. ${ }^{180}$

Beethoven himself was rarely satisfied with a completed work, and rather he continued to work on his music long after it was performed and published. Therefore, it could be argued that we are not obligated to act as though the pieces are finished, simply because the original creator has died. If Beethoven's own standards for his music were always changing, it does not follow that, as independent musicians, our standards for Beethoven's music should be fixed. Again from Benson,

The problem with deciding at what point Beethoven came to a definite decision is that he apparently - at least in some cases - was not fully satisfied and often kept tinkering with his pieces on the day of the performance or even long after a piece had been printed.

\footnotetext{
178 Ibid., xii

${ }^{179}$ E.T.A. Hoffman, Musikalische Novellen und Aufsätze, (Regensburg, 1919), 69, quoted in Lydia Goehr, The Imaginary Museum of Musical Works: An Essay in the Philosophy of Music (New York: Oxford University Press, 1992), 1.

${ }^{180}$ Mary Hunter, "“To Play as If from the Soul of the Composer': The Idea of the Performer in Early Romantic Aesthetics," Journal of the American Musicological Society 58, No. 2 (Summer, 2005): 357.
} 
Furthermore, the changes that he made were not limited to small corrections, for at times he dropped whole movements. Perhaps the best example of this is the last movement of one of his late string quartets, the B-flat Major Quartet (Op. 130): Beethoven replaced this with one that was altogether different, turning the original finale into the Grosse Fuge (Op. 133). An even more interesting case is that of his Leonora Overture- or, more accurately, Leonore Overtures I, II, and III, since Beethoven wrote three different versions. Being unhappy with the first version (Op. 138), he substituted the second (Op. 72a) in the premiere of 1805 . Yet, he went on to revise the opera and wrote still a third version of the overture (Op. 72b) for a performance a year later. As it turns out, these versions are so different that they can be performed in the same concert. ${ }^{181}$

Beethoven himself relieves us of any suspicion we may have that his pieces are "perfect" as they are, and none could ever be submitted for review and change. On March 4, 1809, Beethoven wrote to publishers Breitkopf and Hartel to make them aware of some changes he wished to make in the $5^{\text {th }}$ and $6^{\text {th }}$ symphonies. In his letter, Beethoven explains "One must not hold one's self so divine as to be unwilling occasionally to make improvements in one's creations." ${ }^{182}$

\section{Disturbing the Calm of that Sadness: When Improvisation is not Appropriate}

While many, many examples could be produced of scenarios in which improvisation is not at all the best choice, there is possibly no better example to use than that of Franz Liszt. Liszt's relatively casual treatment of Beethoven's works seemed to stem from his genuine motive to study and understand the music in his own sensational language, and also to present it to his audience in a way that would inspire more enthusiastic applause. We must recognize that even Liszt understood the genius and significance of Beethoven's masterpieces, though. Hector Berlioz provides us with his recollection of two fascinating performances of Liszt. These contrasting performances of the iconic first movement of the "Moonlight Sonata" give us multiple insights into Liszt's treatment of Beethoven's works, the Davidsbündler view of

\footnotetext{
${ }^{181}$ Ibid., 60-61.

${ }^{182}$ Friedrich Kerst, Beethoven, as Revealed in His Own Words: The Man and the Artist (Wellington: Floating Press, 2009; 1904), 42.
} 
Liszt's performances and Beethoven's legacy, and also the power of not improvising. This section of the chapter will consider the two performances individually.

One day...Liszt was executing this adagio before a few friends of whom I was one; and he took upon himself to distort it somewhat, after the manner which he had then adopted in order to make himself applauded by the fashionable public; and...he used shakes and tremolos--he hurried and slackened the time--thus disturbing, by passionate accents, the calm of that sadness; and causing the roll of thunder to issue from that cloudless sky, which was but slightly overcast by the setting sun. This caused me to suffer cruelly, I avow...for, added to the torture, was the chagrin of seeing such an artist fall into the pit which is generally reserved for mediocrities... ${ }^{183}$

Berlioz claims that this performance occurred thirty years before he wrote of it, when Liszt was still a young man. One can better understand his pained response to Liszt's liberty-taking when one reads his rapturous description of the Adagio movement as Beethoven wrote it:

There is a work of Beethoven known by the name of "Sonata in C sharp minor," the adagio of which is one of those poetical productions which human language cannot describe. The means employed are extremely simple; for the left hand merely displays some wide chords of a sadly solemn character, holding each one sufficiently long for the vibrations of the strings to die away; whilst the right employs its lower fingers to arpeggio an ostinato accompaniment, the form of which scarcely caries from end to end; and during which the other fingers cause a sort of lamentation to be heard--the melodic efflorescence of a sombre harmony. ${ }^{184}$

Clearly, according to Berlioz, the great crime of Liszt was that he interrupted "the calm of that sadness" which Berlioz so greatly cherished in the adagio movement. The steady, uninterrupted pattern of triplets contributes to the steady march of sorrow that most associate with this piece. It appears that Liszt tried to drastically change the intended affect of this piece with his tremolos and frequent tempo changes. While it seems apparent that Liszt's performance was demonstrably tasteless and impertinent, we must consider all the facts before drawing our conclusions.

To be fair, there is nothing written in the original score that directly implies Beethoven's intention that this piece be played steadily and without elaboration or change in tempo. It is marked "Adagio

\footnotetext{
${ }^{183}$ Hector Berlioz, A Critical Study of Beethoven's Nine Symphonies: With "A Few Words on His Trios and Sonatas, " a Criticism of "Fidelio" and an Introductory Essay on Music (London: William Reeves, 1958), 124-125

${ }^{184}$ Berlioz, A Critical Study, 124.
} 
sostenuto," indicating that we are to play slowly and prolonging the written note values. The second directive is Si deve suonare tutto questo pezzo delicatissimamente e senza sordini, or "This whole piece ought to be played with the utmost delicacy and without damper[s]." Here we come to a frequent conundrum in the piano world, where we cannot faithfully follow the composer's instructions due to the differences in instrument. Our modern pianos can certainly not accommodate Beethoven's wish that the pedal is held down throughout the entire piece. The metal frames and steel strings of modern pianos give the sonorities more power, resulting in longer-lasting sounds than the instruments of Beethoven's day would have produced. As a result, the rich harmonies in this movement will swirl together and create an unpleasant, dissonant cloud of sound if not regulated by frequent changes in pedal. However, the smaller, lighter wood frames of the pianos in Beethoven's day would have supported his directive very well. Sonorities died quickly on these early fortepianos, and the dampers could be raised for this entire movement without harmonies bleeding into one another.

This is an example of how separation of time demands that we set aside the composer's wishes in order to truly access the spirit and intention of the music. Perhaps Liszt was, in his own way, setting aside certain wishes of Beethoven in order to deliver what he believed was a more faithful interpretation of the spirit and intention of this piece. However, it is possible that his interpretation was not as distant from Beethoven's wishes as we might think. An argument can certainly be made that Liszt transgressed Beethoven's wish for "utmost delicacy" by adding shakes and tremolos, but what of his changes in tempo? We know that Beethoven himself was known for frequently changing tempo in performance, and the name "Sonata quasi Fantasia" certainly opens up the possibility of improvisatory interpretation. 
Example 1: Sonata in c-sharp minor, Op. 27, no. 1, Movement 1, mm. 1-7

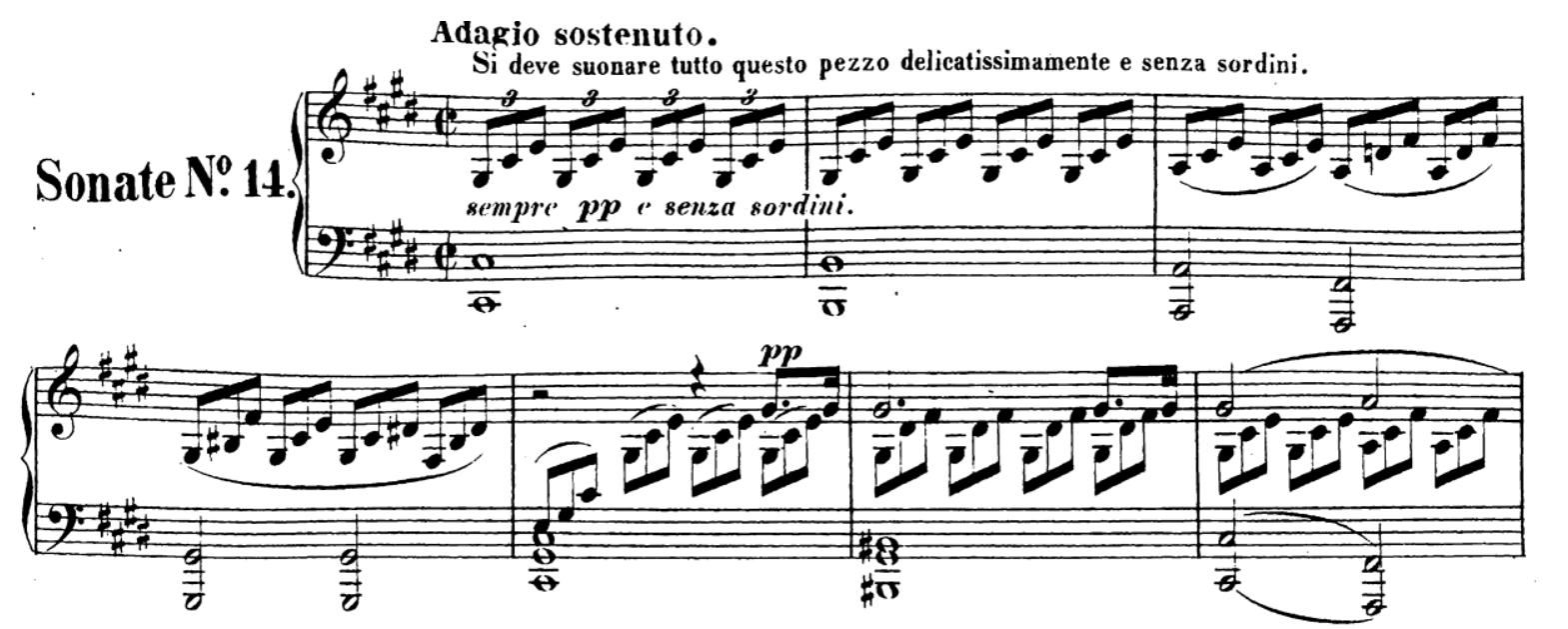

Source: Beethoven, Ludwig van. Sonaten für das Pianoforte. New York: Edwin F. Kalmus, n.d. (193370).

Let us turn to Berlioz's second recollection of Liszt's performance of Beethoven's piece, which was a recent incident at the time that Berlioz was writing. Liszt had appeared at a dinner party where he played for the guests, and after he played,

the lamp seemed about to go out; and one of the company was preparing to light it again. "Don't do so," said I, "if he will only play us the $\mathrm{C}$ sharp minor adagio of Beethoven, the faint light will certainly not spoil it." "With pleasure," said Liszt, "only, put out the light altogether, and screen the fire; let us have complete darkness." Then, in the obscurity, and after a moment's composure, the noble elegy--the same which formerly he had so strangely distorted, appeared in all its sublime simplicity. Not a note or emphasis was added to what the composer had written. It was the shade of Beethoven, brought forth by the virtuose, and whose great voice we heard. Each one of us was trembling in silence; and, after the last chord, no one stirred--for it had moved us to tears. ${ }^{185}$

There are many things to observe in this short description. To begin with, it is perplexing that Berlioz would ask Liszt to again play a masterpiece which he had apparently once brutalized to Berlioz's

${ }^{185}$ Berlioz, A Critical Study, 126. 
great pain and distress. Perhaps the charm of Liszt's playing was truly irresistible, even for Berlioz? Or maybe he was not as traumatized by Liszt's first performance as he would like for us to believe? Secondly, it appears that Liszt was capable of observing the needs of the moment, like any great musician and every great improviser. While he certainly was able to add all manner of filigree and decoration to this Adagio movement, he chose not to because the situation was calling for something different. Improvisers can only truly use the gift of improvisation by meeting the needs of the moment. This requires reading the audience, reading the situation and honestly considering one's own needs, in order to present a genuine performance that will have the effect of this powerful performance of Franz Lisztmade all the more powerful for the absence of improvisation.

\section{Conclusion}

This revolutionary pedagogy is fraught with many challenges for teachers and would expose many insecurities in modern pianists. In a classical pedagogy which is marked by precision, clarity, security and respect for the masters of composition, this type of improvisation is vague, messy, dangerous, and irreverent. It is difficult to imagine implementing a pedagogy which has no strict guidelines, and which has few standards of perfection or excellence. Perhaps the age of machines, social movements and math-driven academic music has made performance practice too much of an exact science, or an irrefutable conviction which should not be contradicted. Improvisation would upset all of that. That is why it is referred to in this research as "revolutionary."

Improvisation is not for everyone. It is a plain fact that not every pianist is prone to improvise, and therefore will not naturally excel in historically-informed improvisation. However, this research argues that historically-informed improvisation should be a legitimate option for pianists in higher levels of study who are interested in it. If this revolution is truly too messy to allow, then it is important for the leaders of modern music education to at least acknowledge that the absence of improvisation in modern pedagogy is not the result of historically aware choices, but is rather the symptom of a new, modern philosophy of piano pedagogy. 


\section{Practical Examples}

This chapter will provide practical examples of the types of improvisation that have been discussed in previous chapters. The first section will provide some simple exercises to help pianists begin to interact with the written score. The following sections will provide written-out examples of specific ways to embellish Beethoven's piano music. Many of these examples are drawn from John Salmon's ${ }^{186}$ handout from his lecture on "Improvising in Beethoven," in which he also demonstrated various ways of embellishing the score. ${ }^{187}$ Other examples are created by the author.

This chapter will condense the numerous categories of Beethoven's improvisations into three categories which can be easily compared to the original score: embellishing the recurring refrains of rondos, making passages "more brilliant," 188 and inserting Eingang into the texture at appropriate places. The chapter will examine issues such as choosing improvisations which are consistent with the intended character of the composition, as described by Daniel Gottlob Turk, who (as already mentioned) asserted that "every embellishment must suit the character of the composition," 189 considering appropriate ways of decorating harmonies, and other important aspects of successful improvisations in Beethoven's piano music.

\footnotetext{
${ }^{186}$ Dr. John Salmon is an innovative pianist who delivered a lecture in 2002 entitled "Improvising in Beethoven" at a Keyboard Literature conference at the University of North Carolina at Greensboro. At this conference Dr. Salmon presented evidence which supports his thesis that Beethoven was a constant and creative improviser, and that we as modern pianists have the option of imitating his example in our performances of his pieces. Salmon has also delivered similar lectures such as "Adding Notes to Classical Scores" at the Conservatorio de Música, Morelia, Mexico. He has also published two books of his additions to Bach's compositions, “Add-On Bach" and "Jazz Up The Inventions." Salmon presented music from “Add-On Bach" at West Virginia University's "Intersection of Jazz and Classical Music" festival in 2014.

${ }^{187}$ John Salmon, "Improvising in Beethoven." Lecture at Focus on Piano Literature, Greensboro, NC, June, 2002. June 1, 2016.

${ }^{188}$ International Beethoven Congress, Robert Winter, and Bruce Carr. Beethoven, Performers, and Critics: The International Beethoven Congress, Detroit, 1977. Detroit: Wayne State University Press, 1980. 106-107

${ }^{189}$ David Polan, “The Eingang in Early Beethoven," Performance Practice Review 7, no. 1 (1994): 81.
} 
Simple Exercises to Help Pianists Get Started

One of the most basic ways to start interacting creatively with the written score is to try embellishing music material when it is repeated. The concept of varying the repeated material is much older than Beethoven, but was still used in performance practice during his lifetime. Audiences in the eighteenth century did not expect to hear the same music repeated verbatim. C.P.E. Bach remarks, "Variation upon repetition is indispensable today. It is expected of every performer." 190 There are some simple ways that pianists can approach this task. ${ }^{191}$ This section will examine three: 1) by filling in intervals with smaller note values, 2) by enlivening the texture by using broken instead of blocked sonorities, and 3) by creating continuous passagework out of a theme or motif.

Possibly the easiest way to vary musical material is by filling in open intervals in the melody. In Example 1 we see a triadic melody of three consecutive leaps. While this may not be very common in Beethoven's music, the treatment of individual leaps can be the same. Example 2 provides the most direct way of filling in the intervals and therefore activating the texture with faster note values. This technique is used frequently in jazz improvisation and can be an effective way of introducing pianists to a more creative relationship with the written score.

\footnotetext{
${ }^{190}$ From the foreward of C.P.E. Bach's Sechs Sonaten für Clavier mit veränderten Reprisen (1760) (Translation, 1961, from Ferand, Die Improvisation in Beispielen, 1956), quoted in Nettl, Bruno, et al. "Improvisation." In Grove Music Online. Oxford Music Online, http://www.oxfordmusiconline.com/subscriber/article/grove/music/13738pg2 (accessed April 9, 2012).

${ }^{191}$ For more rigorous reading on this subject, consider: G. Mazzola, Joomi Park, and Florian Thalmann, Musical Creativity: Strategies and Tools in Composition and Improvisation. Berlin: Springer, 2011.
} 
Example 1: Melody of Consecutive Thirds

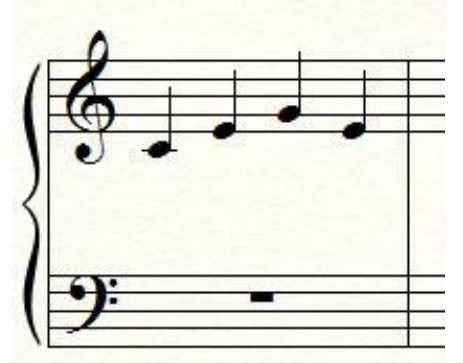

Source: Author

Example 2: Filling in the Spaces

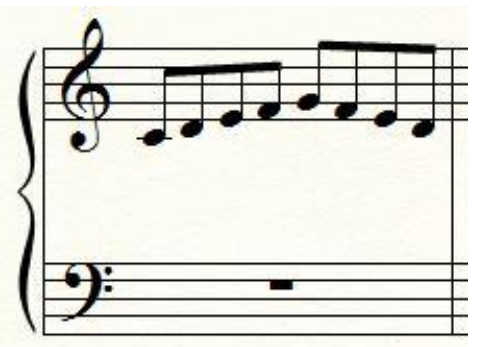

Source: Author

The second way of enlivening the texture is by breaking chords or intervals which were originally blocked. In Example 3, the right hand material spells out the triad as a series of two dyads. To make things a bit more exciting (and, in a fast tempo, more virtuosic), these thirds can be broken and played from the bottom note up, as we see in Example 4. This technique can also be particularly effective when applied to octaves in the right hand or the left hand, as we shall see later in Example 17. 
Example 3: Two Blocked Sonorities

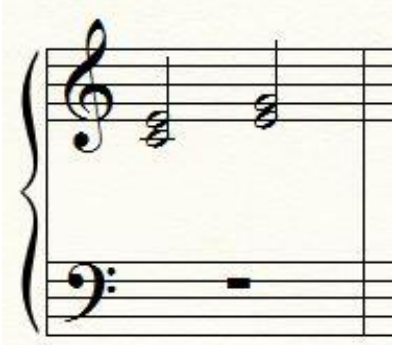

Source: Author

Example 4: Activating the Texture

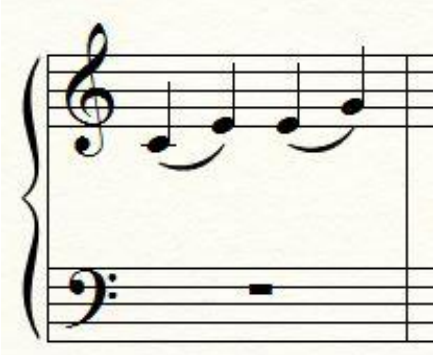

Source: Author

In Example 5 there is a rhythmic/melodic motif which can be commonly found in eighteenthcentury styles. A simple way to provide more interest and variety on the return of this motif is by eliminating the rhythmic pause and making continuous passagework which maintains the original contours of the melody, as we see in Example 6. 
Example 5: Melodic Fragment

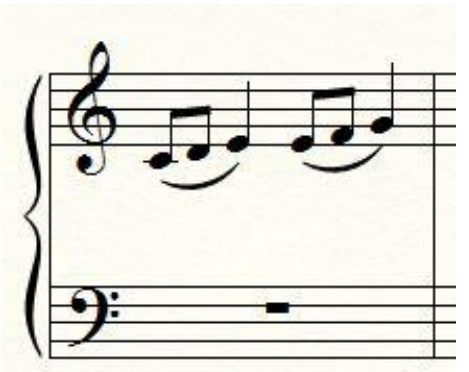

Source: Author

Example 6: Transforming Melodies into Passagework

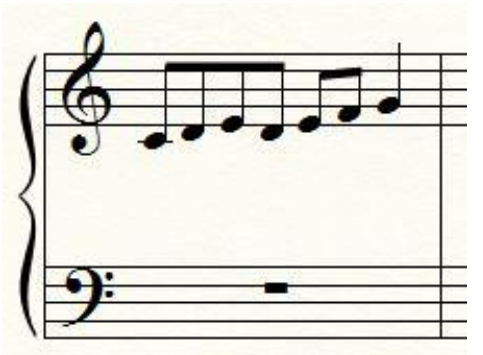

Source: Author

These are only a few ways to decorate the repeated material in Beethoven's piano works. These may be more effective in his earlier compositions, such as the first sonata or the first concerto, but there are tasteful places in his later works which can also be embellished on the repeat. We know that Beethoven "enlivened" his sonata expositions in impressive ways, though Czerny is not specific about whether he only varied the repeat. ${ }^{192}$ We also know that he instructed Ferdinand Ries to vary the return of the refrain in two rondos. ${ }^{193}$ It seems consistent with these reports to assume that pianists are also at

\footnotetext{
192 Tilman Skowroneck, Musical Performance and Reception: Beethoven the Pianist (Cambridge, GB: Cambridge University Press, 2010), 156.

${ }^{193}$ International Beethoven Congress, Robert Winter, and Bruce Carr. Beethoven, Performers, and Critics: The International Beethoven Congress, Detroit, 1977 (Detroit: Wayne State University Press, 1980), 106-107
} 
liberty to consider variations on the return of musical material in Scherzo and Trio movements, for example, and in certain song-form movements, such as the adagios. ${ }^{194}$

\section{Embellishing Refrains of Rondo Movements}

The next two categories of this chapter are largely based on Ferdinand Ries's comment regarding Beethoven's instruction to add notes to the original score in the following ways: "once in the Rondo of the Sonata Pathétique (Op. 13), and again in the theme of the Rondo of his first concerto in C major, where he specified several doublings to make it more brilliant..." ${ }^{195}$ This vague description from Ries

\footnotetext{
${ }^{194}$ Many helpful books have been written with exercises to help students learn to improvise. Among these are the following:

Tony Wigram, Improvisation: Methods and Techniques for Music Therapy Clinicians, Educators, and Students. London: J. Kingsley Publishers, 2004.

Ed Sarath, Music Theory through Improvisation: A New Approach to Musicianship Training. New York: Routledge, 2010

Ingrid T. Monson, Saying Something: Jazz Improvisation and Interaction, 2nd ed. Chicago: University of Chicago Press, 1996.

T. Carl Whitmer, The Art of Improvisation: A Handbook of Principles and Methods for Organists, Pianists, Teachers, and All who Desire to Develop Extempore Playing, Based upon Melodic Approach. New York: M. Witmark \& Sons, 1941.

LeBlanc-Kinne, Bronwyn, "Incorporating Beginning Jazz Improvisation Activities and Exercises into an Intermediate-Level Classical Piano Curriculum: A Guide for Private Piano Teachers." Dissertation, San Diego State University, 2014.

Ruth Lloyd and Norman Lloyd, Creative Keyboard Musicianship: Fundamentals of Music and Keyboard Harmony through Improvisation. New York: Dodd, Mead, 1975.

Lee Iacocca, “Teaching Improvisation Confidently.” Music Educators Journal 100, no. 1 (2013): 17.

Carl Czerny and Alice L. Mitchell, A Systematic Introduction to Improvisation on the Pianoforte: Opus 200. New York: Longman, 1983.

${ }^{195}$ International Beethoven Congress, Winter and Carr, Beethoven, Performers, and Critics, 106-107.
} 
allows us to create the examples in this chapter to provide at least an attempt toward realizing the meaning of these words.

The rondo movement of the Pathetique, like most rondos, features a refrain which appears four times (see Example 7 for opening refrain). However, in this sonata the refrain only appears twice in its first form. In the third statement of the refrain, the third part is varied with the melody in the left hand (see Example 9). In the fourth statement, this part is given a thicker texture as it expands to the closing coda (see Example 10). We do not know for sure which appearance of the refrain Beethoven was referring to when he advised Ries to embellish the refrain. It is arguable that it may be best to play the third and fourth refrains as written because they are already embellished in a way. However, the second refrain (Example 8) might benefit from the addition of a few notes in order to avoid redundancy. Salmon seems to believe that the third statement of the refrain could also use a bit of an embellishment in the first part, and in Example 4 he offers a potential route that one might take toward decorating the material. ${ }^{196}$

\footnotetext{
${ }^{196}$ John Salmon, “Improvising in Beethoven.” Lecture at Focus on Piano Literature, Greensboro, NC, June, 2002. June 1, 2016.
} 
Example 7: Sonata Op. 13 in C minor ("Pathetique"), mvt. 3, mm 1-21. First statement of refrain.
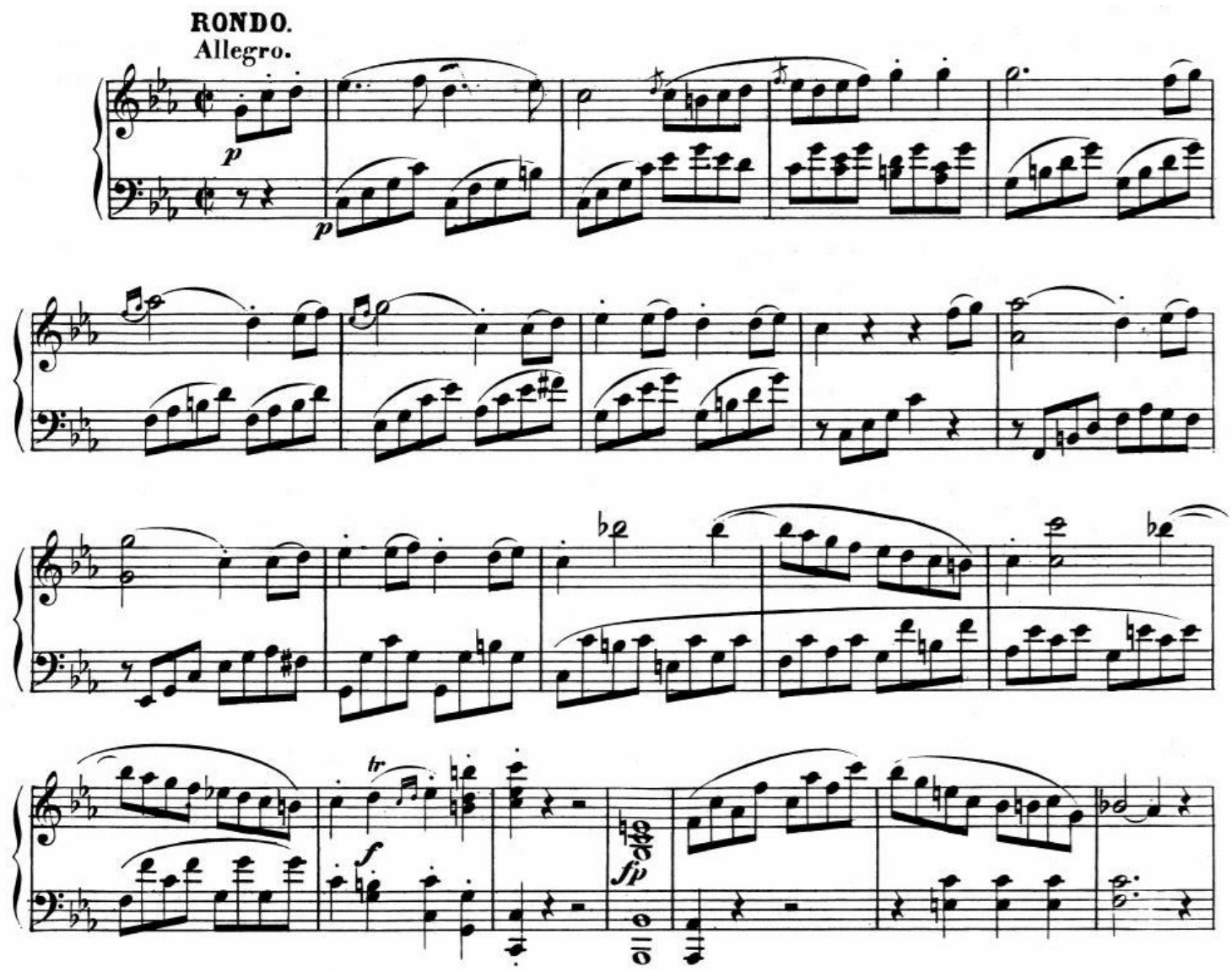

Source: Beethoven, Ludwig van. Sonaten für das Pianoforte. New York: Edwin F. Kalmus, n.d. (1933$70)$. 
Example 8: Sonata Op. 13 in C minor ("Pathetique”), mvt. 3, mm 57-72. Second statement of refrain.
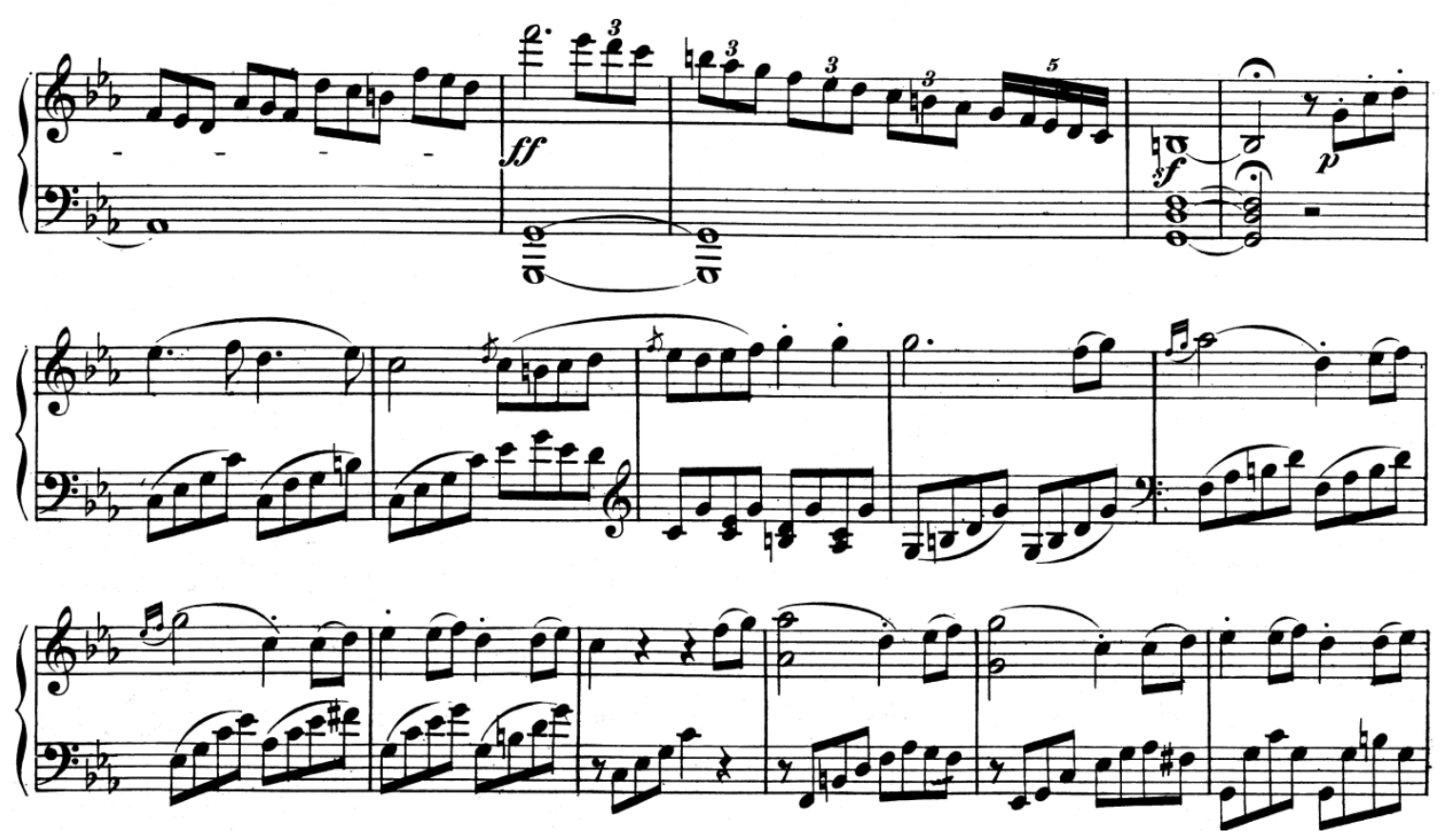

Source: Beethoven, Ludwig van. Sonaten für das Pianoforte. New York: Edwin F. Kalmus, n.d. (193370). 
Example 9: Sonata Op. 13 in C minor ("Pathetique"), mvt. 3, mm 117-136. Third statement of refrain.
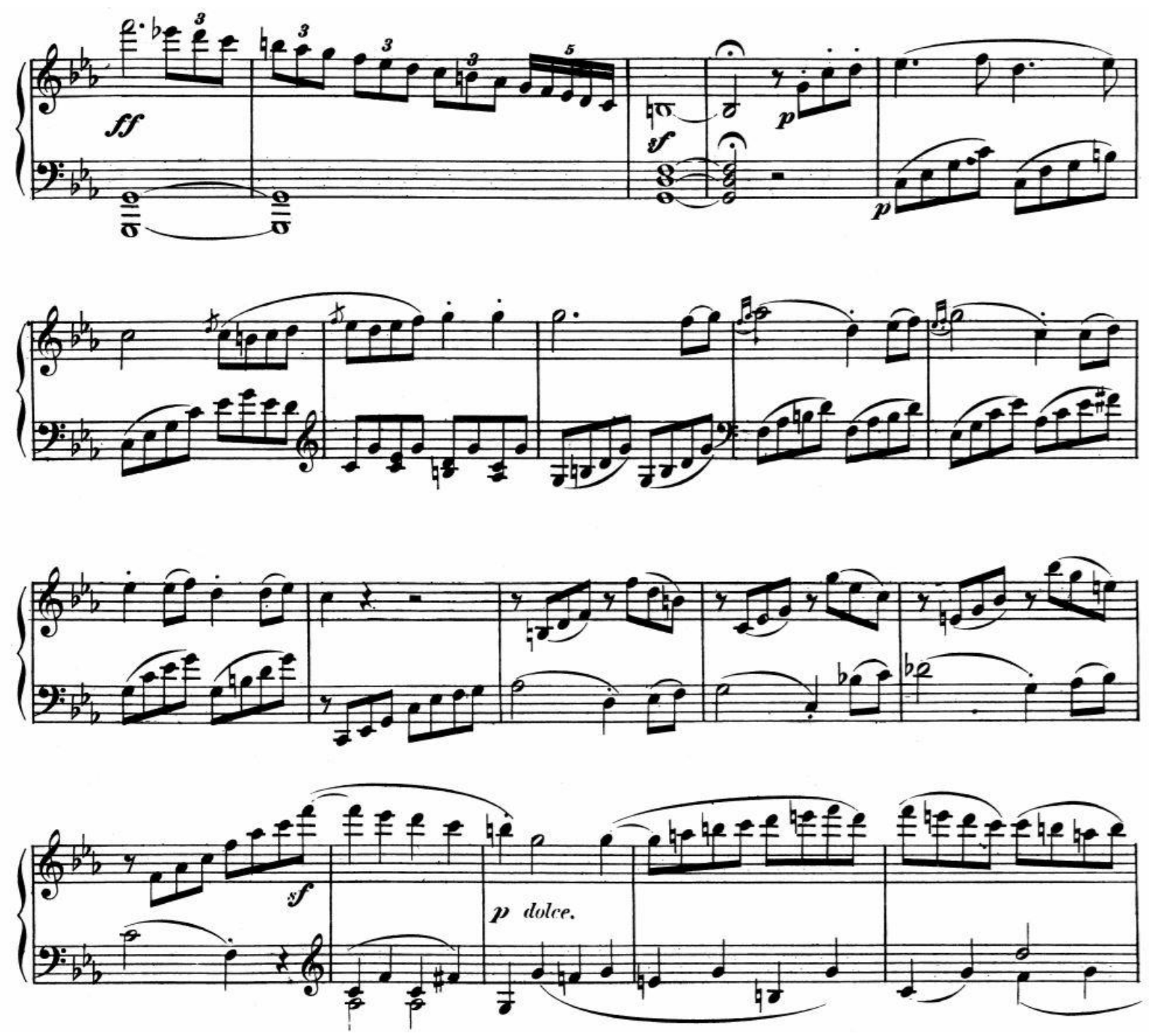

Source: Beethoven, Ludwig van. Sonaten für das Pianoforte. New York: Edwin F. Kalmus, n.d. (1933$70)$. 
Example 10: Sonata Op. 13 in C minor ("Pathetique"), mvt. 3, mm 169-183. Fourth statement of refrain.
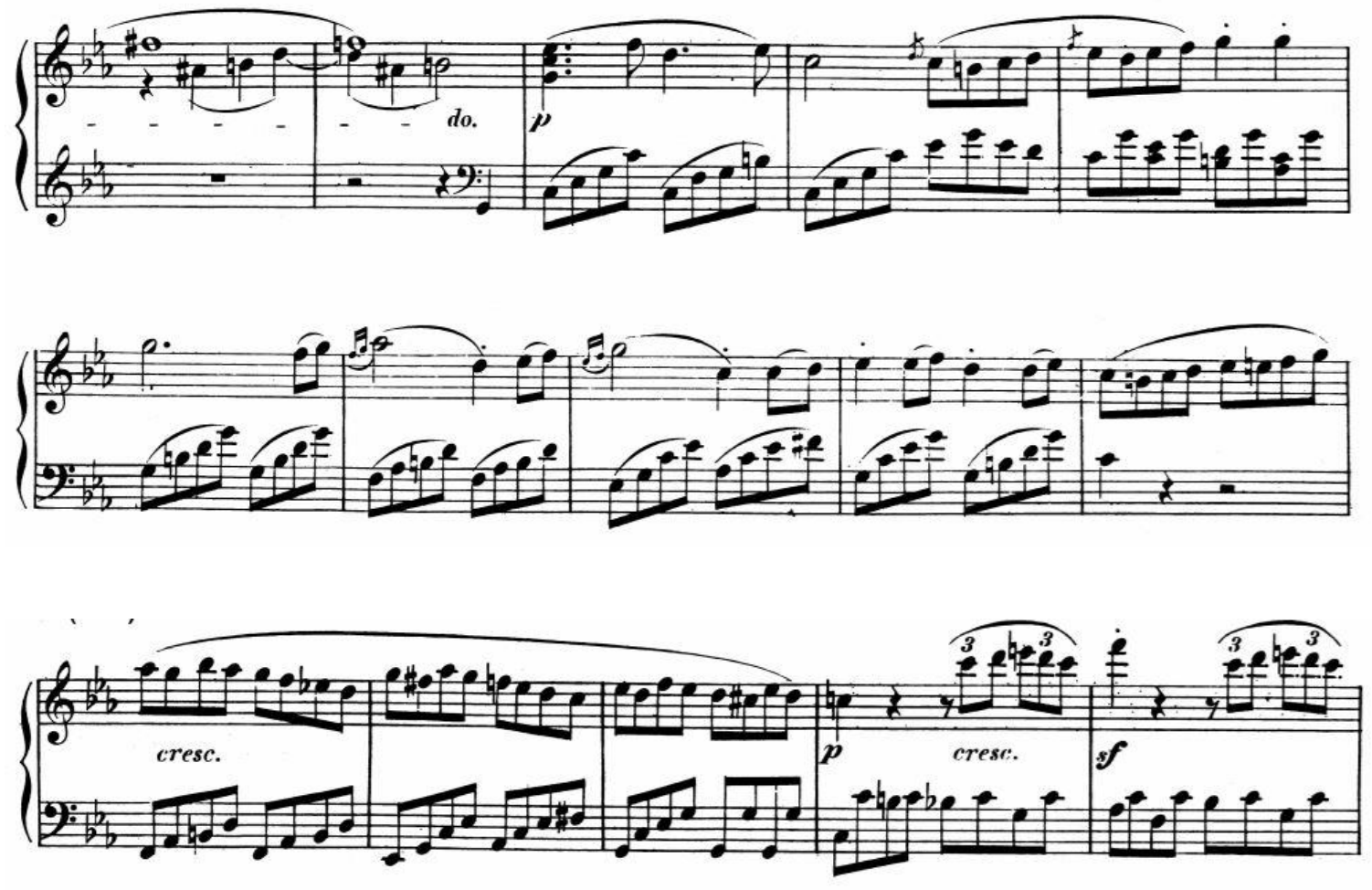

Source: Beethoven, Ludwig van. Sonaten für das Pianoforte. New York: Edwin F. Kalmus, n.d. (193370). 
Example 11: Sonata Op. 13 in C minor ("Pathetique"), mvt. 3, mm 119-124, embellished by John Salmon. N.B. Salmon only provides suggestions for right hand performance. Compare with Example 8.
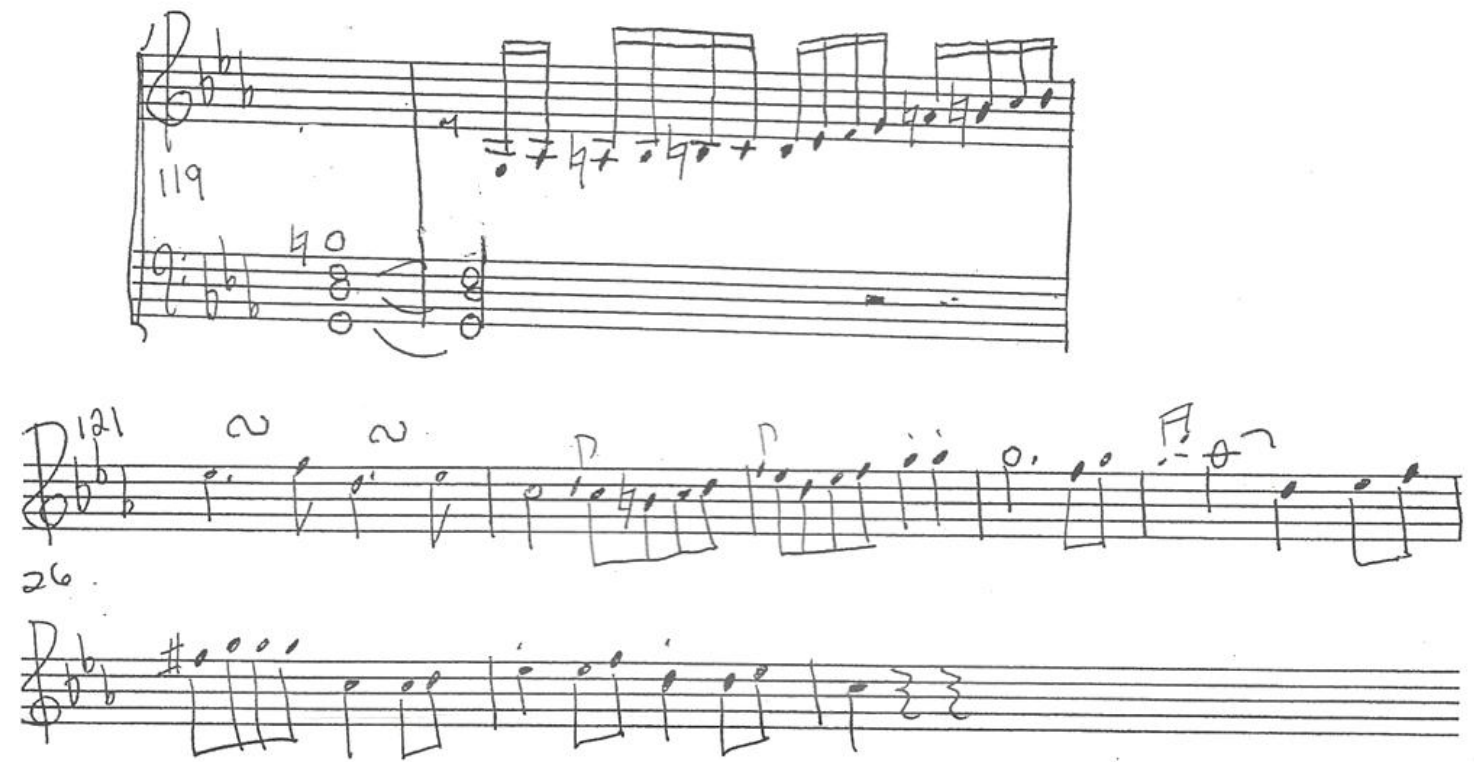

Source: John Salmon, "Improvising in Beethoven." Lecture at Focus on Piano Literature, Greensboro, NC, June, 2002.

The first thing to notice in Example 11 is the chromatic scale leading up to the downbeat of the first full measure of this refrain. When Salmon's embellishment is compared to the original score in Example 8, we find that he has also bypassed the three eighth notes which typically lead into the downbeat in favor of the chromatic scale. Secondly, in measure 121, Salmon adds an ornament on the dotted quarter notes in the right hand. These are particularly lovely and full of the perky, mischievous personality that Beethoven seems to have intended for this piece. In measure 126, Salmon activates the texture by adding eighth notes and even a dissonant passing tone on the downbeat. Again, these embellishments enhance the sly character of the rondo and do not seem to distract from it.

Another potential embellishment is provided in Example 12. This one is designed to fit in the second refrain, which is provided in Example 8. This example represents a more conservative approach. The ornaments used by Salmon are also represented here, with the addition of a slightly longer ornament 
in measure 63 on the third beat and 64 on the first beat. Like Salmon's embellishment, eighth notes are also used to activate the texture, this time in measure 64 rather than measure 67 , which corresponds to measure 126 in Salmon's example. In measures 67 and 68, the diminished fifth and the perfect fifth intervals are filled in to accentuate the distance between the original notes.

Example 12: Sonata Op. 13 in C minor ("Pathetique"), mvt. 3, mm 60-70, embellished
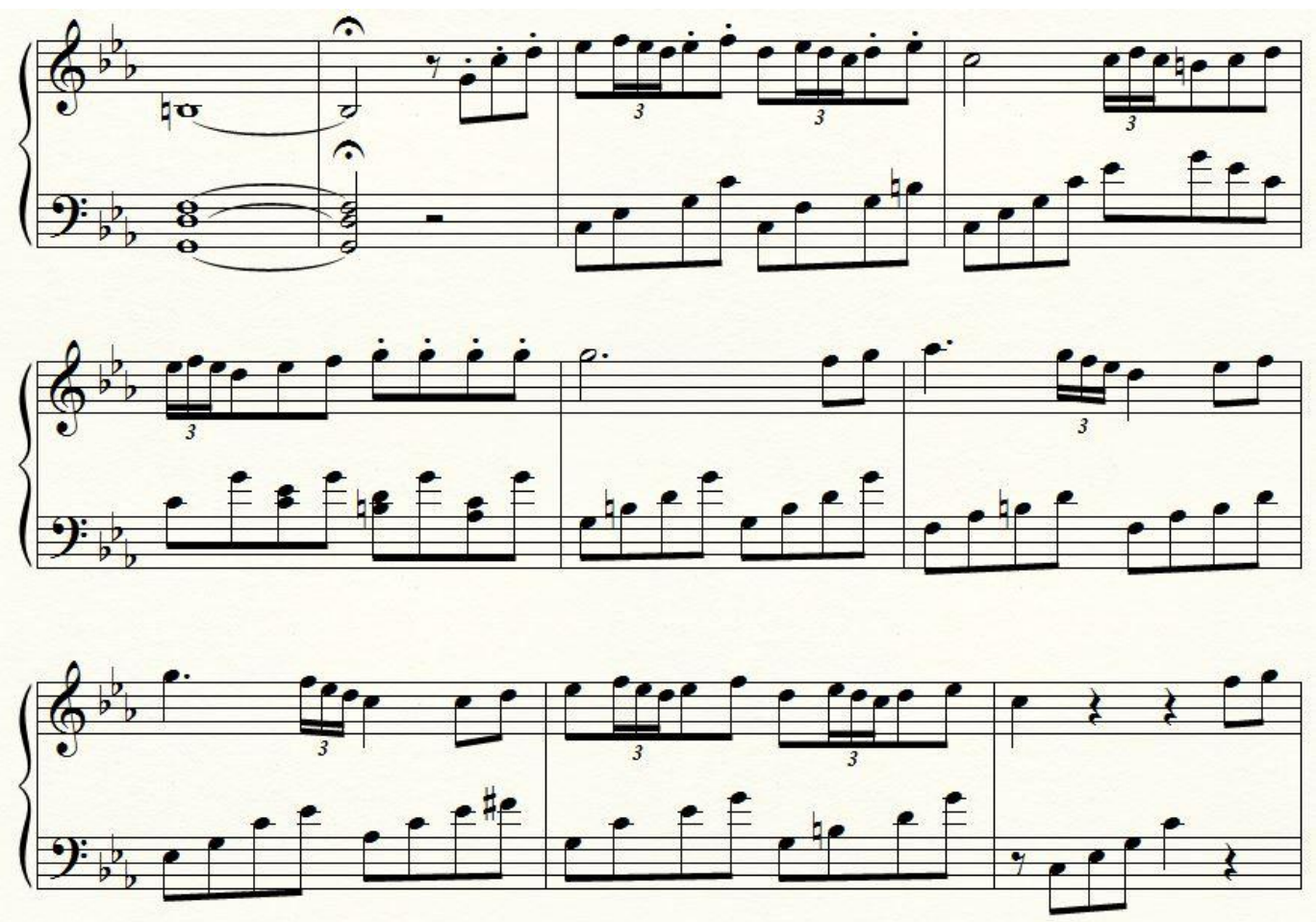

Source: Author

These embellishments may be considered conservative and consistent with the intended character of the music. An example of a less successful embellishment is also provided (Example 13). Consider the marked departure of style and character, and the needlessly loud and difficult additions. 
Example 13: Sonata Op. 13 in C minor ("Pathetique"), mvt. 3, mm 61-65, embellished.

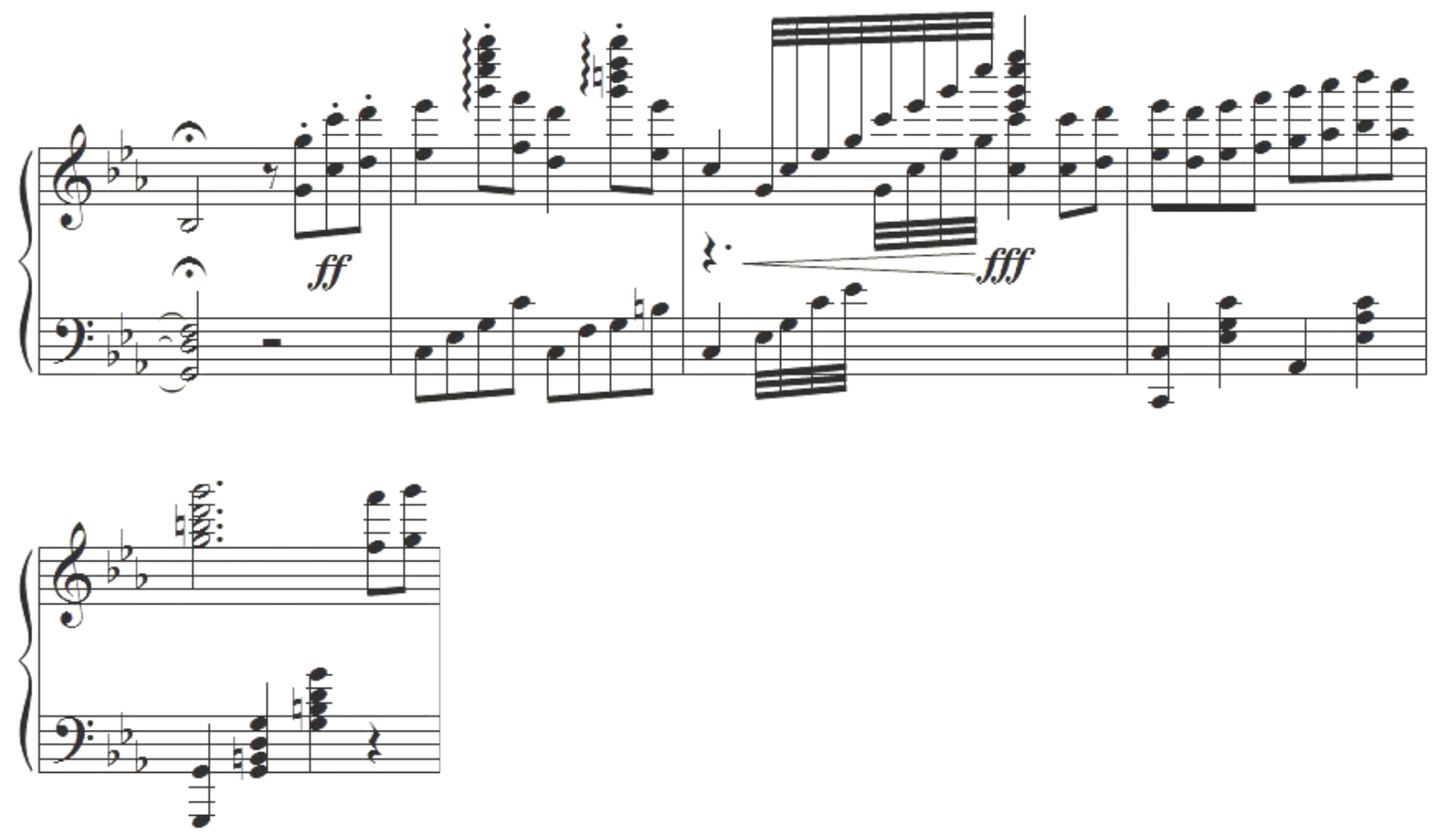

Source: Author

The right hand octaves in this example are certainly not consistent with Beethoven's early style, and the showy, boisterous flourishes contradict the quaint mischief that seems to be intended in this rondo. The dynamics exceed reasonable expectations for early Beethoven. Additionally, the use of the Bflat in the right hand on the fourth beat of measure 64 is questionable in eighteenth century voice leading, which would rarely use a melodic flat seventh scale degree followed by a raised seventh scale degree in the following harmony.

The other specific reference that we have from Ries is the rondo from the first concerto. Again, we do not know specifically where or how Beethoven intended for this to be embellished, but Example 15 provides one possibility. 
Example 14: Concerto No. 1 in C major, Mvt 3, mm 49-68 (Beethoven's original score)
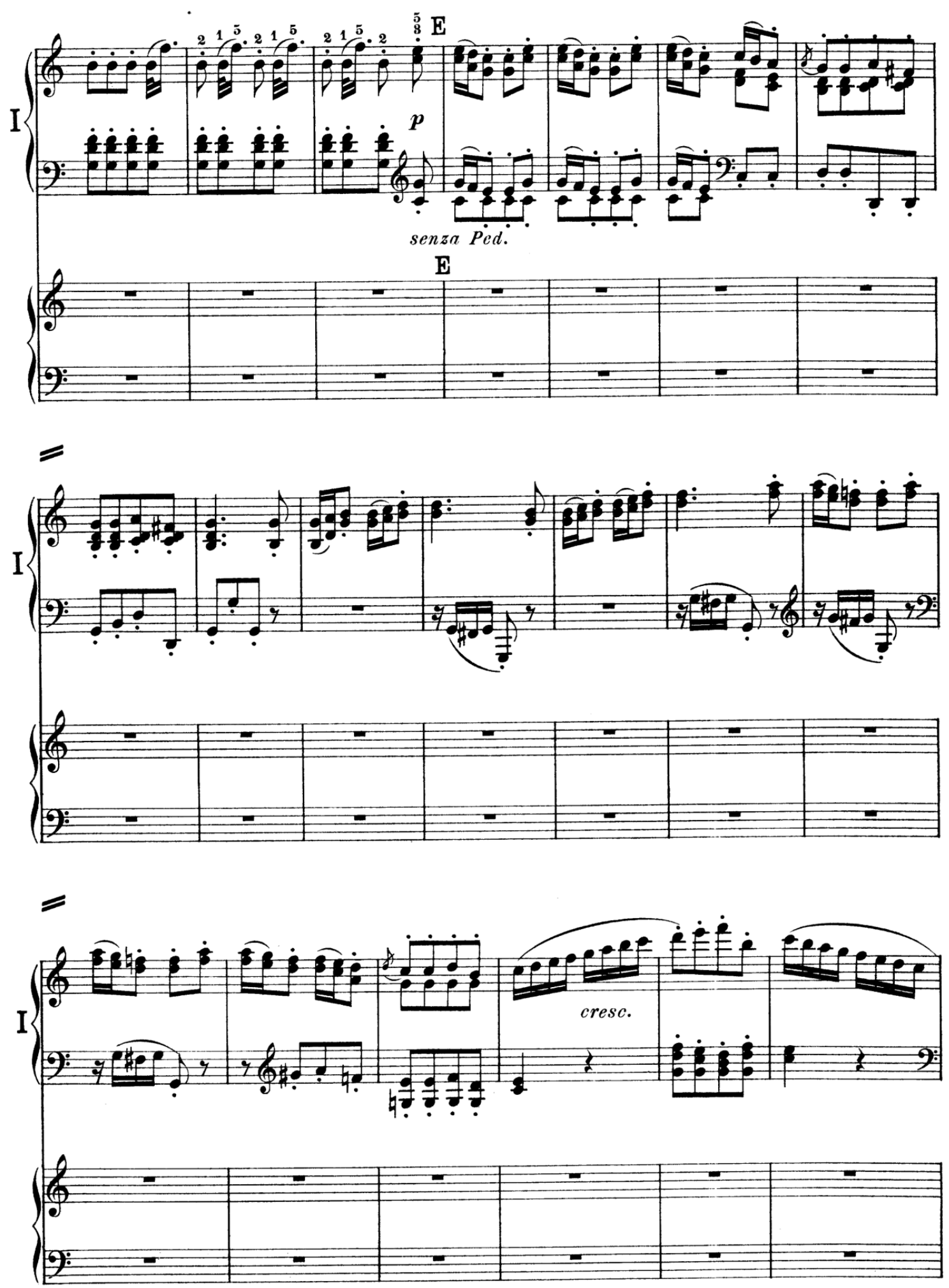
Source: Beethoven, Ludwig van, Arr. Adolf Ruthardt. Concert für Pianoforte von L. van Beethoven. Leipzig: C.F. Peters, ca. 1895.

Example 15: Concerto No. 1 in C major, Mvt 3, mm 49-61 (embellished version)
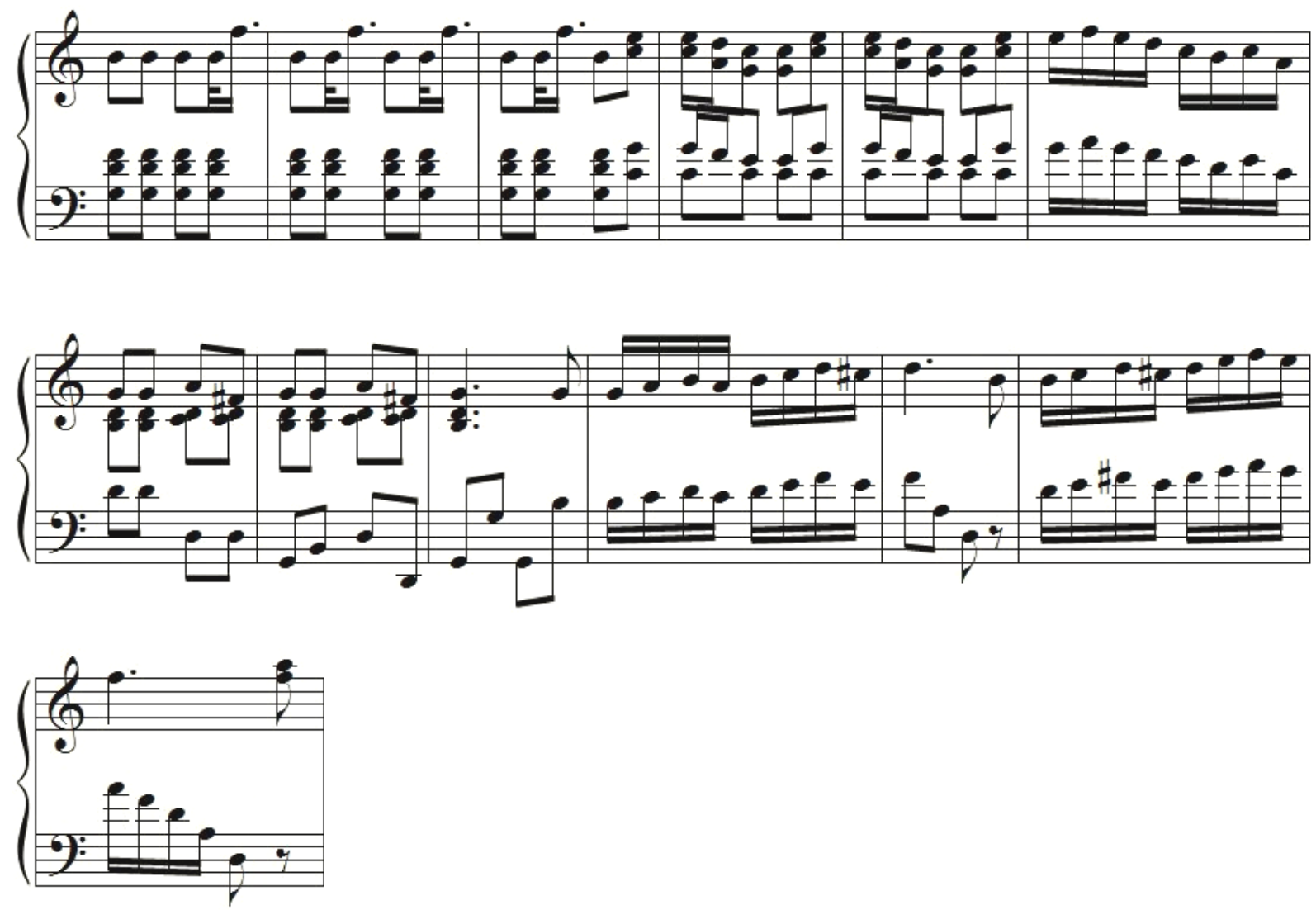

Source: Author

Compare Examples 14 and 15 and notice the departure from the score in measures 54, 58 and 60-61 of Example 15. This refrain makes much use of parallel thirds and sixths, and so the texture is changed in order to incorporate some simple passagework in sixths.

If Beethoven encouraged embellishments of these rondos, surely he allowed similar embellishments in other rondos as well. Salmon offers the following alternative (Example 17) to the plain 
left hand octaves at the end of the rondo of Beethoven's first piano sonata (Example 16). The broken effect enlivens the texture and creates a more stunning effect for the end of the piece.

Example 16: Sonata Op. 2 No. 3 in a minor, mvt. 4, mm 301-312 (Beethoven's original score)

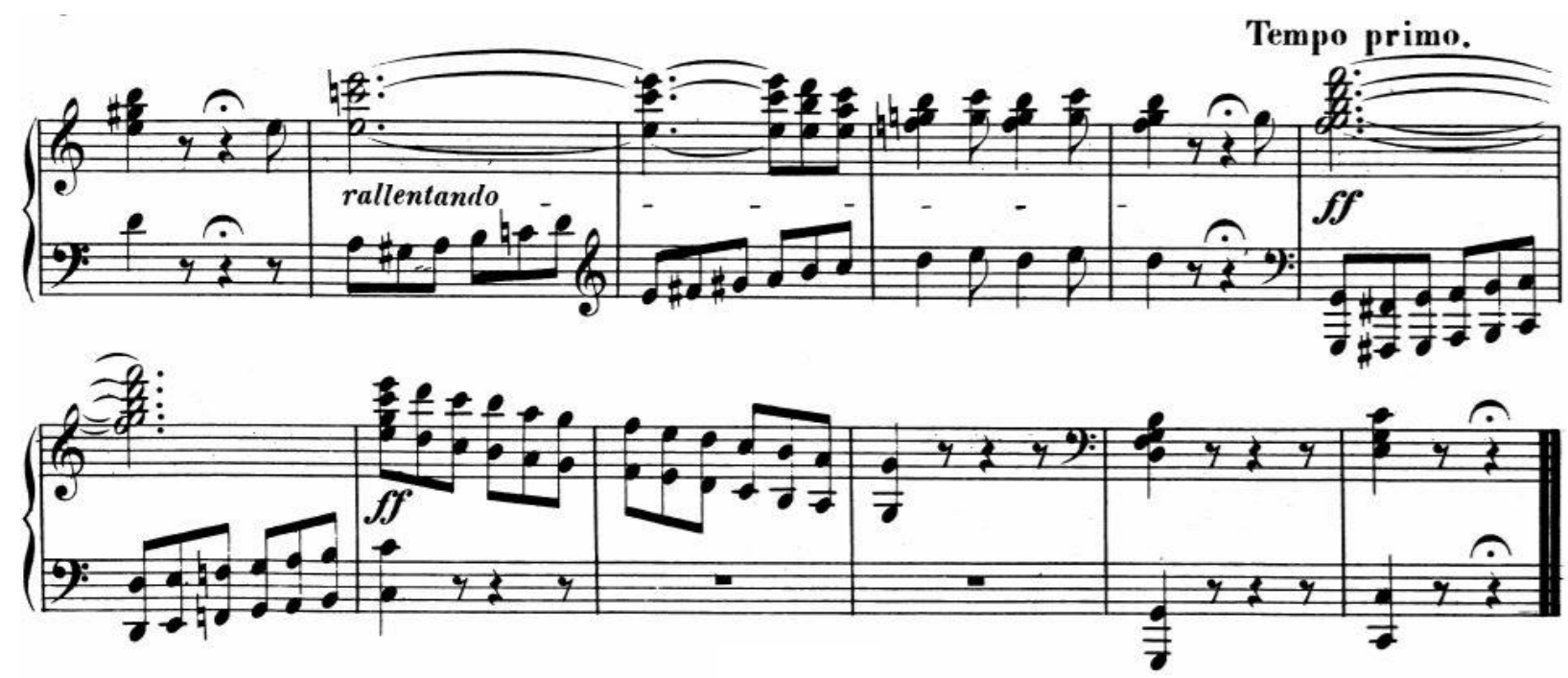

Source: Beethoven, Ludwig van. Sonaten für das Pianoforte. New York: Edwin F. Kalmus, n.d. (193370).

Example 17: Sonata Op. 2 No. 3 in a minor, mvt. 4, mm 306-307, embellished by Salmon

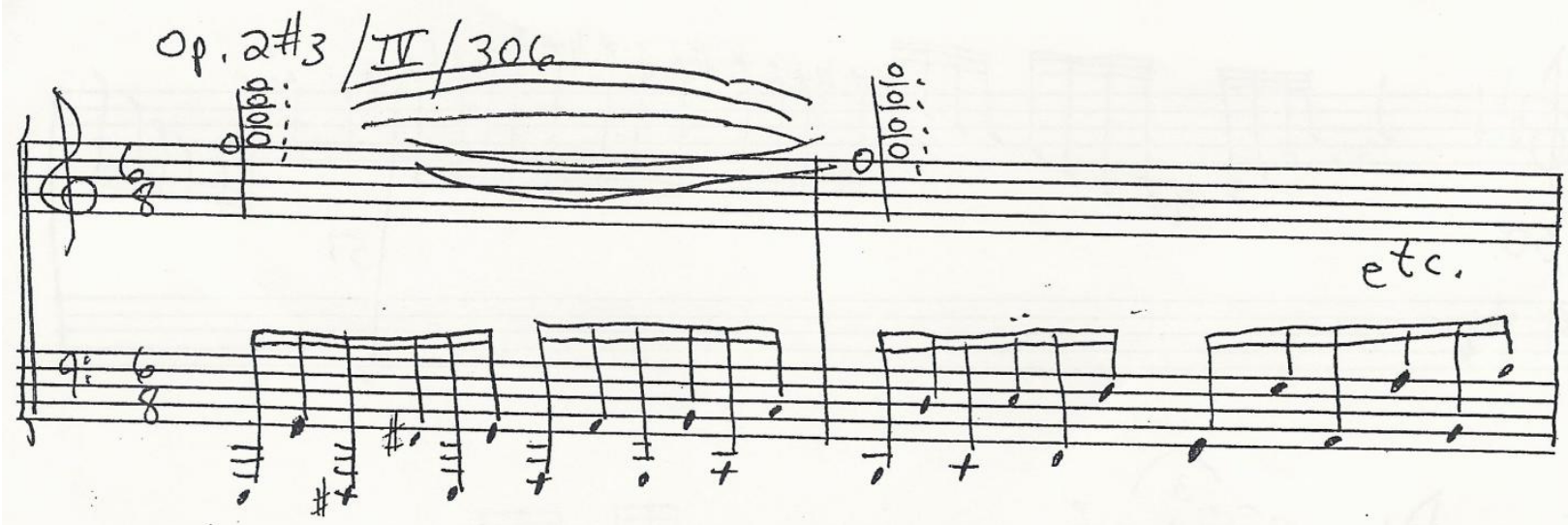


Source: John Salmon, "Improvising in Beethoven." Lecture at Focus on Piano Literature, Greensboro, NC, June, 2002. June 1, 2016.

Rondos provide the ideal context for improvised embellishments. The constant return to the A section is a challenge for any artistic pianist who wants to keep things interesting and avoid redundancy. Adding a few notes to repeated sections can make an enormous difference for the benefit of one's audience, in order to keep the musical narrative flowing and not becoming stagnant. These examples deal only with the returning refrain, but in an $\mathrm{ABACADABA}$ rondo one may also try to embellish the return of the B section.

\section{Making Material More "Brilliant"}

This section examines areas where it may enhance the interest of Beethoven's music to add difficulties to the score for the purpose of making it "more brilliant." The first example is from the Scherzo of Beethoven's sonata Op. 26.

Example 18: Sonata in A flat Major, Op. 26, No. 12, mvt. 2, mm. 1-4

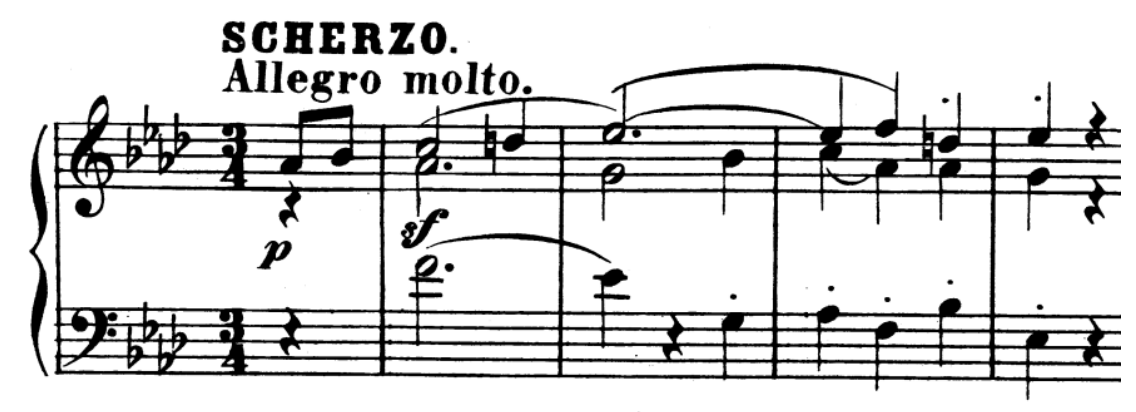

Source: Beethoven, Ludwig van. Sonaten für das Pianoforte. New York: Edwin F. Kalmus, n.d. (193370).

This particular phrase resurfaces once more in the course of performing the piece, as the pianist is directed to return to the beginning of the Scherzo. Here is a possible way to vary it once it returns: 
Example 19: Sonata No. 12 in A flat Major, Op. 26, mvt. 2, mm. 1-4, with embellishment.

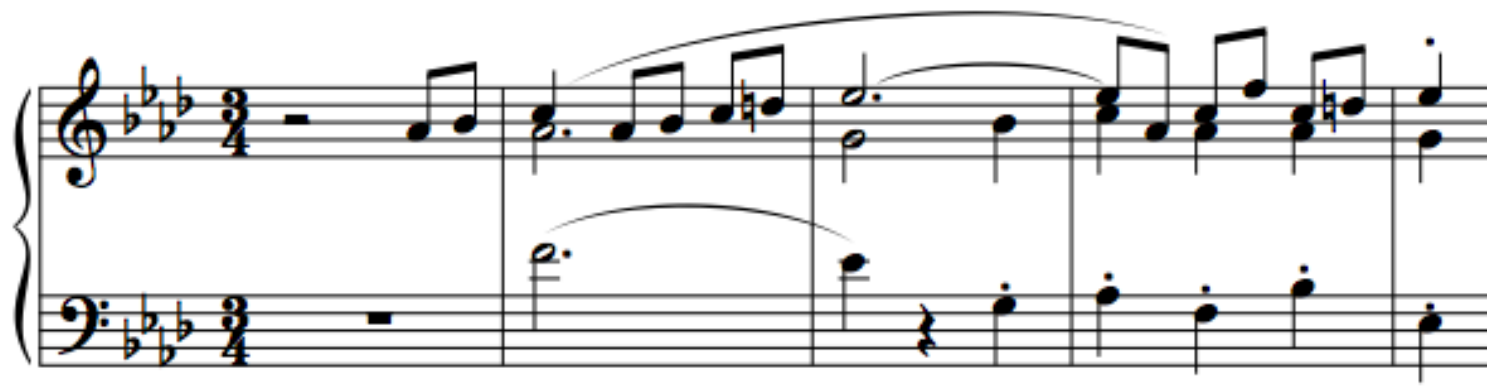

Source: Author

The use of smaller note values is employed to activate the texture. This is a typical scherzo in its playful character, and the addition of some scattered decorations only enhances the playfulness.

Another example is drawn from the same movement a few measures later:

Example 20: Sonata No. 12 in A flat Major, Op. 26, mvt. 2, mm. 17-21 (Beethoven's original score)

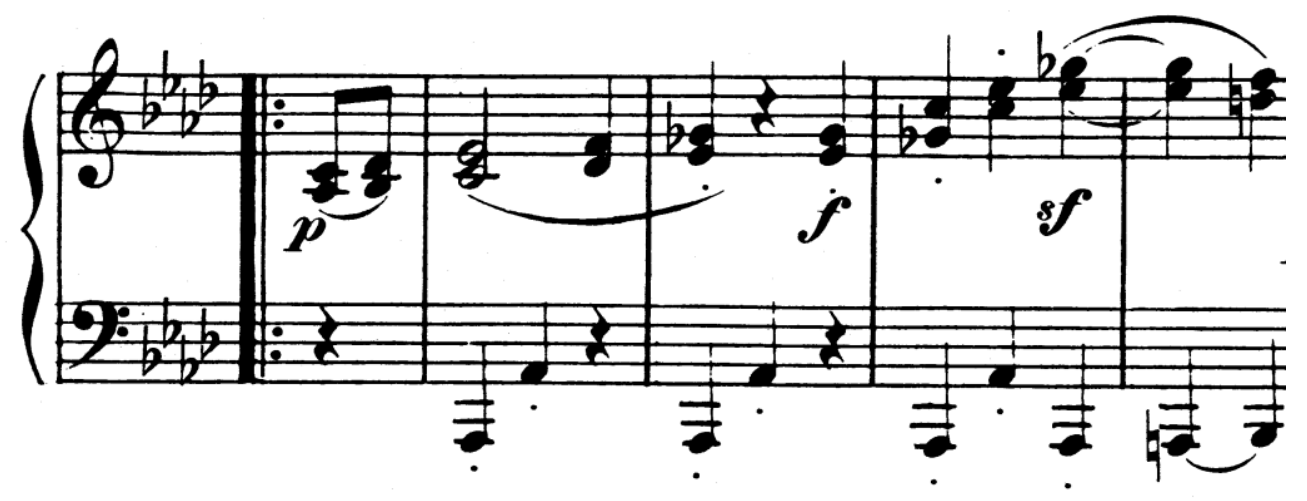

Source: Beethoven, Ludwig van. Sonaten für das Pianoforte. New York: Edwin F. Kalmus, n.d. (193370). 
This pattern will return three times if all of the repeats are taken, so it seems preferable to vary it at least once if not every time. Here is one possible way of doing this:

Example 21: Sonata No. 12 in A flat Major, Op. 26, mvt. 2, mm. 17-21, with example of variation.

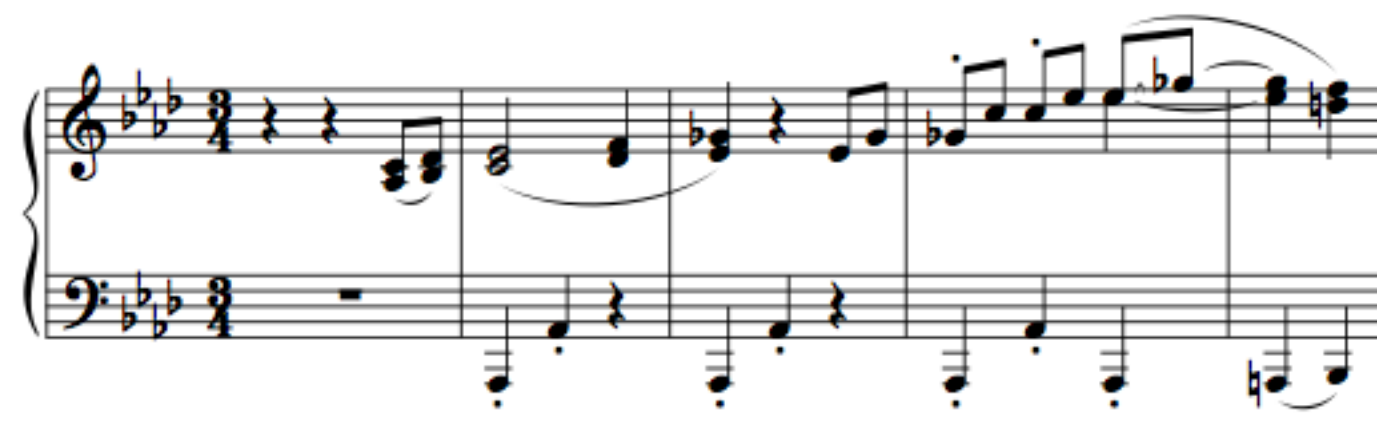

Source: Author

Here, the technique of breaking the blocked sonorities is used in order to enliven the texture and provide even more forward momentum as the melody rises to its peak at the G-flat in measure 20.

The next example from the Sonata Op. 110 is more daring. Salmon further decorates an already fantasy-like passage and, maintaining a consistency with the original style, simply makes the music his own. 
Example 22: Sonata Op. 110, mvt. 3 mm 1-11 (Beethoven's original score)
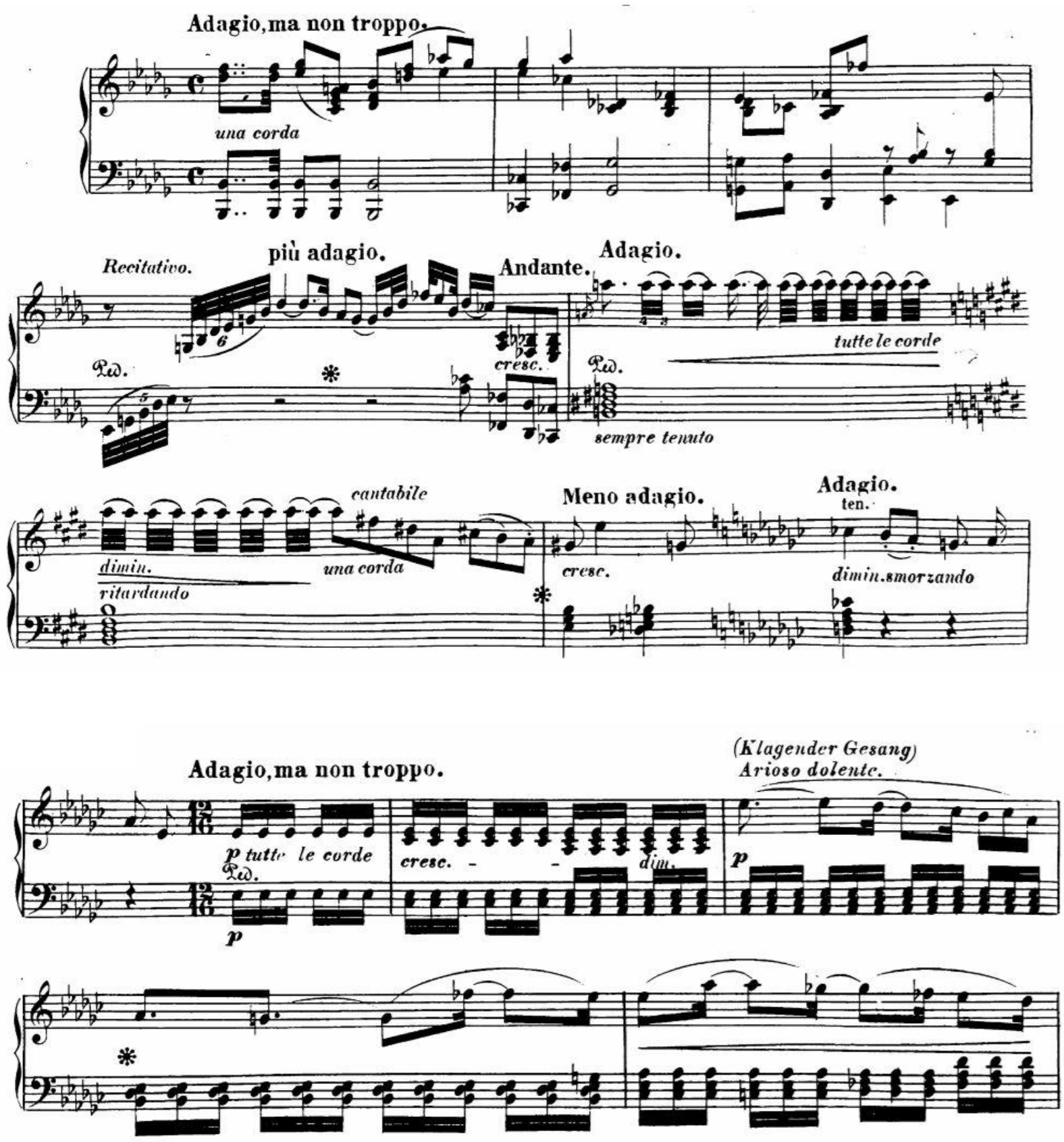

Source: Beethoven, Ludwig van. Sonaten für das Pianoforte. Leipzig: Breitkopf und Härtel, 1862. 
Example 23: Sonata Op. 110, mvt. 3 mm 4-9 (with embellishment)
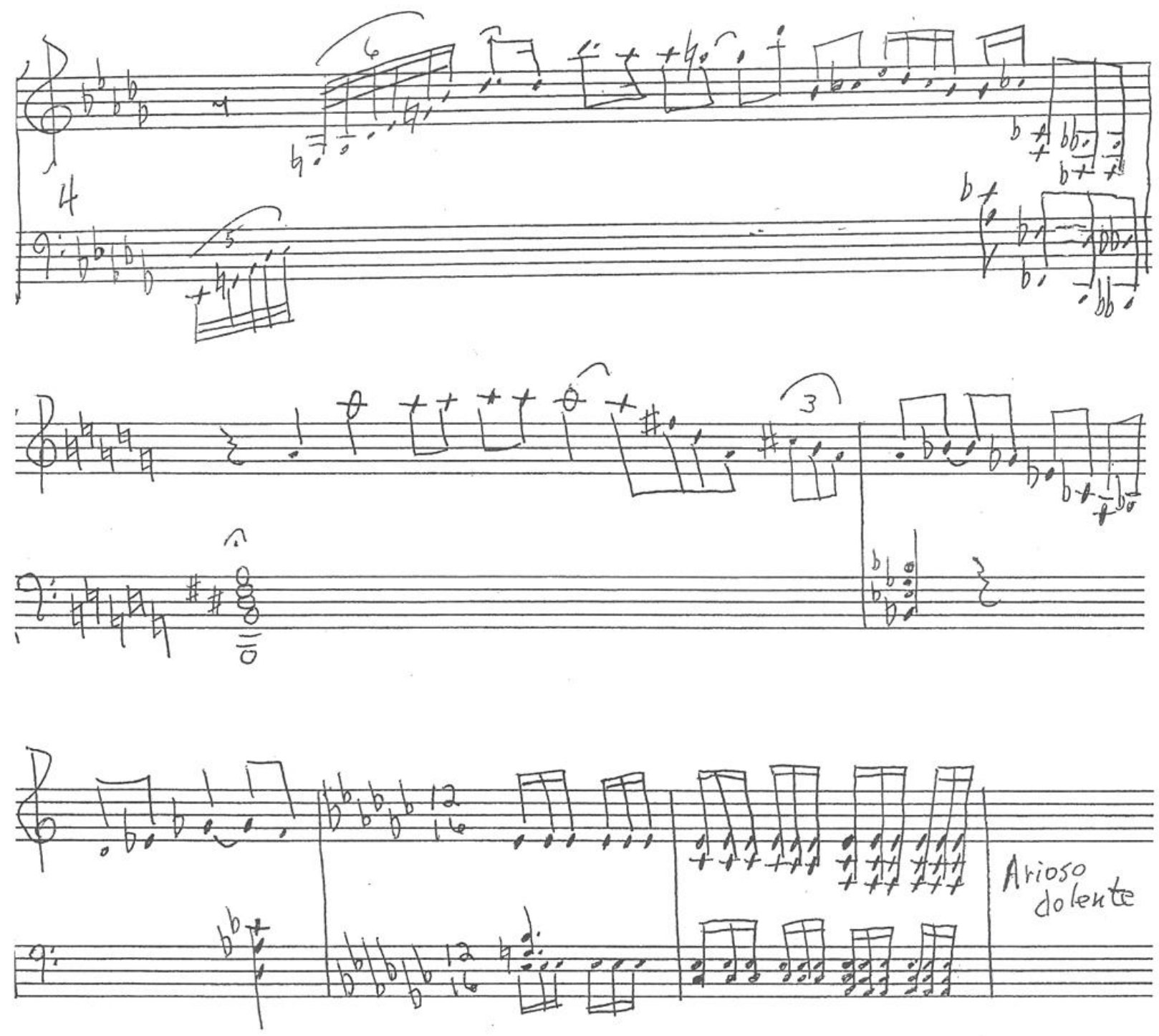

Source: John Salmon, "Improvising in Beethoven." Lecture at Focus on Piano Literature, Greensboro, NC, June, 2002. June 1, 2016.

The next example is taken from the Sonata Op. 22. Here, similarly, Salmon takes an improvisatory passage from the second movement and adds his own personal flair to it. Notice in particular measures 52 and 53, where Salmon takes the same gestures that Beethoven has already placed in the score and simply expands them, making them more virtuosic by reducing the note values. 
Example 24: Sonata Op. 22, Mvt. 2, mm 49-54 (Beethoven’s original score)
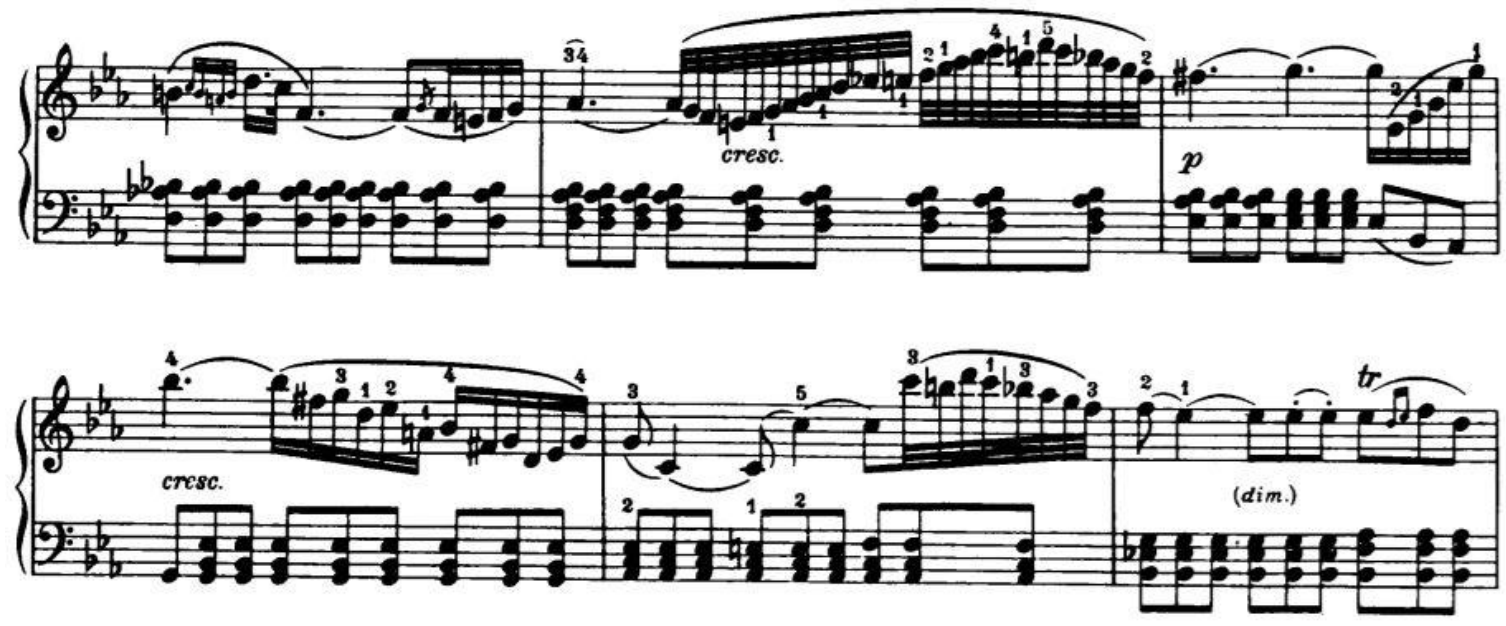

Source: Beethoven, Ludwig van. Sonaten für Klavier zu zwei Händen, Bd.1. Ed. Max Pauer. Rev. Ed. Carl Adolf Martienssen, Leipzig: C.F. Peters, ca. 1920. 
Example 25: Sonata Op. 22, Mvt. 2, mm 50-53
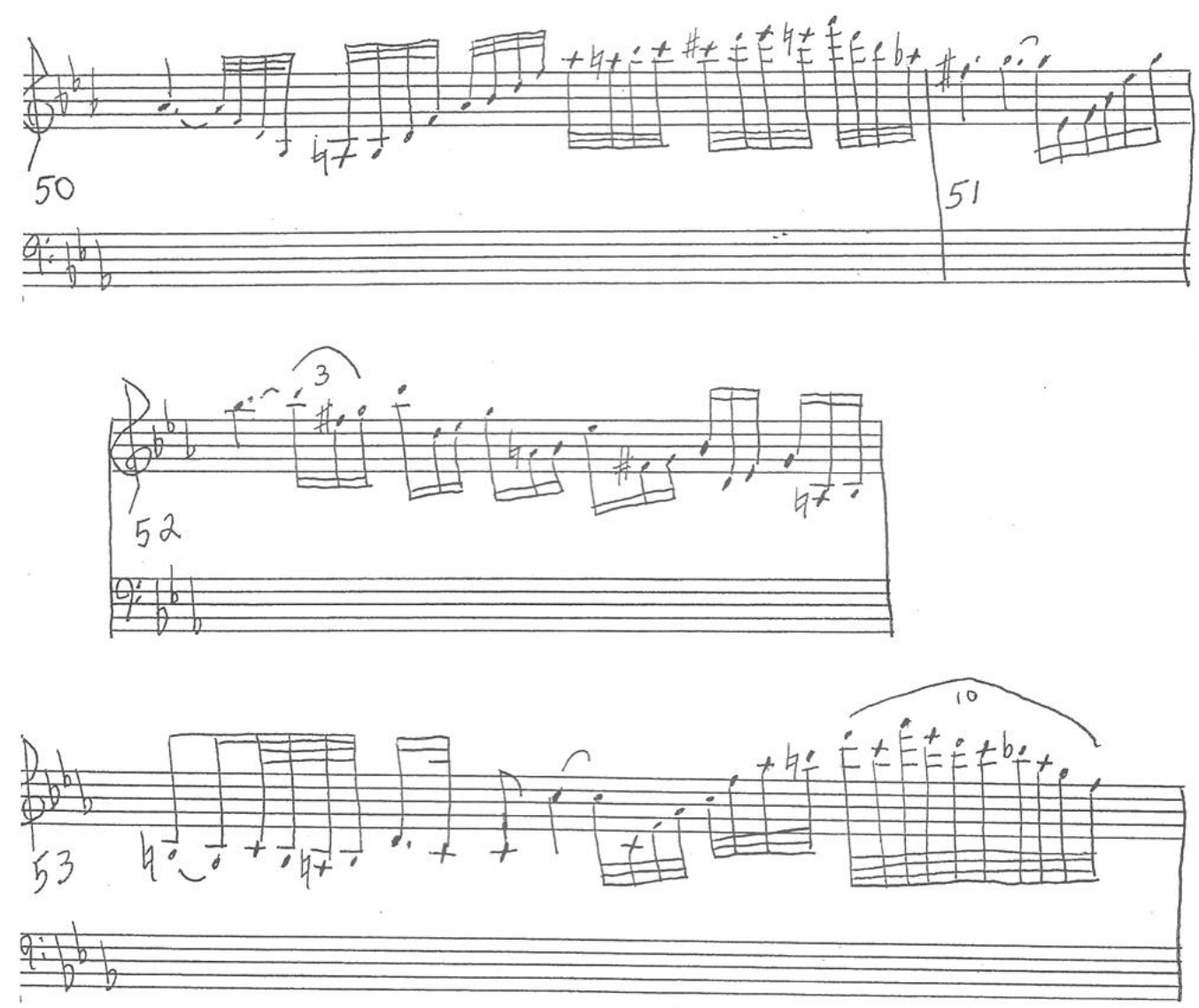

Source: John Salmon, "Improvising in Beethoven." Lecture at Focus on Piano Literature, Greensboro, NC, June, 2002. June 1, 2016.

In his Systematic Introduction to Improvisation, Carl Czerny provides exercises to help pianists learn how to dramatically enliven a simple texture. He applies this practice to "preludizing," which he describes as choosing a few chords to improvise on as an introduction to another piece of music. Czerny explains,

It is akin to a crown of distinction for a keyboardist, particularly in private circles at the performance of solo works, if he does not begin directly with the composition itself but is capable by means of a suitable prelude of preparing the listeners, setting the mood, and also thereby ascertaining the qualities of the pianoforte, perhaps unfamiliar to him, in an appropriate fashion. 
But it is also necessary to observe the limits of propriety at the same time. With the accompaniment of other instruments, one must cut it very short and accomplish the thing with a few chords and a brilliant run. In a public performance of a solo piece with orchestra, (especially if it begins with a Tutti), preludizing of any sort is unsuitable. ${ }^{197}$

The exercises that Czerny uses to help pianists develop this "crown of distinction" can be particularly helpful to understanding more dramatic ways of making simple textures more "brilliant." Every prelude used in these excerpts is based on the simple, six-chord harmonic progression at the beginning.

${ }^{197}$ Czerny, Systematic Introduction, 6. 
Example 26: pages 7-9, Systematic Introduction

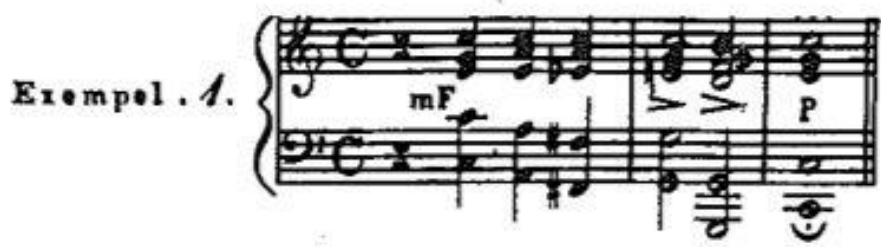

And now one may see what can be made out of this (ex, 2-6).
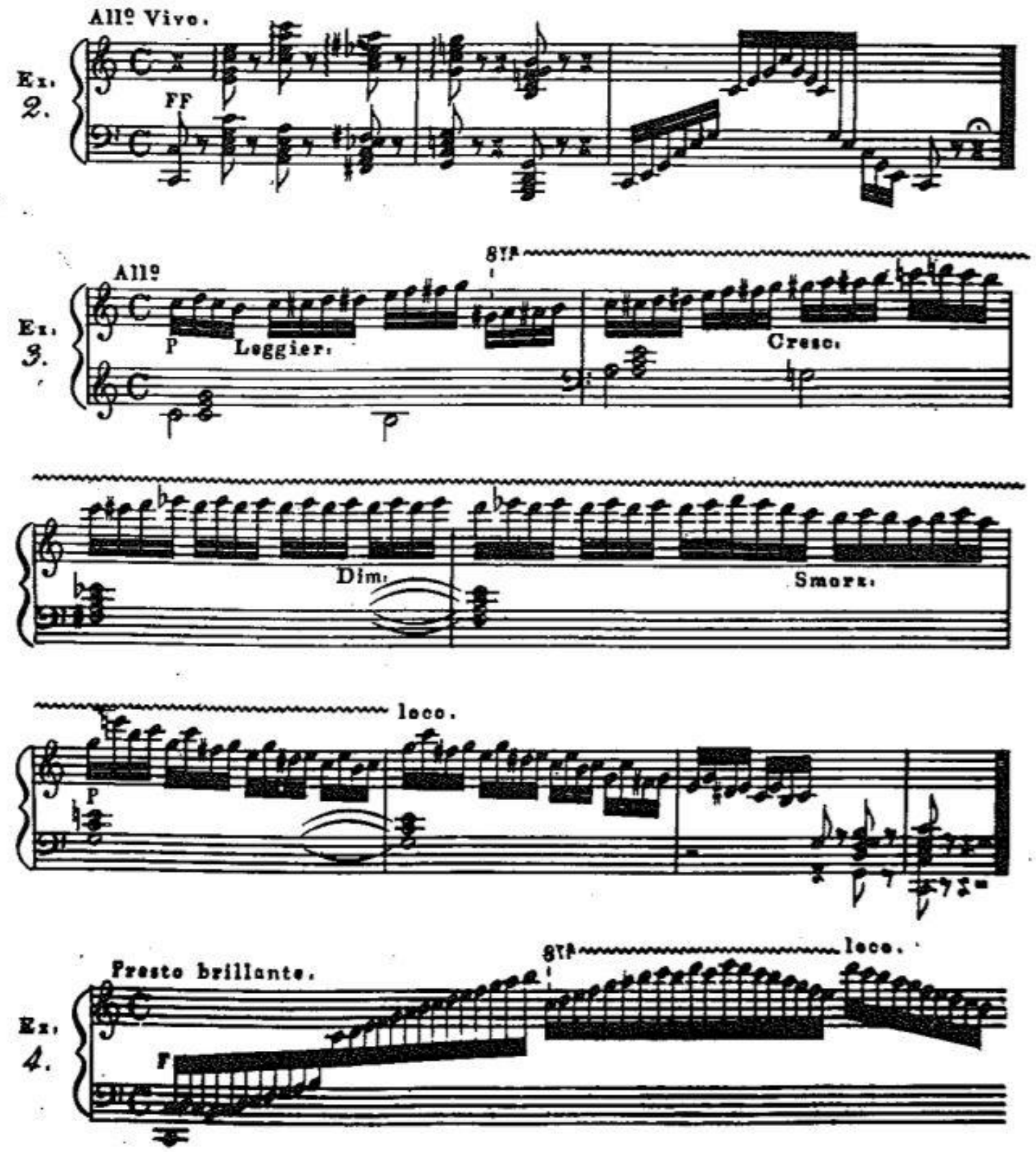

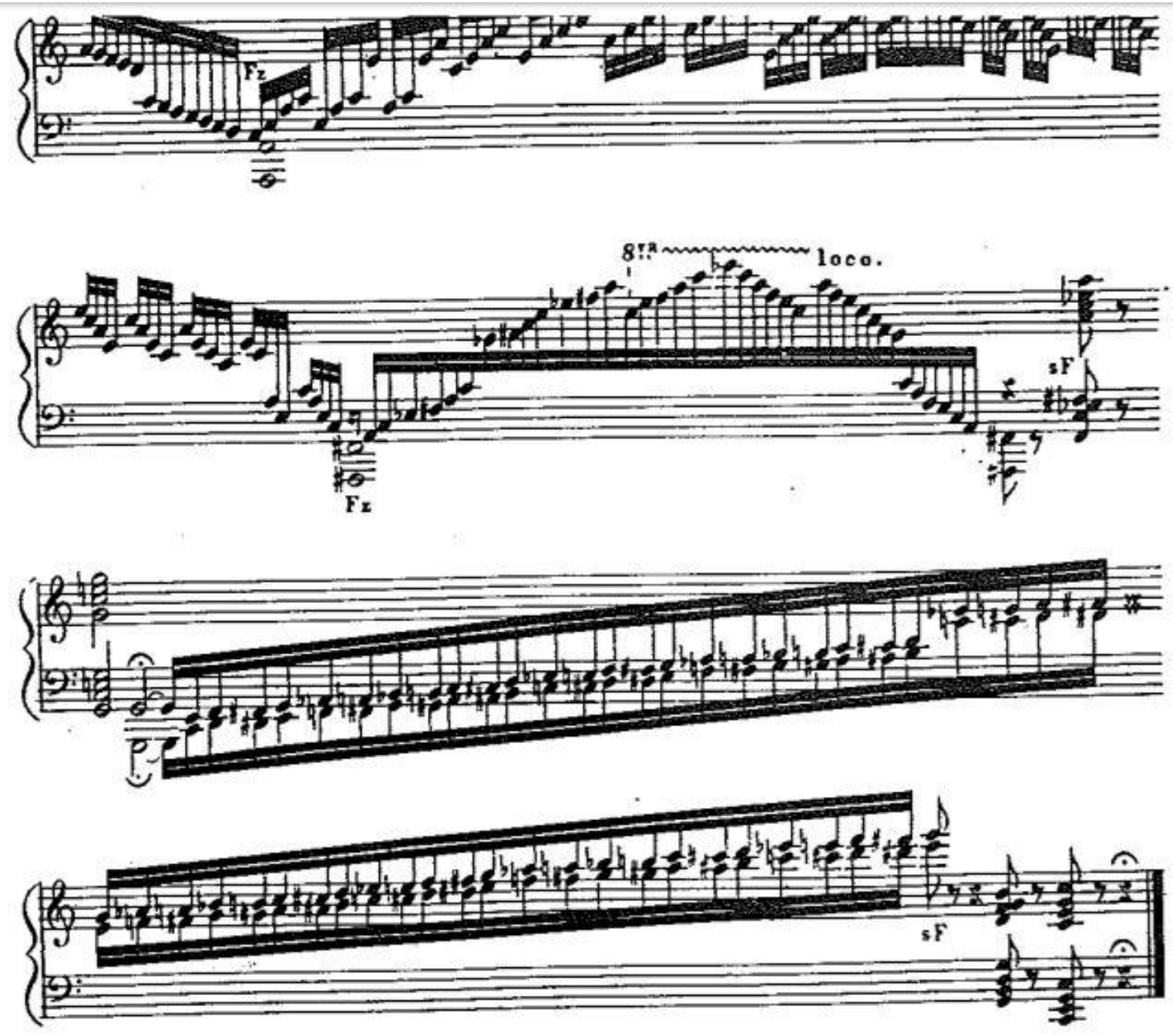

In connected ${ }^{7}$ chords $(e x, 5)$.

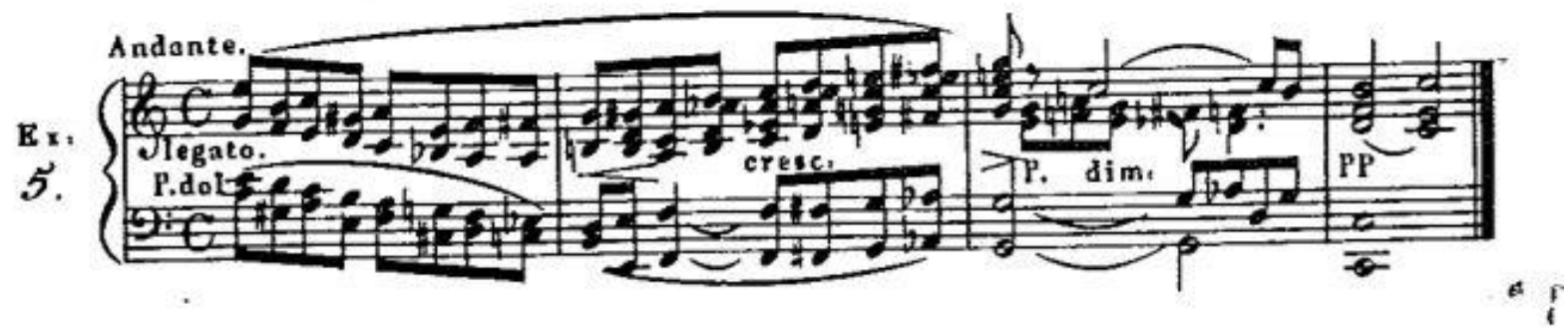

7. Gebunden is translated here as "connected", based on the context of the musical illustration (Ex. 5) that follows. Legato is also implicit in this example, although Czerny is usually explicit with his use of that designation (see footnotes 2 and 3 , seventh chapter.) Neither "sustained-note" nor "strict", more common translations for the style designated as gebunden, are appropriate here. 


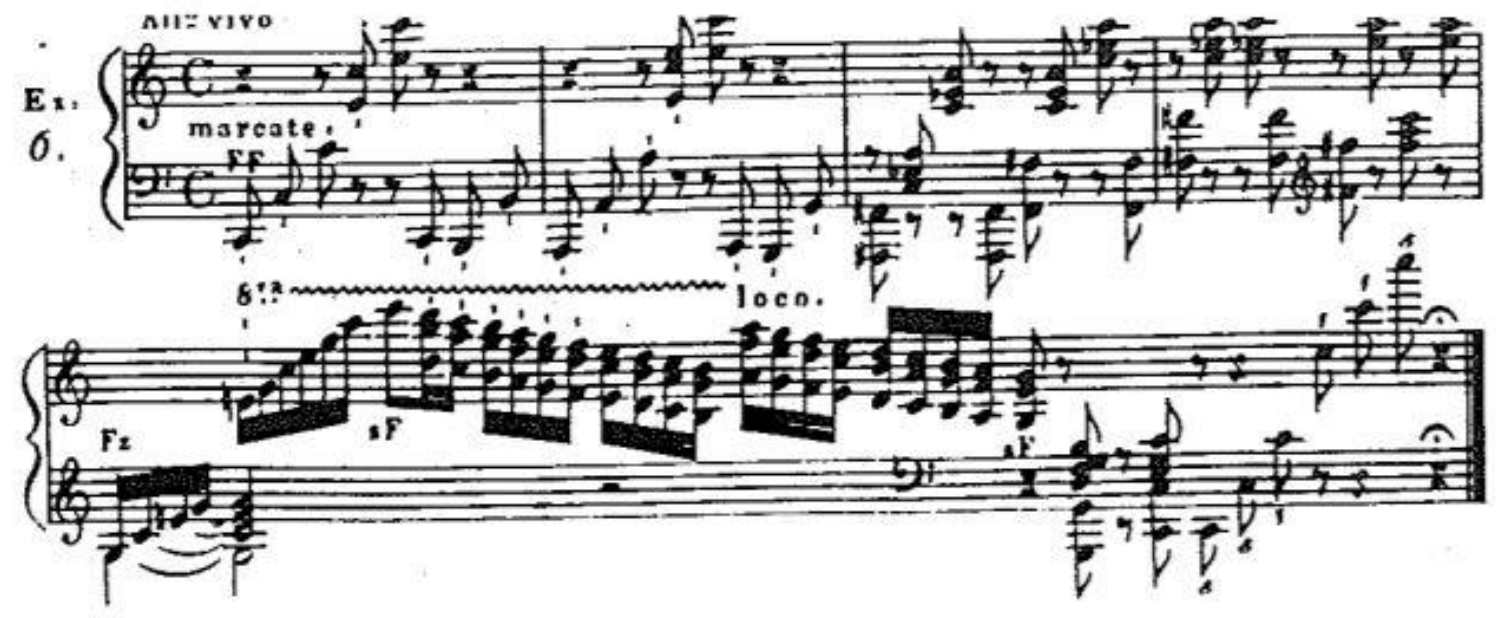

Source: Czerny, Carl and Alice L. Mitchell. A Systematic Introduction to Improvisation on the Pianoforte: Opus 200. New York: Longman, 1983.

Eingang

This section will address the use of Eingang in Beethoven's pieces. As was already discussed in the second chapter, an Eingang is a small, cadenza-like figure which is inserted into the original texture, serving as a functional "lead-in" to a new section. Potential Eingänge, according to David Polan, are "recognized by certain notational conventions: the presence of a fermata before recurrent principal thematic material over a functioning dominant chord or a rest. In this way the Eingang both served to elaborate the given harmony and to facilitate a smooth thematic transition. The properly constructed Eingang was not to be too long, was not necessarily to be played in strict meter, and above all had to conform to the principle of unity of affect." ${ }^{198}$ Polan's research deals primarily with early Beethoven works, but this section will apply the principle to a few later works as well.

In the second movement of the Appassionata, Beethoven places fermate over two chords (measures 95 and 96) which lead dramatically into the next section. In Example 27, we see how Salmon

${ }^{198}$ David Polan, “The Eingang in Early Beethoven," Performance Practice Review 7, no. 1 (1994): 82. 
connects these chords with a simple melody that increases the tension and propels the musical narrative forward into the new section.

Example 27: Sonata Op. 57 (“Appassionata”), mvt 2, mm 82-96

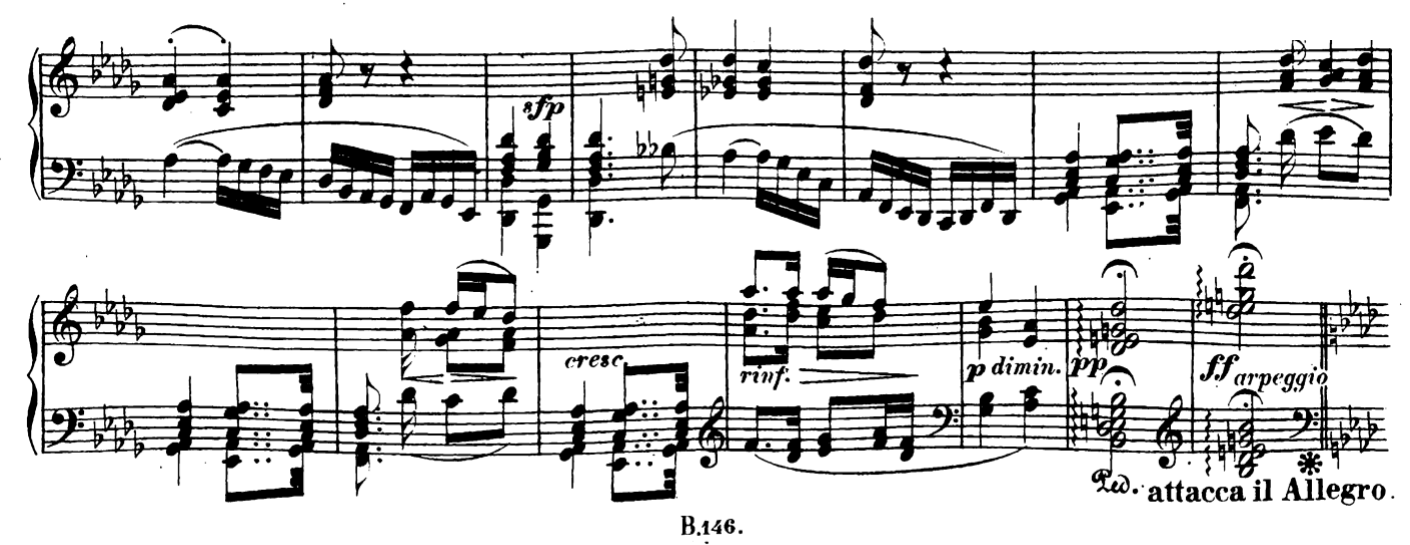

Source: Beethoven, Ludwig van. Sonaten für das Pianoforte. Leipzig: Breitkopf und Härtel, 1862-90.

Example 28: Sonata Op. 57 (“Appassionata”), mvt 2, mm 95-96

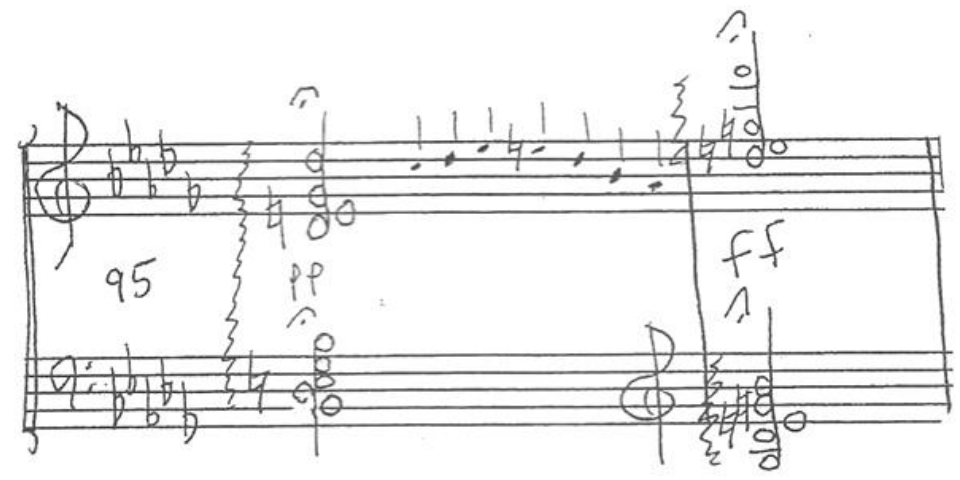

Source: John Salmon, "Improvising in Beethoven." Lecture at Focus on Piano Literature, Greensboro, NC, June, 2002. June 1, 2016. 
In this next example from the Rondo of Sonata Op. 14 No. 2, Salmon makes use of two fermate, along with enlivening the texture in other places as well. In measure 138 (Example 29), we see that he inserts a quick scale up to the downbeat of measure 139 (skipping the first two sixteenths of the theme, similar to his treatment of the theme in Example 11). At the fermata in measure 154, Salmon uses a simple suspension to decorate the climactic arrival, seeming to reference vocal practices frequently used in recitative and other contexts.

Example 29: Sonata Op. 14 No. 2 mvt. 3, mm 131-160
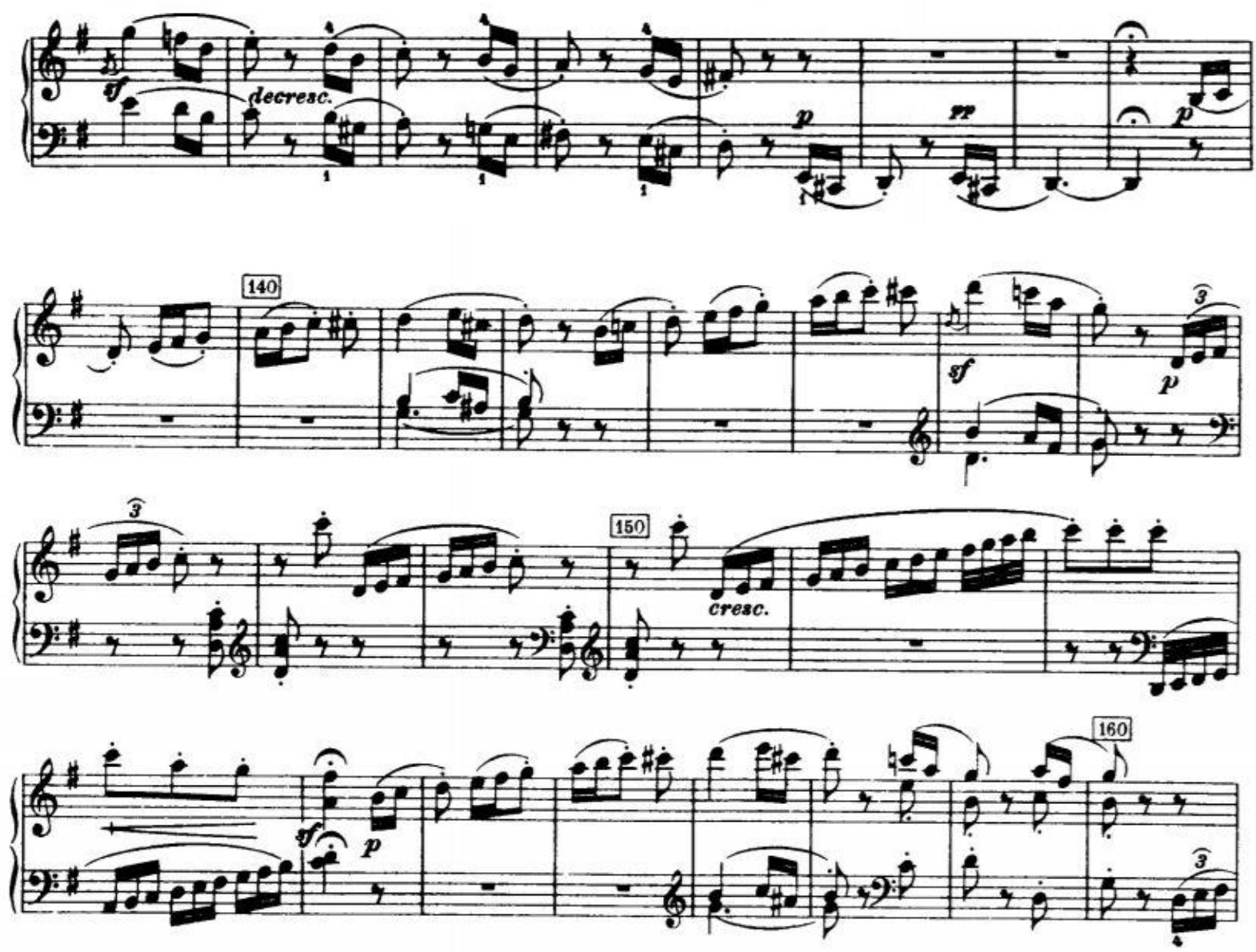

Source: Beethoven, Ludwig van. Sonaten für das Pianoforte. New York: Edwin F. Kalmus, n.d. (193370). 
Example 30: Sonata Op. 14 No. 2 mvt. 3, mm 138-154
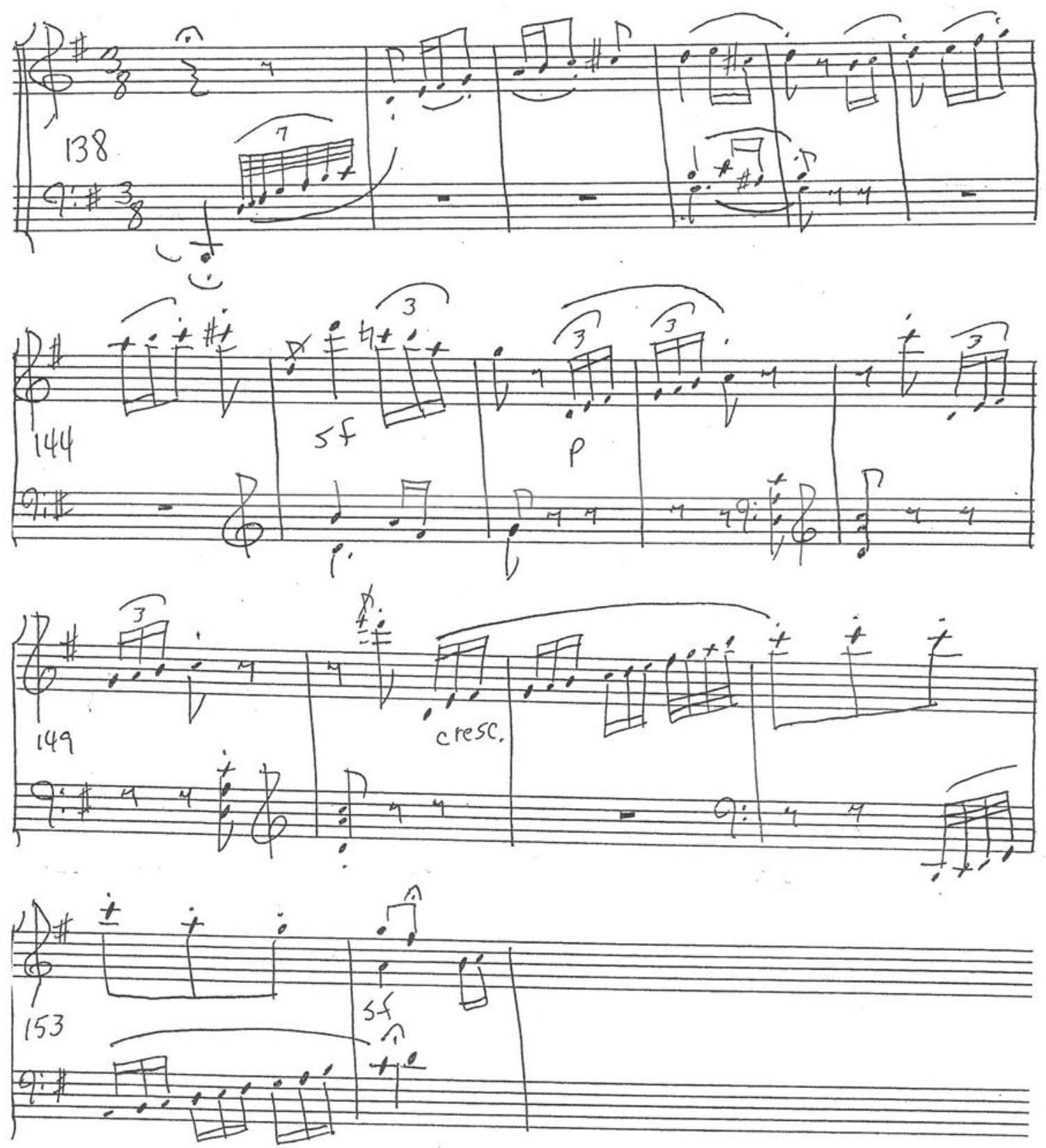

Source: John Salmon, "Improvising in Beethoven." Lecture at Focus on Piano Literature, Greensboro, NC, June, 2002. June 1, 2016.

In his Systematic Introduction to Improvisation, Carl Czerny provides written-out examples of many varieties of improvised embellishment. One section is devoted to inserting short cadenzas into 
written music at fermate. These are sometimes quite elaborate, but they can be compared to the Eingang that David Polan speaks of. Several examples from a single page are provided below. 
Example 31: Carl Czerny, "A Systematic Introduction to Improvisation," page 23
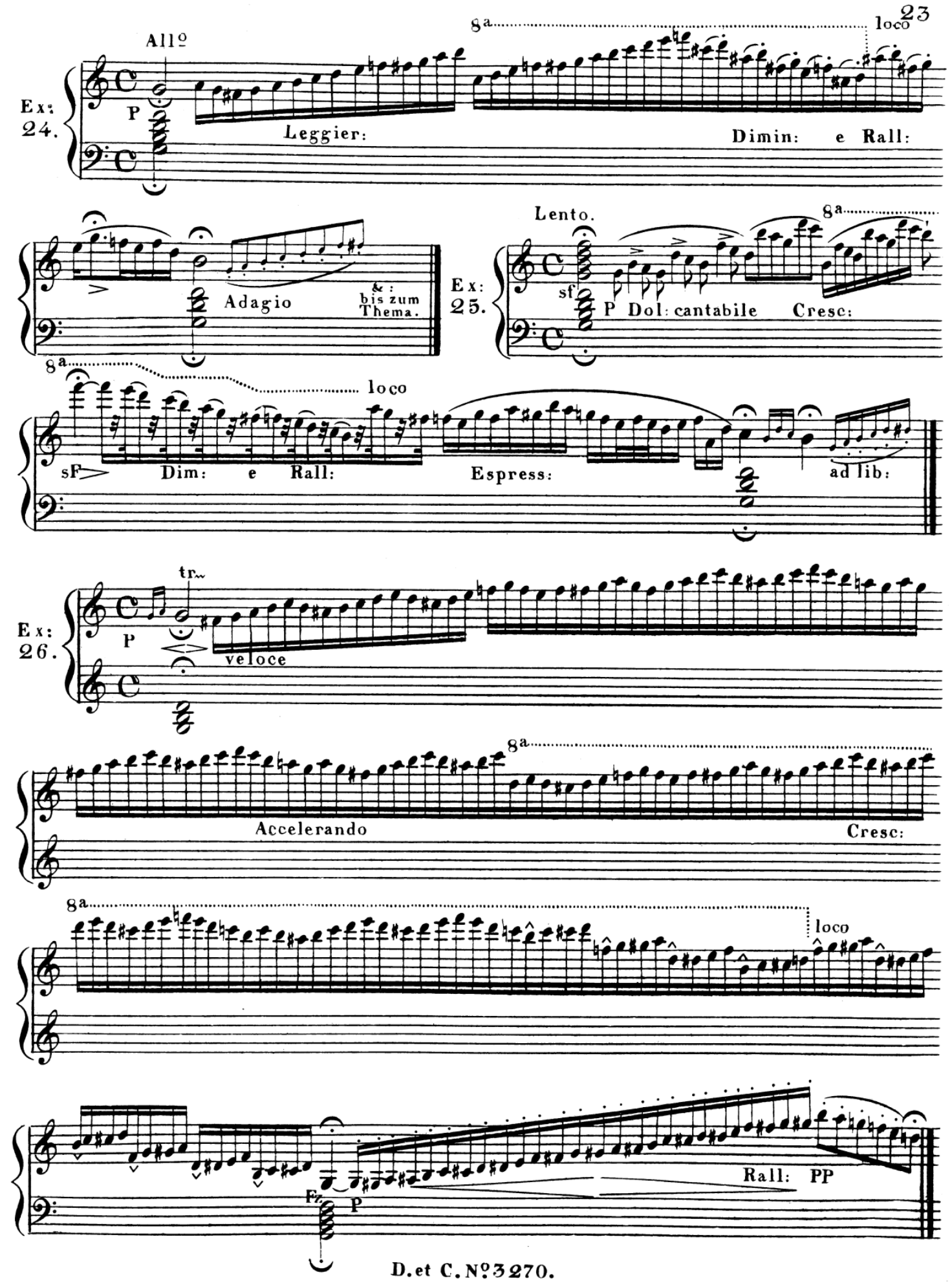
Source: Czerny, Carl and Alice L. Mitchell. A Systematic Introduction to Improvisation on the Pianoforte: Opus 200. New York: Longman, 1983.

It may be hard to imagine successfully playing these cadenzas without intense preparation beforehand, but these examples give us a glimpse into the kind of passagework and figuration that pianists had in their arsenal of improvisations during the time of Beethoven and Czerny.

These examples provide only a small glimpse into the resources that exist for teaching pianists how to improvise in Beethoven. There are countless textbooks, treatises and articles devoted to this topic, not to mention the wealth of support that classical pianists could find in the world of jazz music.

However, there is no better teacher than Beethoven himself. Keeping a steady diet of Beethoven's works for piano in one's repertory is essential for developing the kind of intuition that is required to make artistic and meaningful additions to his works. Additionally, it is critical to create a safe performing environment in which pianists can try out successful and unsuccessful ideas. Perfection cannot be the centerpiece of good performance if improvisation is a factor in the performance. 


\section{The Path Forward}

I recently overheard a piano lesson that was taking place in a room near where I was sitting. The young student had brought a simple composition by Beethoven to her lesson, and she cheerfully plopped down on the piano bench and immediately began to play the piece she had been working on. The teacher screeched in dismay and exclaimed, "You don't just sit down and start playing Beethoven! This isn't just any music - this is Beethoven! You must have greater respect for him! Take a few minutes and consider what you are about to play first!" While I agreed with the teacher's advice to wait and reflect before playing, I was surprised and saddened by her hysterical reaction to the student's innocent act of disrespect toward Beethoven. This extreme reverence for the music of Beethoven and the person of Beethoven seems to have narrowed the horizons of artistic potential, not broadened them. It has placed arbitrary restrictions on pianists, not promoted freedom and creativity. Modern pianists function under the prevailing mentality that has already been referenced from E.T.A. Hoffman: "The genuine artist lives only for the work, which he understands as the composer understood it and which he now performs. He does not make his personality count in any way. All his thoughts and actions are directed towards bringing into being all the wonderful, enchanting pictures and impressions the composer sealed in his work with magical power."199

This philosophy has created a performance culture which cannot accept improvisation as a legitimate aspect of performance practice. If music educators wish to reincorporate improvisation as a standard skill, in keeping with historical practices, there are several specific ways of counteracting the current philosophy. This conclusion will offer six possible ways of channeling modern performance practice in a more creative direction: 1), as teachers, to intentionally portray Beethoven as a flawed person

\footnotetext{
${ }^{199}$ E.T.A. Hoffman, Musikalische Novellen und Aufsätze, (Regensburg, 1919), 69, quoted in Lydia Goehr, The Imaginary Museum of Musical Works: An Essay in the Philosophy of Music (New York: Oxford University Press, 1992), 1.
} 
who was capable of making mistakes, rather than a divinely-inspired genius; 2), to make students aware of the large role of improvisation in Beethoven's life, and his limited attachment to the written score; 3), to make composition and improvisation a larger aspect of theory training; 4), to eliminate the dividing walls between art music, jazz and popular music in academic studies of music; and 5), to making creative skills such as arranging, composing and improvising a more basic aspect of various music courses at the college level.

\section{Making Beethoven Human Again}

One of the most powerful ways to encourage creative engagement with Beethoven's music is to remind students that Beethoven was not a god; rather, he was a flawed person who created a lot of wonderful music and some mediocre music. Teachers should be willing to point out those parts of his compositions which are not as successful as the iconic masterpieces. My first piano teacher at the college level, Dr. John Cheek, had a wonderful way of making Beethoven more human in my eyes: When I was working on early Beethoven repertoire, Dr. Cheek would often point out places in the music that betray Beethoven's youth and compositional immaturity. He would often say, "if Beethoven was older when he composed this, he might have written it this way:" and then proceed to improvise an amazing and quite different version of the music using the same themes. Dr. Cheek also pointed out specific works of Mozart which had influenced Beethoven, explaining that even the great Beethoven was not above being inspired by the music of other masters. This helped me to develop a more realistic perspective on Beethoven, and I believe it has given me greater joy and freedom in interpreting his music for piano. 


\section{Beethoven was not Restricted by the Score}

It is also important to remind students that Beethoven was an improviser first and foremost, ${ }^{200}$ and that his performances of published pieces were seriously flawed in the view of most of his contemporaries. ${ }^{201}$ It is important for students to know the stories about Beethoven deviating dramatically from the score, ${ }^{202}$ such as when he left his fellow musicians waiting awkwardly while he improvised a long cadenza in the performance of his Piano Quintet, ${ }^{203}$ or how he mysteriously changed the written notes in the closing themes of his sonata expositions. ${ }^{204}$ Students should know that Beethoven instructed his students to embellish repeated material, ${ }^{205}$ not just that he reprimanded Czerny for his wild and uncouth additions to the score. ${ }^{206}$

Students should also receive help and encouragement in their experimentations with creativity. Following the example of Beethoven, ${ }^{207}$ students can give structure and security to their improvisations by preparing them beforehand. Teachers can help them by steering the improvisations away from stylistically questionable choices, encouraging simple and meaningful choices over empty virtuosity, and applauding their students' courage in trying new and potentially uncomfortable things. Teachers should also be bold in persuading students to improvise only when improvisation is fitting and appropriate, and

\footnotetext{
${ }^{200}$ Kinderman, William. "Improvisation in Beethoven's Creative Process." In Musical improvisation: Art, Education, and Society, edited by Gabriel Solis and Bruno Nettl, 296-312. Urbana: University of Illinois Press, 2009. 297.

${ }^{201}$ Beethoven, Ludwig van, Friedrich Kerst, and Inc ebrary. Beethoven, as revealed in his own words: The man and the artist (Wellington: Floating Press, 2009; 1904), 45.

${ }^{202}$ Scherman, Biancolli, The Beethoven Companion. 106

${ }^{203}$ International Beethoven Congress, Robert Winter, and Bruce Carr. Beethoven, Performers, and Critics: The International Beethoven Congress, Detroit, 1977. Detroit: Wayne State University Press, 1980. 55-56.

${ }^{204}$ Skowroneck, "Beethoven the Pianist," 156

${ }^{205}$ International Beethoven Congress, Winter, and Carr, Beethoven, 106-107

${ }^{206}$ Polan, "Eingang in Early Beethoven," 78

${ }^{207}$ Tilman Skowroneck, Musical Performance and Reception: Beethoven the Pianist (Cambridge, GB: Cambridge University Press, 2010), 158.
} 
not just for improvisation's sake. There are times, such as the evening that Berlioz remembered, when improvisation actually detracts from the performance rather than adding to it. ${ }^{208}$

\section{Making Improvisation a Bigger Part of Music Theory}

As Robert Levin described, the softer standards in modern theory training have led to a widespread ignorance of the language of music, resulting in even greater problems with creativity. ${ }^{209}$ Students who are not taught how to creatively manipulate the facets of the musical language will not be able to improvise. Making creativity a central aspect of theory training can make a significant difference in counteracting the modern performance philosophies. Currently, students are asked to create music which will demonstrate the rules that they are learning at the time (voice leading exercises, four-voice chorales, etc.). However, they are rarely asked to create music which they can perform on their instrument of choice, or even perform at all. Bridging this gap between theory and performance is critical in the endeavor to help students become more creative and fluent in the language of music. There are several teaching sources which can provide support for incorporating improvisation into the classroom. One impressive textbook which relies heavily on creativity is Music Theory for the Music Professional by Richard Sorce. $^{210}$

\section{Respecting the Audience by Bringing Down Walls}

As we saw in the third chapter, the absence of improvisation in modern performance practice can be largely attributed to the rise of the middle class and the subsequent high-class culture of art music

\footnotetext{
${ }^{208}$ Hector Berlioz, A Critical Study of Beethoven's Nine Symphonies: With "A Few Words on His Trios and Sonatas," a Criticism of "Fidelio" and an Introductory Essay on Music, 1958, 124-125

${ }^{209}$ Robert D Levin, "Improvised Embellishments in Mozart's Keyboard Music." Early Music, 20 (1992): 221.

${ }^{210}$ Richard Sorce, Music theory for the music professional: a comparison of common-practice and popular genres, New York: Ardsley House Publishers, 1995.
} 
which formed. As popular music, which was associated with the lower and middle class, became a larger industry, art music became a smaller and more rigid tradition. As popular music artists tried to appeal more and more to the mainstream audience, classical performers began to accept being misunderstood and underappreciated by mainstream audiences. ${ }^{211}$ Improvisation no longer had a place in art music, and instead took up residence in jazz and popular styles, where it remains today.

Encouraging university students to play popular music as well as classical music could lead to a generation of pianists who look at musical style in an entirely new way. The heavy component of improvisation in popular styles ${ }^{212}$ can easily transfer into its historical function in classical styles. ${ }^{213}$ Additionally, teaching students to respect and react to their audiences can make a significant difference in the philosophy of performance practice. As we saw in the example with Liszt and Berlioz, ${ }^{214}$ every performance situation is different, and pianists should be aware of the expressive needs of the performance at hand. Students should be encouraged to reach out to their audience in real and genuine ways, of which improvisation is one example. ${ }^{215}$ Taking themes from the audience to improvise on, speaking to the audience between pieces and explaining the personal significance of music on the program, and, when the atmosphere is particularly playful, freely improvising — these are all ways of

\footnotetext{
${ }^{211}$ Moore, "The Decline of Improvisation," 76

${ }^{212}$ For example, many popular styles provide instrumentalists with chord charts or lead sheets rather than fully written-out scores. Pianists frequently are given only a harmonic context with they then improvise upon. Other examples include the fluid formal design in gospel or contemporary Christian music styles, where instrumentalists are ready at any moment to improvise a spontaneous shift back to a chorus or bridge, rather than using the previously agreed-upon form. Sometimes these instrumentalists are expected to improvise a transition to a completely different song which was not rehearsed.

${ }^{213}$ For example, possibly asking students to use chord charts as a figured bass for improvising an ABA passage in the style of Mozart. Another idea would be to ask students to improvise a segue from one piece to another piece with a similar style.

${ }^{214}$ Hector Berlioz, A Critical Study of Beethoven's Nine Symphonies: With "A Few Words on His Trios and Sonatas, " a Criticism of "Fidelio" and an Introductory Essay on Music, 1958, 124-125

${ }^{215}$ Here, it should be explained, the author is not trying to make the argument that improvisation is the only real and genuine way to reach out to an audience. It is a powerful way of connecting with others. However, there are many circumstances where the best way to portray the humanity of music is by playing exactly what is written. Please see the author's remarks on page $72 \mathrm{ff}$.
} 
engaging with and showing respect for the audience, further breaking down the walls that divide music cultures and that divide the classical performer from the audience.

\section{Bringing Improvisation into the Classroom}

Improvisation in modern college situations is often restricted to class piano programs. The oftenused method "Alfred's Group Piano for Adults" 216 is full of interesting and creative exercises, such as harmonization, playing by ear, composition, and loosely structured improvisation. Interestingly, nonkeyboard majors in class-piano are expected to improvise in ways that undergraduate keyboard majors would probably find very difficult. However, using the same techniques that are currently employed in class piano, music educators could introduce improvisation into music history, music theory, ear training, and applied lessons rather easily.

The recent trends toward integrating musical education by making stronger connections between musical subjects can also be extremely useful in reintroducing improvisation. Arranging for students to perform simple, Renaissance virginal music while learning about the Renaissance in music history, for example, could present a perfect opportunity to discuss the dramatic additions that performers made to the original score during the Renaissance. In theory class a teacher might ask a clarinet major and a violin major to collaborate and compose a two-part invention in the style of Bach, and to perform it on their instruments. This would also be an ideal opportunity to talk about all of the added ornaments which are not necessarily reflected in the score, but which were vital aspects of the performance practice of the time.

Some helpful resources have already been mentioned, such as Tony Wigram's Improvisation: Methods and Techniques for Music Therapy Clinicians, Educators, and Students, ${ }^{217}$ Ed Sarath's Music

\footnotetext{
${ }^{216}$ E.L. Lancaster, Alfred's Group Piano for Adults, Van Nuys, CA: Alfred Publishing Co., Inc, 1996.

${ }^{217}$ Tony Wigram, Improvisation: Methods and Techniques for Music Therapy Clinicians, Educators, and Students. New York; London: J. Kingsley Publishers, 2004.
} 
Theory through Improvisation: A New Approach to Musicianship Training, ${ }^{218}$ T. Carl Whitmer's The Art of Improvisation: A Handbook of Principles and Methods for Organists, Pianists, Teachers, and All who Desire to Develop Extempore Playing, Based upon Melodic Approach, ${ }^{219}$ Bronwyn LeBlanc-Kinne's Incorporating Beginning Jazz Improvisation Activities and Exercises into an Intermediate-Level Classical Piano Curriculum: A Guide for Private Piano Teachers, ${ }^{220}$ Ruth and Norman Lloyd's Creative Keyboard Musicianship: Fundamentals of Music and Keyboard Harmony through Improvisation, ${ }^{221}$ and of course, Carl Czerny's Systematic Introduction to Improvisation on the Pianoforte: Opus $200 .{ }^{222}$

Music is powerful when it is true. When we, as the audience, recognize in music an emotion that we have experienced before, or that we have observed before in another person, we are impacted by the music. As performers, we have the opportunity to use the language of music to express true things. Beethoven's compositions provide the perfect vessel for these true things to be communicated, but they are not complete until the performer has put his or her own honesty into the performance. Beethoven's works for piano are like beautiful roles in a play. They are full of potential, but they are not truly "art" until a person has stepped in to fill that role with an honest performance. This important factor of musicianship is certainly not achieved only through improvisation, but through the performer's individual and truthful engagement with the music in every sense-phrasing, rubato, dynamics, articulation, etc. The written score, like the script of a play, is only a springboard into many various worlds of possibility, and the direction a performer takes should be informed not only by the composer's limited instructions, but by

\footnotetext{
${ }^{218}$ Ed Sarath, Music Theory through Improvisation: A New Approach to Musicianship Training. New York: Routledge, 2010

${ }^{219}$ T. Carl Whitmer, The Art of Improvisation: A Handbook of Principles and Methods for Organists, Pianists, Teachers, and All who Desire to Develop Extempore Playing, Based upon Melodic Approach. New York: M. Witmark \& Sons, 1941.

${ }^{220}$ LeBlanc-Kinne, Bronwyn, "Incorporating Beginning Jazz Improvisation Activities and Exercises into an Intermediate-Level Classical Piano Curriculum: A Guide for Private Piano Teachers.” Dissertation, San Diego State University, 2014.

${ }^{221}$ Ruth and Norman Lloyd's Creative Keyboard Musicianship: Fundamentals of Music and Keyboard Harmony through Improvisation. New York: Dodd, Mead, 1975.

${ }^{222}$ Carl Czerny and Alice L. Mitchell, A Systematic Introduction to Improvisation on the Pianoforte: Opus 200. New York: Longman, 1983.
} 
the needs of the moment. This is what it means to deliver an honest performance. This is how Beethoven played, and, in conclusion, this is how modern pianists should learn to play his music. 


\section{Bibliography}

Alexander, Michael L. 2012. "Fearless Improvisation: A Pilot Study to Analyze String Students' Confidence, Anxiety, and Attitude toward Learning Improvisation". Update: Applications of Research in Music Education. 31 (1): 25-33.

Bach, C.P.E. Sechs Sonaten für Clavier mit veränderten Reprisen. Translation, 1961, from Ferand, Die Improvisation in Beispielen, 1956.

Barth, George. 1992. The Pianist as Orator: Beethoven and the Transformation of Keyboard Style. Ithaca, N.Y.: Cornell University Press.

Bechtold, Rebeccah, Patricia Loughran, Justine Murison, Leon Chai, and Gillen Wood. 2012. Composing the Body: Narrative in the Age of Improvisation, 1770-1867. http://hdl.handle.net/2142/34575.

Beethoven, Ludwig van, Friedrich Kerst, and Inc ebrary. Beethoven, as Revealed in His Own Words: The Man and the Artist. Wellington: Floating Press, 2009; 1904.

Benson, Bruce Ellis. The Improvisation of Musical Dialogue: A Phenomenology of Music. Cambridge: Cambridge University Press, 2003.

Berkowitz, Aaron Lee. 2009. Cognition in Improvisation: The Art and Science of Spontaneous Musical Performance. Thesis (Ph. D., Dept. of Music)--Harvard University, 2009.

Berliner, Paul. Thinking in Jazz: The Infinite Art of Improvisation. Chicago: University of Chicago Press, 1994.

Hector Berlioz, A Critical Study of Beethoven's Nine Symphonies: With "A Few Words on His Trios and Sonatas, " a Criticism of "Fidelio" and an Introductory Essay on Music. London: William Reeves, 1958.

Biasutti M., and Frezza L. 2009. "Dimensions of Music Improvisation". Creativity Research Journal. 21 (2-3): 232-242.

Bonds, Mark Evan. Absolute Music: The History of an Idea. New York: Oxford University Press, 2014.

Bowen, José A. "The Value of Beethoven." 19th-Century Music 22, no. 1 (1998): 91-99.

Brown, Clive. Classical and Romantic performing practice 1750-1900. Oxford: Oxford University Press, 1999.

Burnham, Scott. Beethoven Hero. Princeton: Princeton University Press, 1995.

Caines, Rebecca, and Ajay Heble. The Improvisation Studies Reader: Spontaneous Acts. London: Routledge, 2015. 
Callahan, Michael. "Incorporating Long-Range Planning into the Pedagogy of Baroque-Style Keyboard Improvisation." Music Performance Research, published by Royal Northern College of Music, Vol. 5, 2012.

Castagnetta, Grace. "On Improvisation." New York Times, Apr 26, 1942.

Cooper, Barry. Beethoven and the Creative Process. Oxford: Clarendon Press, 1990.

Cumming, Julie E. "Renaissance Improvisation and Musicology." Music Theory Online Volume 19, Number 2, June 2013. McGill University, 2013.

Czerny, Carl and Alice L. Mitchell. A Systematic Introduction to Improvisation on the Pianoforte: Opus 200. New York: Longman, 1983.

Czerny, Carl, Paul Badura-Skoda, and Carl Czerny. On the proper performance of all Beethoven's works for the piano; Reminiscences of Beethoven, and, chapters II and III from volume IV of the Complete theoretical and practical piano forte school: op. 500. Wien: Wiener Urtext Ausgabe, 1970.

Czerny, Carl, and Ernest H. Sanders. Recollections From My Life. (New York: The Musical Quarterly, 1956).

Donington, Robert. Baroque Music: Style and Performance. London: Faber Music, 1982.

Fox-Gieg, Nick, and Margaret Schedel. 2010. "In Strange Paradox: Rationalizing Improvisation." Leonardo Music Journal. 20 (1): 13-15.

Fredrickson, W. E. 2007. "Commentary Improvisation". Journal of Music Teacher Education. 16 (2): 7-9.

Friedman, Richard. 1989. The Original Cadenzas in the Piano Concertos of Beethoven: An Analysis.

Gann, Kyle. 2006. "A Statement on Free Improvisation". Contemporary Music Review. 25 (5-6): 619620.

Goehr, Lydia. The Imaginary Museum of Musical Works: An Essay in the Philosophy of Music. New York: Oxford University Press, 1992.

Gould, Carol S., and Kenneth Keaton, "The Essential Role of Improvisation in Musical Performance." The Journal of Aesthetics and Art Criticism 58, no. 2 (Spring 2000): 143-148.

Hartenberger, Russell, and Boyle, Patrick, "Improvisation and the Politics of Error.” Dissertation, University of Toronto, 2012.

Hamilton, Kenneth. After the Golden Age: Romantic Pianism and Modern Performance. New York: Oxford University Press, 2008. 
Hartenberger, Russell, and Boyle, Patrick. 2012. Improvisation and the Politics of Error. Thesis / Dissertation ETD. http://hdl.handle.net/1807/65461.

Hind, Rolf. "Some Thoughts on Improvisation." Contemporary Music Review 25, No. 5-6 (2006): 631632.

Hoffman, E.T.A. Musikalische Novellen und Aufsätze. Regensburg, 1919.

Hooykaas, Madelon. 2006. "Notes on Improvisation". Contemporary Music Review. 25 (5-6): 447-449.

Hunter, Mary. "To Play as If from the Soul of the Composer': The Idea of the Performer in Early

Romantic Aesthetics." Journal of the American Musicological Society 58, No. 2 (Summer, 2005): 357-398.

Iacocca, Lee. “Teaching Improvisation Confidently.” Music Educators Journal 100, no. 1 (2013): 17.

International Beethoven Congress, Robert Winter, and Bruce Carr. Beethoven, Performers, and Critics: The International Beethoven Congress, Detroit, 1977. Detroit: Wayne State University Press, 1980.

Jones, Stuart. 2001. "Making It Up as You Go Along". Leonardo Music Journal. 11 (1): 61-64.

Jones, Timothy. Beethoven, the Moonlight and Other Sonatas, Op. 27 and Op. 31. New York: Cambridge University Press, 1999.

Kato, Hideki. 2006. "On Improvisation". Contemporary Music Review. 25 (5-6): 629-630.

Kim Y. 2008. "The Effect of Improvisation-Assisted Desensitization, and Music-Assisted Progressive Muscle Relaxation and Imagery on Reducing Pianists' Music Performance Anxiety". Journal of Music Therapy. 45 (2): 165-91.

Kinderman, William. Beethoven. Berkeley: University of California Press, 1995.

Kinderman, William. "Improvisation in Beethoven's Creative Process.” In Musical improvisation: Art, Education, and Society, ed. Gabriel Solis and Bruno Nettl, 296-312. Urbana: University of Illinois Press, 2009.

Lang, Paul Henry. The Creative World of Beethoven. New York: W.W. Norton, 1971.

LeBlanc-Kinne, Bronwyn, "Incorporating Beginning Jazz Improvisation Activities and Exercises into an Intermediate-Level Classical Piano Curriculum: A Guide for Private Piano Teachers." Dissertation, San Diego State University, 2014.

Levin, Robert D. “Improvised Embellishments in Mozart's Keyboard Music.” Early Music, 20 (1992): 221-236.

Lin, ChiaWei. Hidden Histories of Piano Improvisation (1850-1930): Functions, Concepts, and Case 
Studies of Early Recordings. Dissertation, 2014.

http://search.proquest.com/docview/1627792848?accountid=14505.

Lloyd, Ruth, and Norman Lloyd, Creative Keyboard Musicianship: Fundamentals of Music and Keyboard Harmony through Improvisation. New York: Dodd, Mead, 1975.

Mazzola G., Joomi Park, and Florian Thalmann. Musical Creativity: Strategies and Tools in Composition and Improvisation. Berlin: Springer, 2011.

McPherson MJ, M Lopez-Gonzalez, SK Rankin, and CJ Limb. "The Role of Emotion in Musical Improvisation: An Analysis of Structural Features." PloS One, 9, No. 8 (2014).

Moore, Robin. "The Decline of Improvisation in Western Art Music: An Interpretation of Change." International Review of the Aesthetics and Sociology of Music, 23, No. 1 (June 1992): 61-84.

Monson, Ingrid T. Saying Something: Jazz Improvisation and Interaction, 2nd ed. Chicago: University of Chicago Press, 1996.

Montuori, Alfonso. 2003. "The Complexity of Improvisation and the Improvisation of Complexity: Social Science, Art and Creativity". Human Relations. 56 (2): 237-255.

Muxfeldt, Kristina. Vanishing Sensibilities: Schubert, Beethoven, Schumann. New York: Oxford University Press, 2012.

Nachmanovitch, Stephen. 1990. Free Play: Improvisation in Life and Art. New York: G.P. Putnam's Sons.

Nettl, Bruno and Melinda Russell. In the Course of Performance: Studies in the World of Musical Improvisation. Chicago: University of Chicago Press, 1998.

Nettl, Paul. Beethoven encyclopedia. New York: Philosophical Library, 1956.

Newman, William S. "The Beethoven Mystique in Romantic Art, Literature, and Music." The Musical Quarterly 69, no. 3 (1983): 354-87.

Newman, William S. The Sonata Since Beethoven. New York: W.W. Norton, 1983.

Peterson, Lloyd. Music and the Creative Spirit: Innovators in Jazz, Improvisation, and the Avant Garde. (Lanham, MD: Scarecrow Press, 2006).

Piekut B. 2014. "Indeterminacy, Free Improvisation, and the Mixed Avant-Garde: Experimental Music in London, 1965-1975". Journal of the American Musicological Society. 67 (3): 769-823.

Polan, David. “The Eingang in Early Beethoven.” Performance Practice Review. 7, no. 1 (1994): 78-84.

Randall, Mayumi Ogura. 1993. The History of Piano Improvisation in Western Concert Music. 
Rink, John, and Jim Samson. Chopin Studies 2. Cambridge: Cambridge University Press, 1994.

Rolland, Romain. Goethe and Beethoven. New York: B. Blom, 1968.

Rosen, Charles, Franz Liszt, Frédéric Chopin, Franz Liszt, Frédéric Chopin, Robert Schumann, Robert Schumann, Robert Schumann, Robert Schumann, and Franz Liszt. The Romantic Generation. Cambridge, Mass: Harvard University Press, 1995.

Rosenblum, Sandra P. "Pedaling the Piano: A Brief Survey from the Eighteenth Century to the Present." Performance Practice Review 6, no. 2 (1993).

Rothenberg, David. Sudden Music: Improvisation, Sound, Nature. Athens: University of Georgia Press, 2002.

Rumph, Stephen C. Beethoven after Napoleon: Political Romanticism in the Late Works. Berkeley: University of California Press, 2004.

Rzewski, Frederic. “On Improvisation.” Contemporary Music Review 25, no. 5 (2006): 491-5.

Salmon, John. "Improvising in Beethoven." Lecture at Focus on Piano Literature, Greensboro, NC, June, 2002. June 1, 2016.

Sansom, Matthew. 2001. "Imaging Music: Abstract Expressionism and Free Improvisation". Leonardo Music Journal. 11 (1): 29-34.

Sarath, Ed. Music Theory through Improvisation: A New Approach to Musicianship Training. New York: Routledge, 2010.

Scherman, Thomas, and Louis Leopold Biancolli. The Beethoven Companion. 1st ed. Garden City, N.Y: Doubleday, 1972.

Schiaffini, Giancarlo. 2006. "Never Improvise Improvisation". Contemporary Music Review. 25 (5-6): 575-576.

Schönfeld, Johann Ferdinand. Jahrbuch der Tonkunst von Wien und Prag. München: E. Katzbichler, 1976.

Skowroneck, Tilman. Musical Performance and Reception: Beethoven the Pianist. Cambridge, GB: Cambridge University Press, 2010.

Solis, Gabriel, and Bruno Nettl. Musical Improvisation: Art, Education, and Society. Urbana: University of Illinois Press, 2009.

Taub, Robert. Playing the Beethoven Piano Sonatas. Portland, Or.: Amadeus Press, 2002.

Thayer, Alexander Wheelock, Henry Edward Krehbiel, Hermann Deiters, and Hugo Riemann. 1921. The Life of Ludwig van Beethoven. New York: The Beethoven Association.

Tischler, Hans. Practical Harmony: an Integrated Course in the Principles of Harmonic-Melodic Writing, Keyboard Improvisation and Modulation. Boston: Allyn and Bacon, 1964. 
Tosi, Pier Francesco. Observations on the Florid Song. Translated by J. E. Galliard. London, 1724.

Türk, Daniel Gottlob, and Raymond H. Haggh. School of Clavier Playing, or, Instructions in Playing the Clavier for Teachers \& Students. Lincoln: University of Nebraska Press, 1982.

Wegman, Rob C., Johannes Menke, and Peter Schubert. Improvising Early Music: The History of Musical Improvisation from the Late Middle Ages to the Early Baroque. Leuven: Leuven University Press, 2014.

Whitmer, T. Carl. The Art of Improvisation: A Handbook of Principles and Methods for Organists, Pianists, Teachers, and All who Desire to Develop Extempore Playing, Based upon Melodic Approach. New York: M. Witmark \& Sons, 1941.

Wigram, Tony. Improvisation: Methods and Techniques for Music Therapy Clinicians, Educators, and Students. New York; London: J. Kingsley Publishers, 2004.

Woosley, Kevin Daniel. 2013. The Lost Art of Improvisation: Teaching Improvisation to Classical Pianists. http://lib-ebook.colorado.edu/ebook/Dissertation--3550094.pdf.

Zavalloni, Cristina. 2006. "On Improvisation." Contemporary Music Review. 25 (5-6): 539-540. 